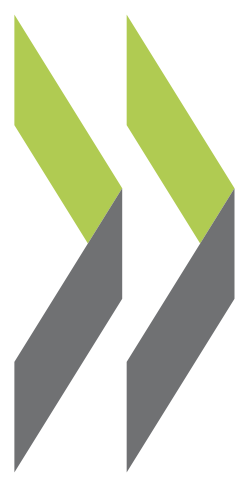

OECD Economics Department Working Papers No. 1669

\title{
Improving the well-being of Canadians
}

\section{Peter Jarrett}




\section{ECONOMICS DEPARTMENT}

\section{IMPROVING THE WELL-BEING OF CANADIANS}

\section{ECONOMICS DEPARTMENT WORKING PAPERS No. 1669}

By Peter Jarrett

OECD Working Papers should not be reported as representing the official views of the OECD or of its member countries. The opinions expressed and arguments employed are those of the author(s).

Authorised for publication by Isabell Koske, Deputy Director, Country Studies Branch, Economics Department.

All Economics Department Working Papers are available at www.oecd.org/eco/workingpapers. 
OECD Working Papers should not be reported as representing the official views of the OECD or of its member countries. The opinions expressed and arguments employed are those of the author(s).

Working Papers describe preliminary results or research in progress by the author(s) and are published to stimulate discussion on a broad range of issues on which the OECD works.

Comments on Working Papers are welcomed, and may be sent to the Economics Department, OECD, 2 rue André-Pascal, 75775 Paris Cedex 16, France, or by e-mail to econ.contact@oecd.org.

All Economics Department Working Papers are available at www.oecd.org/eco/workingpapers.

This document and any map included herein are without prejudice to the status of or sovereignty over any territory, to the delimitation of international frontiers and boundaries and to the name of any territory, city or area.

The statistical data for Israel are supplied by and under the responsibility of the relevant Israeli authorities. The use of such data by the OECD is without prejudice to the status of the Golan Heights, East Jerusalem and Israeli settlements in the West Bank under the terms of international law.

๑ OECD (2021)

You can copy, download or print OECD content for your own use, and you can include excerpts from OECD publications, databases and multimedia products in your own documents, presentations, blogs, websites and teaching materials, provided that suitable acknowledgment of OECD as source and copyright owner is given. All requests for commercial use and translation rights should be submitted to PubRights@oecd.org. 


\section{Abstract/Résumé \\ Improving the well-being of Canadians}

For many years now, a growing number of economists, policy makers, and civil society groups have pointed to the limits of using only GDP as the primary measure of national economic progress. Accordingly, a progressively greater focus has been placed on the concept of well-being and its optimal measurement, as well as its appropriate use in budgeting and other aspects of policymaking. Canada has had a long history of measuring subjective well-being and a good pre-COVID 19 record on many of its determinants but has not yet decided on an official government-wide framework. This chapter delves into the topic and then looks at some of its crucial aspects, in particular: inequality and poverty including food insecurity; housing affordability and homelessness; physical and mental health and long-term care, with a special focus on Pharmacare; and environmental conditions. It includes a special section on the problems facing Indigenous peoples and those belonging to racialise.

This Working Paper relates to the 2021 OECD Economic Survey of Canada, which was finalised on 11 March 2021.

Keywords: well-being, income inequality, poverty, child care, housing, homelessness, guaranteed income, Indigenous People, health care, long-term care

JEL Classification: D3, D6, E2, I1, I2, 13, O51

\section{Améliorer le bien-être des Canadiens}

Depuis plusieurs années déjà, les économistes, les responsables publics et les membres de la société civile sont de plus en plus nombreux à souligner les limites de l'utilisation du seul PIB comme indicateur premier des progrès économiques d'un pays. L'attention s'est donc portée progressivement sur le concept de bien-être et sa mesure optimale, ainsi que sur les moyens de l'utiliser de manière appropriée dans le processus de budgétisation et les autres domaines de l'action publique. Depuis fort longtemps, le Canada s'emploie à mesurer le bien-être subjectif et, avant la crise de la COVID-19, il obtenait des résultats satisfaisants dans bon nombre de ses déterminants, mais le pays n'a pas encore adopté de cadre officiel à l'échelle de l'ensemble de l'administration. Le présent chapitre est consacré à cette question, et examine certaines des principales composantes du bien-être, notamment : les inégalités et la pauvreté, sécurité alimentaire comprise ; l'accessibilité financière du logement et l'itinérance; la santé physique et mentale et les soins de longue durée, et plus particulièrement la couverture des produits pharmaceutiques par l'assurance publique (" Pharmacare »); et les conditions environnementales. II comprend une partie spécifiquement consacrée aux problèmes auxquels sont confrontés les peuples autochtones et les personnes appartenant aux communautés racialisées.

Ce Document de travail a trait à l'Étude économique de l'OCDE du Canada 2021, qui a été finalisée le 11 mars 2021.

Mots Clés: Bien-être, inégalité des revenus, pauvreté, garde d'enfants, logement, sans abri, revenu garanti, Indigènes, soins de santé, soins de longue durée.

Classification JEL : D3, D6, E2, I1, I2, 13, O51 


\section{Table of contents}

\section{Improving the well-being of Canadians}

How do we measure well-being, and what do we know about it? $\quad 7$

The concept of well-being

The known drivers of individual-level subjective well-being

The determinants of country and neighbourhood well-being

The crucial role of social factors $\quad 10$

Using well-being in the policymaking process 10

$\begin{array}{ll}\text { Canada's planned use of well-being in the policymaking process } & 15\end{array}$

Inequality and poverty as negative well-being markers $\quad 16$

$\begin{array}{ll}\text { Canada ranks quite well in terms of equality of opportunity } & 16\end{array}$

Income inequality is close to the OECD average 18

Other dimensions of inequality: life satisfaction, wealth, gender and childcare 20

The pandemic has probably exacerbated inequality along various lines 23

What difference does a focus on poverty instead of inequality make? $\quad 24$

The recent implementation of a national Poverty Reduction Strategy 25

$\begin{array}{ll}\text { Food insecurity as a manifestation of poverty } & 27\end{array}$

A basic income scheme is much discussed but would be expensive 28

Some less costly ways to confront poverty $\quad 29$

The challenges relating to housing affordability and homelessness 31

Affordability problems are widespread and concentrated among those on low incomes $\quad 31$

The federal government has implemented a National Housing Strategy 35

Options for improving housing affordability $\quad 35$

Homelessness is a chronic problem with heavy well-being costs 36

Policies to deal with homelessness 38

The role of physical and mental health status in determining well-being 39

The relative importance of health outcomes in well-being determination 39

Waiting times have been a longstanding concern 41

The primacy of mental health in determining well-being 41

The role of health behaviours, especially problematic substance use $\quad 45$

Policy options for improving the health and well-being of Canadians 47

The need to expand public insurance coverage to include pharmaceuticals $\quad 48$

The lack of paid sick leave for most workers is unfair and risky $\quad 49$

The quality of long-term care can be improved $\quad 49$

The role of environmental factors in the quality of life 52

How does Canada rank according to these environmental indicators? 53

Government policies to deal with these major environmental challenges $\quad 53$

The special case of Canada's Indigenous peoples and racialised populations 54

Indigenous peoples have long had poor well-being outcomes $\quad 54$

Racialised populations are also severely disadvantaged in well-being terms $\quad 58$

$\begin{array}{ll}\text { Main findings and recommendations } & 60\end{array}$

$\begin{array}{ll}\text { Bibliography } & 62\end{array}$ 


\section{Tables}

Table 1. How Canada fares in some country well-being rankings $\quad 7$

Table 2. Selected indicators of childhood and youth well-being, \% 9

Table 3. National well-being frameworks across the OECD, selected countries 12

Table 4. Canada's official dashboard to track progress on poverty reduction, September $2020 \quad 27$

Table 5. Homelessness in an international perspective $\quad 38$

Table 6. Inequalities in life expectancy and hospitalisations for mental illness and suicide 40

Table 7. A cross-country comparison of waiting times 42

Table 8. How Canadian adults and youth assessed their mental health in 2019

Table 9. Inequalities in obesity, high alcohol consumption and smoking 45

Table 10. Selected indicators of comparative well-being of Canada's Indigenous peoples 55

Table 11. Broadband access by First Nations households by speed in Mbps, \%, 2018

\section{Figures}

Figure 1. Strong well-being scores on many fronts going into the crisis 8

Figure 2. The OECD Well-Being Framework 14

Figure 3. Many OECD nations have higher GDP per capita and less inequality than Canada 16

Figure 4. Social mobility in Canada $\quad 18$

Figure 5. Disposable income inequality has been broadly stable at near OECD-average levels 19

Figure 6. Canada's middle-income group has shrunk more than most others since the mid-1980s 20

Figure 7. The dispersion of life satisfaction is relatively low 21

Figure 8. Inequalities in well-being indicators between men and women in Canada 22

Figure 9. Childcare costs and their labour-market incentive effects in Canada 23

Figure 10. Relative poverty is about OECD average despite less redistributive taxes and transfers 26

Figure 11. House price developments $\quad 31$

Figure 12. Household indebtedness $\quad 33$

Figure 13. The homeownership rate is near the OECD average but skewed towards the affluent 33

Figure 14. The size of the social housing stock is relatively low in Canada 34

Figure 15. Spending on mental health $\quad 43$

Figure 16. Opioid availability and related deaths in OECD countries 46

$\begin{array}{ll}\text { Figure 17. Long-term care: number of beds, spending and staffing } & 51\end{array}$

Figure 18. Indigenous groups elsewhere face similar well-being challenges to those in Canada 57

\section{Boxes}

Box 1. Establishing a well-being framework: dashboards or an index of subjective well-being 11

Box 2. The OECD's well-being framework $\quad 14$

Box 3. New Zealand's well-being approach to policy-making $\quad 15$

Box 4. Canada's public measures of low income and the official measure of poverty 24

Box 5. Three options to confront the poverty problem through tax/transfer system reforms 30

Box 6. Indicators of staff shortages and low pay in Canadian long-term care institutions $\quad 50$

Box 7. The environmentalist's paradox: improving well-being despite a worsening ecosystem 52 


\title{
Improving the well-being of Canadians
}

\author{
Peter Jarrett ${ }^{1}$
}

The concept of well-being has become one of increasing interest, as public awareness has spread of the limits of relying on GDP as the only measure of progress. The current federal government has named an Associate Minister of Finance as Minister of Middle Class Prosperity with a mandate to better incorporate quality-of-life measurements into government decision-making and budgeting (beyond the existing Gender Based Analysis Plus), drawing on the experience of other countries. Work is underway in that regard. In the literature on well-being those quality-of-life measurements may be based on either a dashboard of indicators or a single measure of subjective well-being or its variants, life satisfaction and happiness. This chapter will first run through the concept of well-being, its existing proxies and determinants, and then discuss its potential use in the policymaking process. It will then discuss from a well-being perspective various crucial topics in the current Canadian policymaking landscape, which have been brought into sharper focus by the COVID-19 pandemic. That will comprise: inequality and poverty including food insecurity; housing affordability and homelessness; health and long-term care with a special focus on Pharmacare; and environmental conditions. It will finish with a special section on the problems facing Indigenous peoples and racialised populations (the generally accepted term for visible minorities in Canada). Pensions are not considered, because the system is judged to work satisfactorily.

Statistics Canada has a comparatively long history of gathering national subjective well-being data, though, unlike Australia, Germany and the United Kingdom, it lacks a widely used panel data set over time. It also gathers relevant dashboard-type well-being data by province and territory, but infrequently and with long lags, as in other countries. Subjective well-being data are also available from the Canadian Index of WellBeing at the University of Waterloo and the Gallup Organisation. Information on Canada is also covered in the dashboard approach taken by the OECD in its How's Life? report and the associated Better Life Index, the Social Progress Imperative's index, and the United Nations in its Human Development Index and Sustainable Development Goals.

Canada ranked relatively highly in all these measures in their latest manifestations, all of which date from prior to the COVID-19 pandemic (Table 1 But its rankings have been harmed by deterioration in the worklife balance/leisure time component of the dashboard approaches as well as some environmental outcomes. The OECD's How's Life? measure (Figure 1) shows strong well-being scores on many fronts but some weaknesses in current well-being, resources for the future and persistently inferior First Nations outcomes as well as consistent trend deterioration for household debt and housing affordability (in part because of the Great Recession), threatened species, students' science skills and aggregate social connections. In addition, Canadian poll respondents are less frequently self-identifying over time as middle

\footnotetext{
${ }^{1}$ The author was a consultant to the OECD Economics Department at the time this paper was written. It has benefited from extensive comments and suggestions from numerous OECD colleagues, notably Philip Hemmings, Isabelle Joumard, Alvaro Pereira, Patrick Lenain, Oliver Denk and, most especially, Carrie Exton. He is also grateful to all the Canadian experts both within and outside the federal civil service who shared their expertise and tried to make the text as insightful as possible, as well as to the members of the Economic and Development Review Committee who devoted their time to making the advice given both pertinent and in conformity with the evidence. Last, he is indebted to Béatrice Guérard for her expert statistical assistance and to Michelle Ortiz and Heloise Wickramanayake for their excellent administrative and editorial assistance.
} 
class and more as working class or poor as well as fearing that their offspring will be poorer than they are. Finally, evidence suggests that the COVID-19 pandemic is exacerbating a number of existing well-being problems. For example, the latest data shows that the lives of Canada's racialised populations have been harmed to a greater extent than those of the white majority (see below), that neighbourhoods where there are greater numbers of racialised people have suffered COVID-19 mortality rates about double those in other localities (Subedi et al., 2020) and that Indigenous peoples have had less of a recovery in employment outcomes since the spring plunge than others' (Bleakney et al., 2020). These outcomes link to the social determinants of health, which shape the conditions in which Canadians live, work and age.

\section{Table 1. How Canada fares in some country well-being rankings}

\begin{tabular}{|c|c|c|c|c|}
\hline Ranking name and edition & Overall rank & $\begin{array}{c}\text { Number of } \\
\text { dimensions/indicators }\end{array}$ & Weaknesses & Ranking \\
\hline \multirow[t]{4}{*}{ Social Progress Index 2020} & $9 / 1631$ & $12 / 50$ & GHG emissions per capita & 1801 \\
\hline & & & Mobile phone subscriptions & 136 \\
\hline & & & Biome protection & 110 \\
\hline & & & Homicides & 62 \\
\hline Human Development Index 2019 & $13 / 189$ & 4 & Expected years of schooling & 32 \\
\hline World Happiness Report 2020 & $11 / 153$ & 6 & Negative affect (emotional distress) & 54 \\
\hline \multirow[t]{6}{*}{ Environmental Performance Index 2020} & $20 / 180$ & $11 / 32$ & GHGs per capita & 168 \\
\hline & & & Ecosystem services & 110 \\
\hline & & & Species habitat & 101 \\
\hline & & & Nitrous oxide growth rate & 92 \\
\hline & & & Protected areas & 91 \\
\hline & & & Fisheries & 89 \\
\hline \multirow[t]{7}{*}{ OECD How's Life? $2020^{2}$} & $\mathrm{NA} / 37$ & $11+4 / 84$ & Greenhouse gases per capita & 36 \\
\hline & & & Gender wage gap & 32 \\
\hline & & & Material footprint per capita & 29 \\
\hline & & & Housing affordability & 26 \\
\hline & & & Gender gap in feeling safe & 21 \\
\hline & & & Time off & 18 \\
\hline & & & $\begin{array}{l}\text { Trend in Red List Index of } \\
\text { Threatened Species }\end{array}$ & 13 \\
\hline
\end{tabular}

1. There were 163 countries for which data for the overall Index were available, but more than that for individual indicators.

2. The OECD measure has no official ranking, since any set of weights on the individual indicators would be arbitrary.

Source: OECD.

\section{How do we measure well-being, and what do we know about it?}

\section{The concept of well-being}

Well-being has been the subject of philosophical discourse since Aristotle, Bentham and Mill. Its interest to modern-day economists increased following the observation that developed countries were growing steadily richer, but their citizens were not becoming any happier -- the so-called Easterlin (1974) paradox. Researchers then focused on what factors other than income drive individual well-being. It is now widely 


\section{8 | ECO/WKP(2021)20}

accepted that well-being can be measured by a dashboard of objective indicators or through subjective measures derived from responses to surveys using one of several kinds of questions (see below), but most commonly the Cantril ladder with responses from 0 to 10.

\section{Figure 1. Strong well-being scores on many fronts going into the crisis}

2018 or latest available

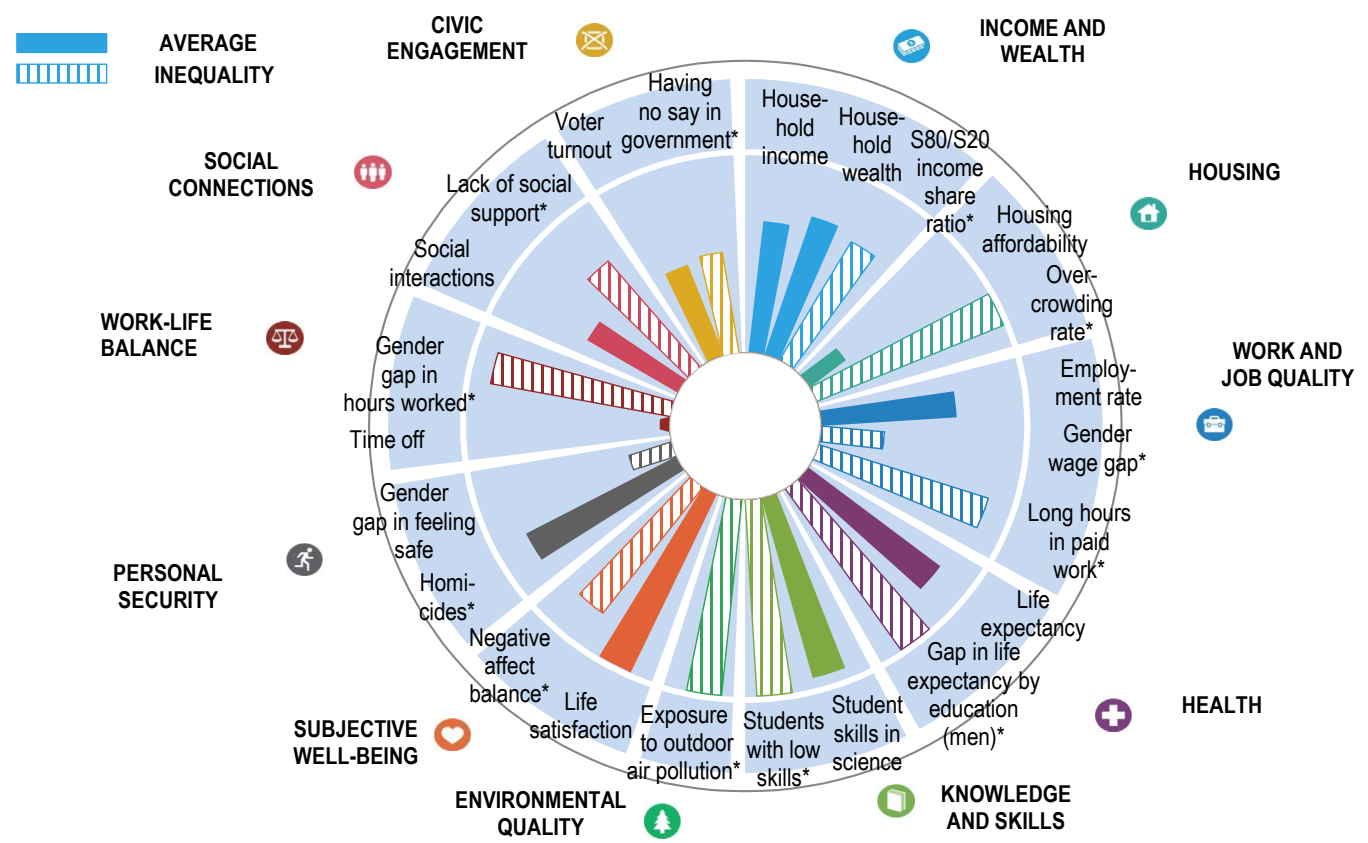

Note: This chart shows Canada's relative strengths and weaknesses in well-being when compared with other OECD countries. For both positive and negative indicators (such as homicides, marked with an "*"), longer bars always indicate better outcomes, whereas shorter bars always indicate worse outcomes. Maximum well-being among countries is achieved when the bar reaches the inner circle. Inequalities (gaps between top and bottom, differences between groups, people falling under a deprivation threshold) are shaded with stripes.

Source: OECD (2020), How's Life? 2020: Measuring Well-being (database), September.

\section{The known drivers of individual-level subjective well-being}

The drivers of individual subjective well-being have not been thoroughly investigated using Canadian data, even if some Canadian researchers are at the forefront of research in the field of well-being. However, in the United Kingdom (which could be fairly similar), a recent effort points to the following factors with their shares of variance of life satisfaction explained: mental health $46 \%$, physical health $15 \%$, partnered $15 \%$ (but thought especially likely to be reverse causality, as happier people are more likely to partner), the logarithm of income $10 \%$, not being unemployed $8 \%$, an absence of criminality $5 \%$ and educational attainment $1 \%$ (Frijters et al., 2020), though much of the education effect is no doubt mediated by the other factors, notably income. Once included, job satisfaction takes about a $25 \%$ share of explained variation, mainly at the expense of mental health (Allas et al., 2020). Other research has shown the importance of social relationships and social capital (e.g. trust in others; see below), U-shaped age effects, ethnicity/discrimination effects, as well as roles for homeownership, disability status and immigration.

Research has also looked at well-being for different demographic groups, such as children. While the OECD maintains a Child Well-Being Data Portal, the Canadian country fact sheet (OECD, 2017) has not been updated since 2017. The Public Health Agency of Canada is now developing a Positive Mental Health Surveillance Indicator Framework for children. Currently available information paints a somewhat worrying picture of child well-being in Canada, particularly for Indigenous children who suffer from a greater burden of ill health (Greenwood and de Leeuw, 2012), a poverty rate more than five times as great as among non- 
Indigenous children (according to the 2011 National Household Survey), twice as much infant mortality (UNICEF, 2019) and various other disadvantages, such as suicidal thoughts and completions and much higher rates of being in foster care.

UNICEF Canada has joined forces with the Canadian Index of Wellbeing to produce 125 indicators of Canadian child well-being across nine dimensions. They also review 38 indicators for the Sustainable Development Goals that pertain to children and youth and measure the distance to target. The median shortfall for Canada is around $15 \%$, but the largest gaps (over $50 \%$ ) are for breastfeeding and experience of discrimination. Overall, considering children's mental well-being, physical health and academic and social skills, UNICEF Innocenti (2020) ranks Canada $30^{\text {th }}$ out of 38 advanced countries, although, separately, grade 6-10 students reported mean life satisfaction of 7.3 out of 10 in 2019, a reputable outcome. As regards child inequality Canada places 17 th out of 29 . Homicide rates and overall mortality rates are comparatively elevated (UNICEF, 2019; Social Progress Imperative, 2020), as is the prevalence of mental disorders for the under-20s. Some of the most worrisome mostly subjective indicators (which may not be comparable internationally because of different starting points and expectations) is given in Table 2. In addition to the immediate harm to children's well-being, the concern is also that poor well-being in childhood could be replicated in similar outcomes in adulthood (Clark et al., 2018).

\section{Table 2. Selected indicators of childhood and youth well-being, \%}

\begin{tabular}{l|l}
\hline Share of 11-15 year-olds rating their life satisfaction as high & 55 \\
\hline Share who feel sad or hopeless for long periods of time & 27 \\
\hline Share of girls who feel sad or hopeless for long periods of time & 35 \\
\hline Share who go to bed or school hungry at least sometimes & 23 \\
\hline Share of 11-15 year-olds who go to school tired & 60 \\
\hline Share of 5-11 year-olds who get less than 1.5 hours daily to play & 79 \\
\hline Share who feel positive about school & 47 \\
\hline Share who get good support from teachers & 43 \\
\hline Share who have experienced violence at home before age 15 & 25 \\
\hline Share of 11-15 year-olds who have feelings of mental distress weekly & 34 \\
\hline Share of 12-17 year-olds who have mood or anxiety disorders & 11 \\
\hline Share who have experienced discrimination or unfair treatment at home, in school or in the community & 35 \\
\hline Share of 5-17 year-olds who are obese & 11 \\
\hline
\end{tabular}

Source: UNICEF Canada ( 2019), Where Does Canada Stand? The Canadian Index of Child and Youth Well-being: 2019 Baseline Report.

\section{The determinants of country and neighbourhood well-being}

Using data from the Gallup World Poll, the literature on the determinants of subjective wellbeing shows that about three-quarters of its variation across countries and over time can be explained by per capita GDP, healthy life expectancy, having someone to count on in times of trouble, freedom to make life choices, generosity and a trusting and supportive environment (proxied by an absence of business and government corruption) (Helliwell, 2019). Other factors most often found to play a significant role in crosscountry regressions are: low unemployment, environmental factors (especially climate, access to green space and low exposure to air and noise pollution - see below) and income inequality (see below). Less frequently, governance factors are also studied (Helliwell et al., 2018), such as public-service delivery quality, participation in public life, social safety net completeness and tax progressivity.

Helliwell et al. (2019) have analysed youth and adult well-being at the neighbourhood level in Canada. They found that people in rural areas are generally happier thanks to a greater sense of community belonging, lower housing costs, a longer time since they moved into their current residence, greater safety, less inequality and shorter commuting times, offset in part by lower average incomes. Of course, this does 
not deny the fact that those in the most remote/Northern communities face a number of important technological, health and cultural challenges. Neighbourhoods in Québec were found to be especially happy, continuing a remarkable uptrend since 1985 first pointed out by Barrington-Leigh (2013).

\section{The crucial role of social factors}

The strong association of well-being with social factors has been emphasised by Helliwell (2019). These factors include: generosity, altruism and volunteering (which have a robust relationship with good health); personal social connections and friends (Helliwell and Huang, 2013) and knowing one's neighbours (Happiness Research Institute and Leaps by Bayer, 2020) and social trust (Helliwell et al., 2020b). Such research results lie behind the recommendation for governments to provide emotional skills teaching and relationship coaching for high-risk groups, as, for example, the UK Healthy Minds curriculum (Frijters, 2020). The OECD's Better Life Index includes a component for the quality of one's support network for which Canada scores above the OECD average but below the leading countries. Declining social interaction and support in Canada since 2010 has been noted by OECD (2020f).

Interestingly, contrary to other dimensions of well-being, trust in institutions increased sharply in a variety of countries at the outset of the COVID-19 pandemic, but especially in Canada, led by a surge in trust in government as well as in other institutions (Edelman Trust Barometer, 2020). Helliwell et al. (2020a) posit that trust is a conditioning factor in terms of how readily people will follow government pandemic advice and restrictions. High social trust is one reason why the Nordic countries perform well on well-being rankings (Helliwell et al., 2020b, Chapter 7). (Unfortunately, the OECD's Trustlab initiative, which is looking at the determinants of trust and the levels of trust by institution across six countries, excludes data for Canada.) Besides direct benefits, a better social environment lowers the cost of adversity and enhances resilience (op.cit., Chapter 2). Other social factors influencing well-being include access to arts, culture and sports (Lemyre et al., 2018).

The impact of social justice and inclusiveness considerations on average subjective well-being and on optimal policy has also been demonstrated. Inequality of well-being seems to be more powerful than income inequality in various contexts, because it captures and people care about inequality in other dimensions, such as legal rights, education, health, housing and economic opportunities (Goff et al., 2018). Indeed, the effect of inequality of subjective well-being on its average level is large enough to fully offset the $35 \%$ difference in per capita income between, say, the United States and New Zealand in well-being terms. In the Canadian context this points to the importance of various factors such as local governance, access to social programmes and availability of modern infrastructure in determining average subjective well-being in areas with depressed incomes such as the Maritime Provinces.

\section{Using well-being in the policymaking process}

Typically OECD countries have adopted well-being frameworks initially primarily with a monitoring function. Only later have some of them moved on to integrate them in budget policymaking, for example. What difference does the adoption of a well-being focus make to policymaking? According to country summaries made by Stiglitz et al. (2018) and Durand and Exton (2019), it could:

- give a more complete picture of people's lives and highlight the diversity of their experiences using more granular data;

- foster a more holistic and integrated inter-ministerial approach through a more structured organising framework that recognises explicit trade-offs;

- provide needed incentives to improve the measurement of and allow an explicit role for aspects of well-being heretofore downplayed, such as work-life balance, job quality and ability to work remotely, and social capital and trust, as well as resources for future well-being;

- bring in distributional considerations for many well-being dimensions other than income; and ensure more comprehensive regulatory impact and cost-benefit analyses of specific policies. 
It could also more easily allow inclusion of externality considerations, which are rife in areas like the environment and public health, and support government decision-making, priority-setting, funding, programme design and policy development based on common goals.

Adopting a well-being framework entails a choice as to a dashboard of subjective and objective indicators, with or without any weighting to form an index, or effectively a single measure of subjective well-being (current life satisfaction) (Box 1). Even though work is ongoing and no single framework has been endorsed by OECD countries, nearly two-thirds of them have by now developed official well-being measures, almost all of which are multi-dimensional dashboards, consistent with the OECD Well-Being Framework described in Box 2(OECD, 2011; Exton and Fleischer, 2020) (Table 3). Only three have combined their indicators into an illustrative aggregate index, and none rely solely on any subjective well-being measure, though many include such a measure in their dashboard, including the OECD. Only four have followed the OECD in making an explicit distinction between indicators for current well-being and those for resources for future well-being. Dashboard sizes vary enormously: the number of dimensions ranges from 3 to 26 , while the number of indicators stretches from 8 to 147, still less than the Sustainable Development Goals' 231 in its 2020 revision. Despite this diversity, there are areas of commonality across many countries' approaches at both the dimension and indicator level (Exton and Fleischer, 2020). The revised 2020 OECD framework retains its 11 dimensions but now has 84 indicators, up from the former 57 , reflecting the progress made in international measurement, but also to provide better alignment with the aspects of well-being most consistently captured across Member country approaches.

\section{Box 1. Establishing a well-being framework: dashboards or an index of subjective well-being}

A first option is to use a direct measure of subjective well-being (e.g. life satisfaction). Key supporters of this approach are the Global Happiness and Wellbeing Policy Report 2019 (2019), Barrington-Leigh (2020), Birkjaer et al. (2020) and Richard Layard and John Helliwell (including their contributions to OECD (2019a)). This solution has three crucial limitations, and indeed no country has yet adopted it. First, the variance of such measures is only partially ascribable to the dimensions typically included in any dashboard, with much explained by a multitude of other factors that are not normally considered to be the proper domain of policymakers, such as personality, religiosity and culture. Second, shifting "frames of reference" will influence the way respondents answer survey questions; similarly, individuals are known to adapt to some types of adversity as well as positive life events (the so-called "hedonic treadmill" or hedonic adaptation in psychology). Together these effects restrict the information content of survey information (OECD, 2013, Chapter 4). Finally, subjective well-being proxies only current wellbeing and thus largely fails to address the other pillars of the "beyond-GDP" critique, namely distributional and sustainability considerations. Even if individuals' life satisfaction scores reflect their personal preferences as to inequality and an accurate assessment of their likely future well-being, the majority of people are poorly informed as to the level of inequality in their home countries (Balestra and Cohen, forthcoming), bad at predicting future systemic risks and tend to have a clear bias for the present, even if time preference varies considerably across individuals and cultures (Sircova et al., 2014) (see below for a discussion of relating subjective well-being to the Sustainable Development Goals relating to the environment). While it is technically possible to handle these weaknesses by deriving an aggregate index of current and future well-being by estimating a monetary value for these missing considerations, they are not really substitutable, because more income will not suffice beyond a certain point in offsetting more inequality or non-sustainability (for instance, in the case of extreme civil unrest or human extinction).

The result is that countries have unanimously chosen dashboard approaches, which get around these three problems. The main disadvantage of a dashboard approach is the lack of a single aggregate figure that would allow calculations of the impact of any particular policy on aggregate well-being, inclusiveness and sustainability, would automatically allow trade-offs to be taken into account and 
thereby facilitate policymakers' decision-making and their communication with the public. Choosing the indicators and then possibly aggregating them into a single index raises the question of the design of the selection process and of the appropriate weights (top-down or bottom-up), and missing data can also be a problem (see, for example, Boarini et al., 2016). To understand why any change in the index has occurred, one has to look at the underlying components in any case. The weights need to be clearly evident to all groups in society so they can be openly debated.

So the best way forward is to tailor the dashboard to the particular situation and time, recognising that there is no single ideal framework but to move forward and place well-being at the heart of policymaking.

Table 3. National well-being frameworks across the OECD, selected countries

\begin{tabular}{|c|c|c|c|c|c|}
\hline & Lead body & $\begin{array}{l}\text { Launch } \\
\text { year }\end{array}$ & $\begin{array}{l}\text { Public } \\
\text { consultation }\end{array}$ & $\begin{array}{l}\text { Number of } \\
\text { dimensions }\end{array}$ & $\begin{array}{l}\text { Number } \\
\text { of } \\
\text { indicators }\end{array}$ \\
\hline OECD Well-being Framework & OECD & 2020 & & 15 & 84 \\
\hline $\begin{array}{l}\text { Measures of Australia's } \\
\text { Progress }\end{array}$ & Australian Bureau of Statistics & 2002 & $\checkmark$ & 26 & 147 \\
\hline Australia's Welfare & Australian Institute of Health and Welfare & 2015 & & 19 & 61 \\
\hline How's Austria? & Statistics Austria & 2012 & & 3 & 81 \\
\hline $\begin{array}{l}\text { Belgium Complementary } \\
\text { Indicators to GDP }\end{array}$ & $\begin{array}{l}\text { National Accounts Institute + Federal } \\
\text { Planning Bureau }\end{array}$ & 2016 & & 13 & 67 \\
\hline $\begin{array}{l}\text { Belgium Sustainable } \\
\text { Development Indicators }\end{array}$ & Federal Planning Bureau & 2019 & & 17 & 70 \\
\hline Finland Findicators & Statistics Finland & 2009 & & 12 & 97 \\
\hline Well-being in Germany & Federal Chancellery & 2016 & $\checkmark$ & 11 & 48 \\
\hline $\begin{array}{l}\text { Italy Measures of Equitable and } \\
\text { Sustainable Well-being (full set) }\end{array}$ & $\begin{array}{l}\text { National Institute of Statistics + National } \\
\text { Council for the Economy and Labour }\end{array}$ & 2013 & $\checkmark$ & 12 & 130 \\
\hline $\begin{array}{l}\text { Israel Well-being, Sustainability } \\
\text { and National Resilience } \\
\text { Indicators }\end{array}$ & Central Bureau of Statistics & 2015 & $\checkmark$ & 11 & 88 \\
\hline Korea Quality of Life Indicators & Statistics Korea & 2014 & & 11 & 71 \\
\hline Luxembourg Index of Well-being & $\begin{array}{l}\text { Statec, Economic and Social Council + the } \\
\text { Higher Council for Sustainable Development }\end{array}$ & 2017 & $\checkmark$ & 11 & 63 \\
\hline Regional Well-being Indicators & $\begin{array}{l}\text { Instituto Nacional de Estadistica y Geografia } \\
\text { (INEGI) Mexico }\end{array}$ & $2014 / 15$ & $\checkmark$ & 9 & 16 \\
\hline Indicadores de bienestar & $\begin{array}{l}\text { Instituto Nacional de Estadistica y Geografia } \\
\text { (INEGI) Mexico and National Consultation } \\
\text { Council }\end{array}$ & $2014 / 15$ & & 12 & 36 \\
\hline $\begin{array}{l}\text { Indicators Aotearoa New } \\
\text { Zealand }\end{array}$ & Stats NZ & 2019 & $\checkmark$ & 24 & 110 \\
\hline Norway - How We Are Doing & Statistics Norway & 2017 & & 10 & 41 \\
\hline Well-being Index & Statistics Portugal & 2017 & & 10 & 79 \\
\hline $\begin{array}{l}\text { Indicators of Well-being in } \\
\text { Slovenia }\end{array}$ & $\begin{array}{l}\text { Institute of Macroeconomic Analysis and } \\
\text { Development, Statistics Slovenia, Slovenian } \\
\text { Environment Agency + National Institute of } \\
\text { Public Health }\end{array}$ & 2015 & $\checkmark$ & 20 & 90 \\
\hline Quality of Life Indicators & Instituto Nacional de Estadistica Spain & 2019 & & 9 & 59 \\
\hline MONET 2030 Indicator System & Federal Statistical Office Switzerland & 2018 & & 17 & 106 \\
\hline
\end{tabular}




\begin{tabular}{|c|c|c|c|c|c|}
\hline $\begin{array}{l}\text { United Kingdom Measures of } \\
\text { National Well-being }\end{array}$ & The UK Office for National Statistics & 2011 & $\checkmark$ & 10 & 43 \\
\hline \multirow{2}{*}{$\begin{array}{l}\text { Australian Treasury's Well-being } \\
\text { Framework }\end{array}$} & Treasury & 2004 & & 5 & N/A \\
\hline & Lead body & $\begin{array}{l}\text { Launch } \\
\text { year }\end{array}$ & $\begin{array}{l}\text { Public } \\
\text { consultation }\end{array}$ & $\begin{array}{l}\text { Number of } \\
\text { dimensions }\end{array}$ & $\begin{array}{l}\text { Number } \\
\text { of } \\
\text { indicators }\end{array}$ \\
\hline $\begin{array}{l}\text { Finland Strategic Government } \\
\text { Programme Indicators }\end{array}$ & Prime Minister's Office & 2015 & & 5 & 29 \\
\hline France New Indicators of Wealth & Prime Minister's Office & 2015 & $\checkmark$ & 3 & 10 \\
\hline Iceland Indicators of Well-being & $\begin{array}{l}\text { Statistics Iceland (commissioned by Prime } \\
\text { Minister's Office) }\end{array}$ & 2021 & $\checkmark$ & 12 & 39 \\
\hline $\begin{array}{l}\text { Italy Measures of Equitable and } \\
\text { Sustainable Well-being (short } \\
\text { set) }\end{array}$ & Ministry of Economics and Finance & 2016 & $\checkmark$ & 8 & 12 \\
\hline Latvia 2030 & $\begin{array}{l}\text { Cross-Sectoral Coordination Centre, under } \\
\text { the authority of the Prime Minister }\end{array}$ & 2010 & $\checkmark$ & 7 & 55 \\
\hline $\begin{array}{l}\text { Netherlands Monitor of Well- } \\
\text { being }\end{array}$ & Netherlands Cabinet + Statistics Netherlands & 2017 & & 15 & 47 \\
\hline $\begin{array}{l}\text { New Zealand Living Standards } \\
\text { Framework Dashboard }\end{array}$ & Treasury & $2011 / 18$ & $\checkmark$ & 16 & 55 \\
\hline $\begin{array}{l}\text { Northern Ireland Outcomes } \\
\text { Delivery Plan }\end{array}$ & Northern Ireland Executive Office & 2018 & & 12 & 54 \\
\hline $\begin{array}{l}\text { Poland Responsible } \\
\text { Development Index }\end{array}$ & Polish Economic Institute & 2019 & & 3 & 8 \\
\hline $\begin{array}{l}\text { Scotland National Performance } \\
\text { Framework }\end{array}$ & Scottish Government & 2007 & $\checkmark$ & 11 & 81 \\
\hline $\begin{array}{l}\text { Slovenia National Development } \\
\text { Strategy } 2030\end{array}$ & Slovenian Government & 2017 & $\checkmark$ & 12 & 30 \\
\hline $\begin{array}{l}\text { Sweden New Measures of Well- } \\
\text { being }\end{array}$ & Ministry of Finance & 2017 & & 15 & 15 \\
\hline $\begin{array}{l}\text { United Kingdom Personal and } \\
\text { Economic Well-being bulletin }\end{array}$ & Office for National Statistics & 2019 & & 2 & 12 \\
\hline Well-being of Wales & $\begin{array}{l}\text { National Assembly for Wales + Welsh } \\
\text { Government Chief Statistician }\end{array}$ & 2015 & $\checkmark$ & 7 & 46 \\
\hline
\end{tabular}

Note: Launch time refers to the actual release of a framework, rather than the commissioning of its development. Number of indicators refers to the dashboards as of Q3 2019 unless specified otherwise. Measures of Australia's Progress was discontinued in 2013, and the Australian Treasury's Well-being Framework in 2016. Australia's Welfare reports have been published since 1993. The Scottish Government's National Performance Framework was first launched in 2007; the number of dimensions and indicators refers to the refreshed 2018 edition.

Source: C. Exton and L. Fleischer (2020), "The Future of the OECD Well-being Dashboard: Discussion Paper", draft paper.

In principle, well-being can be used at all the stages of policy-making: agenda and priority setting, ex ante policy formulation, implementation, monitoring and ex post evaluation (Stiglitz et al., 2018). The majority of countries' dashboards are currently intended merely to measure, monitor and report on progress. However, some use well-being in policy applications, in particular their budget process (notably New Zealand; Box 3 ) or in devising development strategies with a well-being focus. And some do both with separate dashboards (Finland, Italy, New Zealand and the United Kingdom). A few -- most prominently Italy, New Zealand and the United Kingdom -- assess specific policy measures through a well-being lens by using modified cost-benefit analysis to examine their effects on any or all of: material conditions, subjective well-being, relational well-being, inequalities and the environment. The United Kingdom has created ministerial positions to address Loneliness and Suicide Prevention, strengthened civil service 
training and capabilities in this field using principles and procedures given in the "Green Book" (HM Treasury, 2018) and established in 2014 the What Works Centre for Wellbeing to do research and give advice on how government should integrate wellbeing analysis into its policymaking (see, for example, Hardoon, 2020). However, there is as yet no empirical evidence as to the extent that these efforts to place a stronger emphasis on well-being has changed policy priorities and ultimately improved well-being.

\section{Box 2. The OECD's well-being framework}

Following the "beyond-GDP" critique initiated by Stiglitz et al. (2009), the OECD's Wellbeing Framework was first outlined in 2011 and then revised in 2020 (OECD, 2020e; Exton and Fleischer, 2020) (Figure 2. It includes a diagnostic dashboard along 11 dimensions of current well-being (measured by population averages, dispersion and deprivations), plus resources for future well-being in the form of four kinds of capital (natural, human, economic and social, measured by stocks, flows, risk factors and resilience proxies). In total there are now 84 indicators and three mini-dashboards containing 12 indicators each selected for communications purposes: they cover current well-being levels, current well-being inequalities and resources for future well-being.

\section{Figure 2. The OECD Well-Being Framework}

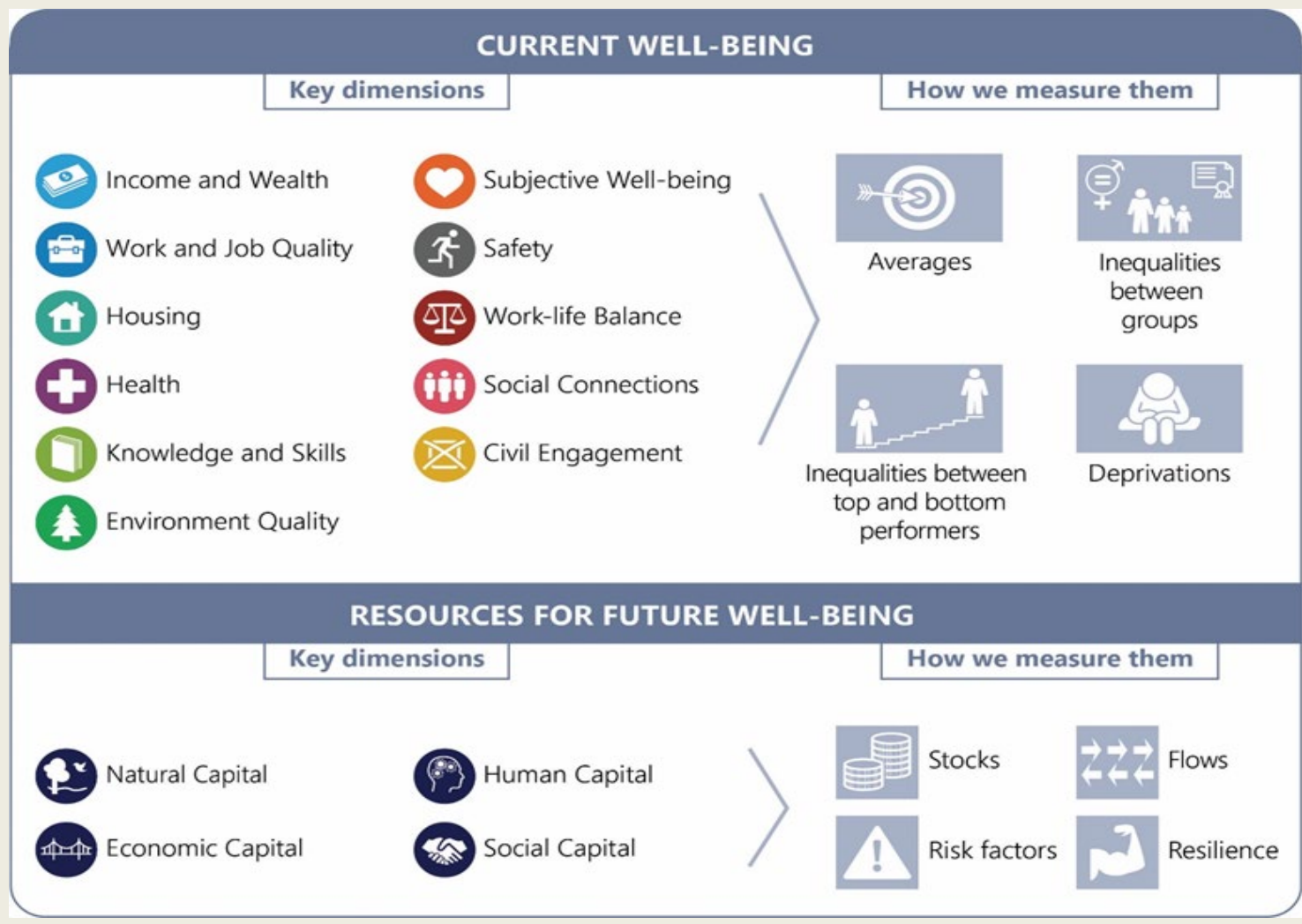

Source: OECD (2020), How's Life? 2020, Measuring Well-Being, OECD Publishing, Paris. 


\section{Box 3. New Zealand's well-being approach to policy-making}

The OECD Economic Survey of New Zealand (2019) included an in-depth description and assessment of its well-being approach to policy-making, which "aims to inform policy and support better decisionmaking through taking on board a broad range of impacts, including distributional effects (by gender, age, ethnicity and household structure), examining trade-offs and improving transparency" (p. 44). The well-being framework uses 12 domains plus 4 capital stocks (which are identical to the OECD's, except it adds cultural identity as a separate domain) in its Living Standards Framework dashboard, which comprises 55 indicators. However, greenhouse gas emissions, the soil nutrient balance and R\&D investment are not among them. This will be updated in 2021. But some government agencies have their own well-being approaches and dashboards providing greater depth, and without a common core and better articulation of the links among them, this risks creating confusion. The Treasury uses available well-being evidence to set Budget priorities, encourage collaboration across ministries and assess spending proposals (but only the marginal spend, which amounts to about $4 \%$ of Core Crown expenditure, and not the baseline as yet). The framework is not used for regulatory impact assessment at this stage. Assessment on progress achieved is to be reported by the Treasury at least every four years, less frequently than the current three-year electoral cycle, but recent amendments to the Public Finance Act balance this by requiring the government of the day to report on progress against its wellbeing objectives annually in the Budget.

\section{Canada's planned use of well-being in the policymaking process}

The federal government should follow through on its plan to adopt a quality-of-life (well-being) framework with an economic lens to help guide the policy agenda to enhance long-term inclusive and environmentally sustainable growth. As stated above, Canada is one of a minority of OECD countries without an official framework. Although Environment and Climate Change Canada has had a Sustainable Development Strategy with 13 dimensions and 25 indicators since 2008 and Gender Based Analysis+ was adopted more broadly already in 1995, there is no overarching, whole-of-government framework. Statistics Canada does not have its own framework, though it hosts a Dimensions of Poverty hub and is currently working on a Canadian Indicator Framework with Employment and Social Development Canada. In July 2019 that department released its Towards Canada's 2030 Agenda National Strategy to establish the structures, processes and activities that have to be implemented to achieve the Sustainable Development Goals. The Canadian Indicator Framework is intended to track and report on progress toward the 17 Goals.

The framework should include the federal government tasking Statistics Canada to ensure the key measures of subjective well-being and a dashboard of relevant indicators are produced through surveys with timely frequency and adequate sample size both at the national and provincial/territorial levels so that Indigenous peoples (distinguishing between First Nations - including, if possible, those on reserve -- Métis and Inuit) and those from racialised populations can be separately identified. The survey instruments and other administrative data sources involved would need to cover all required subjective and objective indicators integrated across the different domains so that how they fit together in the larger picture can be assessed. Having data availability at the regional level would allow jurisdictions to compare their outcomes. The case for such an initiative has recently been made by Hicks (2020), who argues that such information will enable assessment of the combined effects of income-replacement and public-service programmes by all levels of government on the lives of Canadians. Some consideration could be given to the establishment of a well-being Commission that would write an annual report to Parliament, timed to feed into the federal budget process. 
Engaging in a process of public consultations before finalising the list of indicators has been common practice among other OECD countries when developing well-being dashboards (Exton and Shinwell, 2018). It would form a good starting point for a Canadian framework. The COVID-19 pandemic galvanises the urgent need for such measures - given its wide-ranging impacts on people's well-being and the deepening of existing inequalities. The process now underway should therefore aim to quickly finalise a new framework with discussion in each budget. Indeed, it might help the government to defend whatever strategy it uses to "build back better" and balance its promises to ensure a green recovery that is also inclusive and supports the broad social, economic and health needs of Canadians. Once the framework is well established the authorities could choose to extend the use of well-being measures to budget policy formulation and cost-benefit analysis, as the United Kingdom and New Zealand have done.

\section{Inequality and poverty as negative well-being markers}

Policymaking on income inequality needs to recognise that there is no sharp over-arching trade-off with average income. There is no evidence that only by sacrificing income can distributional outcomes be rendered less unequal. Eleven OECD countries have both higher per capita GDP and less income inequality than Canada, demonstrating that improvement along both dimensions is eminently possible (Figure 3).

\section{Figure 3. Many OECD nations have higher GDP per capita and less inequality than Canada}

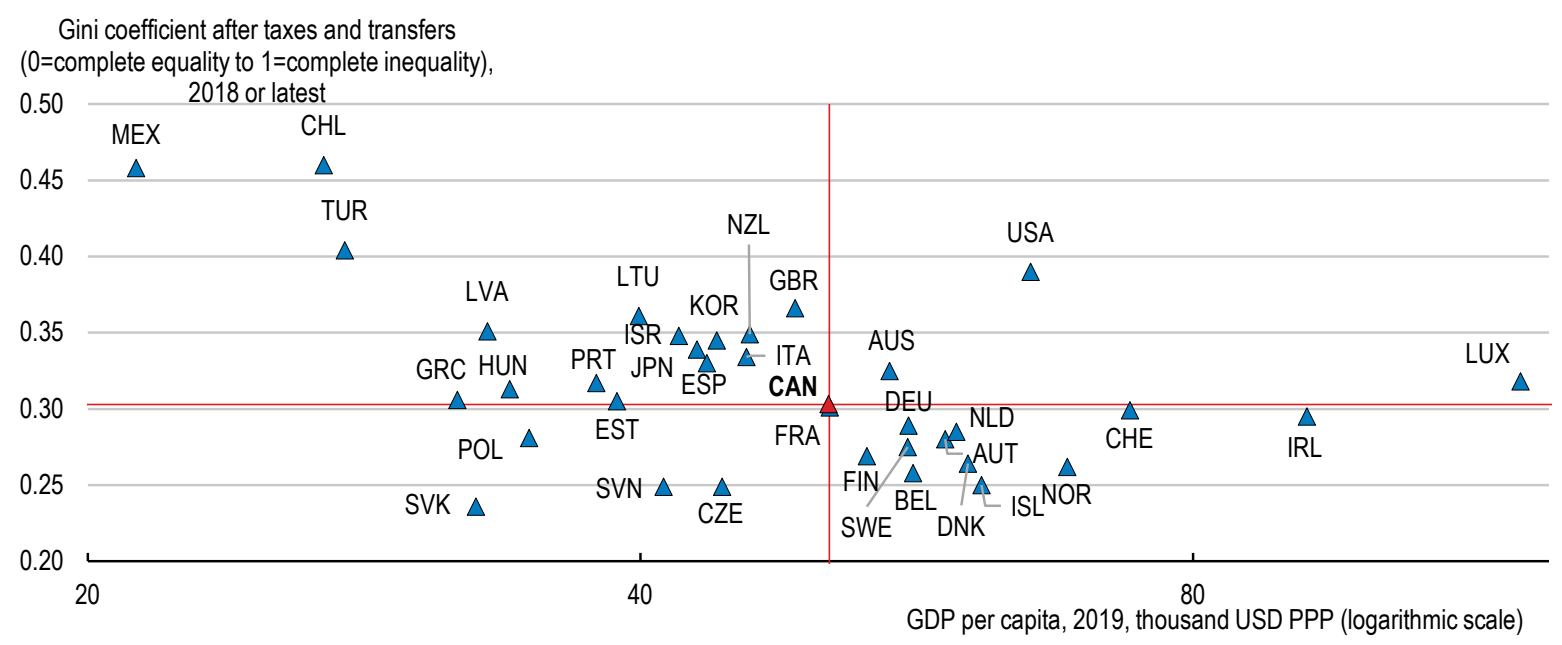

Source: OECD Economic Outlook database; OECD (2020), Income inequality (indicator). doi: 10.1787/459aa7f1-en.

StatLink त्गाड़ https://stat.link/le0z1q

\section{Canada ranks quite well in terms of equality of opportunity}

Distributional considerations matter for individuals' sense of dignity, self-worth, trust in others and social development. Income differences are relevant not just for well-being differences, but for various aspects of health and longevity (see below). The case for inequality to be a public policy concern is strengthened because of the inter-relationship between the well-being of the poor and the rich (Goff et al., 2018); indeed, the well-being of the poor is a more powerful driver than their income in determining average individual subjective well-being and social trust. So long as inequality is due to differences in initial opportunity, economic rents and market failures, rather than greater effort by the fortunate, then the resulting social exclusion is worthy of policy attention. 
Perhaps the best justification for government action on inequality is that income differences align quite well with equality of opportunity as measured by inter-generational earnings mobility (Corak, 2013) in what has become known in its cross-national version as the "Great Gatsby Curve". According to this relationship Canada is seen to have fairly low income inequality and high mobility across generations compared, say, to the United States and the United Kingdom, but less so than several Nordic countries. It takes only 4 generations for those born in low-income families to reach the mean income (the OECD average is 4.8). This is consistent with the very small impact of parental background on children's achievement in secondary education in Canada according to PISA results (OECD, 2010, Figure 5.3), though access to tertiary education does appear importantly determined by parental income and, especially, education, besides the extra barriers faced by Indigenous youth. However, Canada has a quite sticky withingenerations mobility floor (proxied by a high share of people who remained in the bottom income quintile over the years 2005-10) (Figure 4, Panel A). Yet, when within-generations social mobility is measured by occupation rather than income, Canada is seen to have the OECD's highest mobility, above average both upward and downward (Panel B). Canada's good standing for social mobility is confirmed by the World Economic Forum (2020), which ranked it 14th out of 82 countries. However, mobility has been falling at both the national and provincial levels while parental income inequality has been rising (Connolly et al., 2019). The largest decline in mobility is for children from the bottom income quintile; hence, opportunities for the disadvantaged have worsened the most. Combined with the evidence on child well-being presented above, this is a warning sign for future levels of well-being and social mobility. 


\section{Figure 4. Social mobility in Canada}
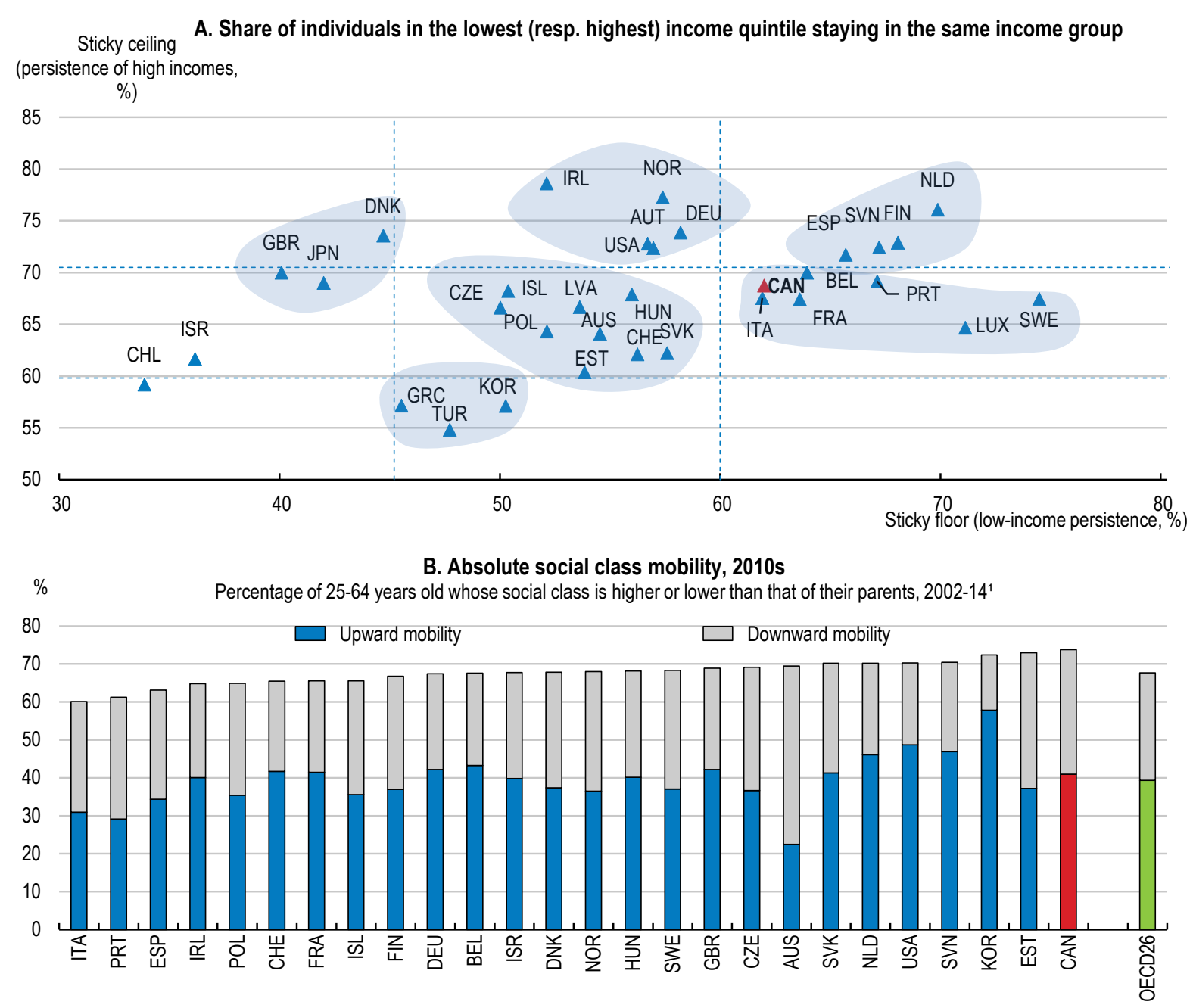

1. Social class is based on the nine European Socio-Economic Classification (ESEC) categories constructed based on occupation. Source: OECD (2018b), A Broken Social Elevator? How to Promote Social Mobility, http://dx.doi.org/10.1787/9789264301085-en.

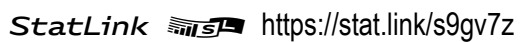

\section{Income inequality is close to the OECD average}

Canadian market-income inequality increased during the 1980s and 1990s and has been stable since 2000 , but the share of the top $1 \%$ continued to rise until around 2008. At first, the tax-transfer system offset all of that, but when the levels of social assistance and Employment Insurance fell in the mid-1990s, that was no longer the case, and disposable-income inequality rose as well. The Great Recession saw disposable income inequality recede as it did again from 2015 in the latest data, bringing it back to muchearlier levels. Overall, disposable income inequality has been at near-OECD-average levels (around 0.30 for the Gini) over the last decade (Figure 5, Panel A), despite Canada's modest market-income inequality (Panel B), as its tax-transfer system offsets only $28 \%$ of it, compared to an OECD average of $36 \%$ (the United States manages only $23 \%$ ). The OECD (2019c) has also recently focused on the size of the middle class, i.e. those earning $75-200 \%$ of median income. By this definition Canada is a middle-ranked country but with a large middle-income-group shrinkage since the mid-1980s (other than for the elderly) (Figure 6). Among family types shrinkage has been especially pronounced among couples with children and single parents (op.cit., Table ). Developments in commodity prices have had an impact on income inequality both 
across individuals and across regions. Income shares have varied with the magnitude of resource rents, which accrue mainly to the wealthiest. With oil and gas resources mostly located in Alberta, income inequality across regions has particularly reflected energy price developments. Specifically, Alberta and Newfoundland and Labrador residents have no doubt suffered a drop in well-being thanks to lower energy prices both post-2014 and during the COVID-19 crisis. Inequality has also been influenced by the growing importance of computer skills, automation and globalisation, as well as changing corporate governance, as is the case throughout the OECD (Corak, 2016). This too has had a differential impact on well-being in Canadian communities, as displaced workers from single-industry areas have faced especially difficult prospects in the labour market.

Figure 5. Disposable income inequality has been broadly stable at near OECD-average levels

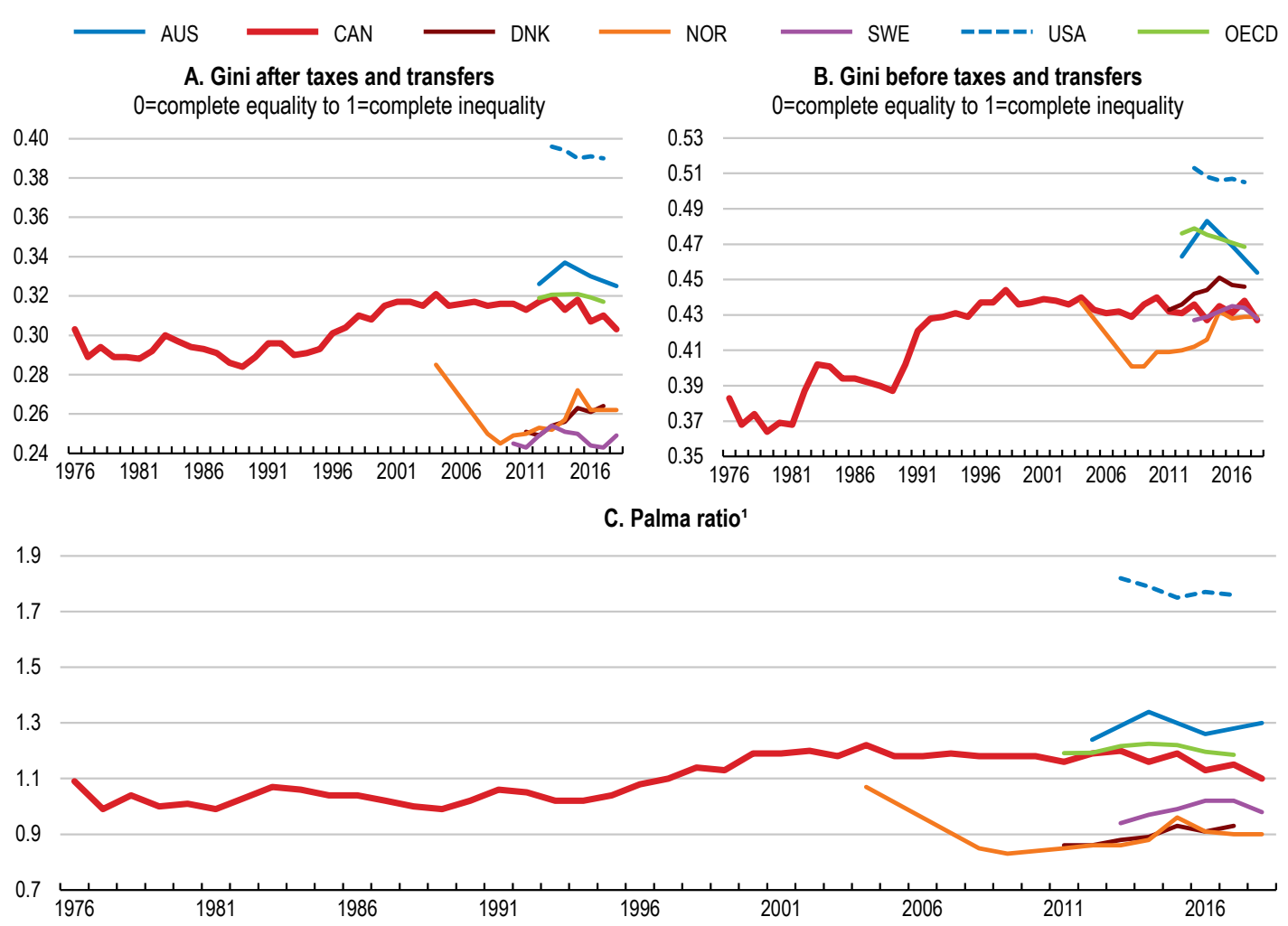

1. The Palma ratio is the share of all income received by the $10 \%$ of households with highest disposable income divided by the share of all income received by the $40 \%$ with the lowest disposable income.

Source: OECD (2020), Income and Inequality Distribution database. 


\section{Figure 6. Canada's middle-income group has shrunk more than most others since the mid-1980s}

Percentage point changes in the shares of population in the middle-income class, mid-1980s to mid-2010s

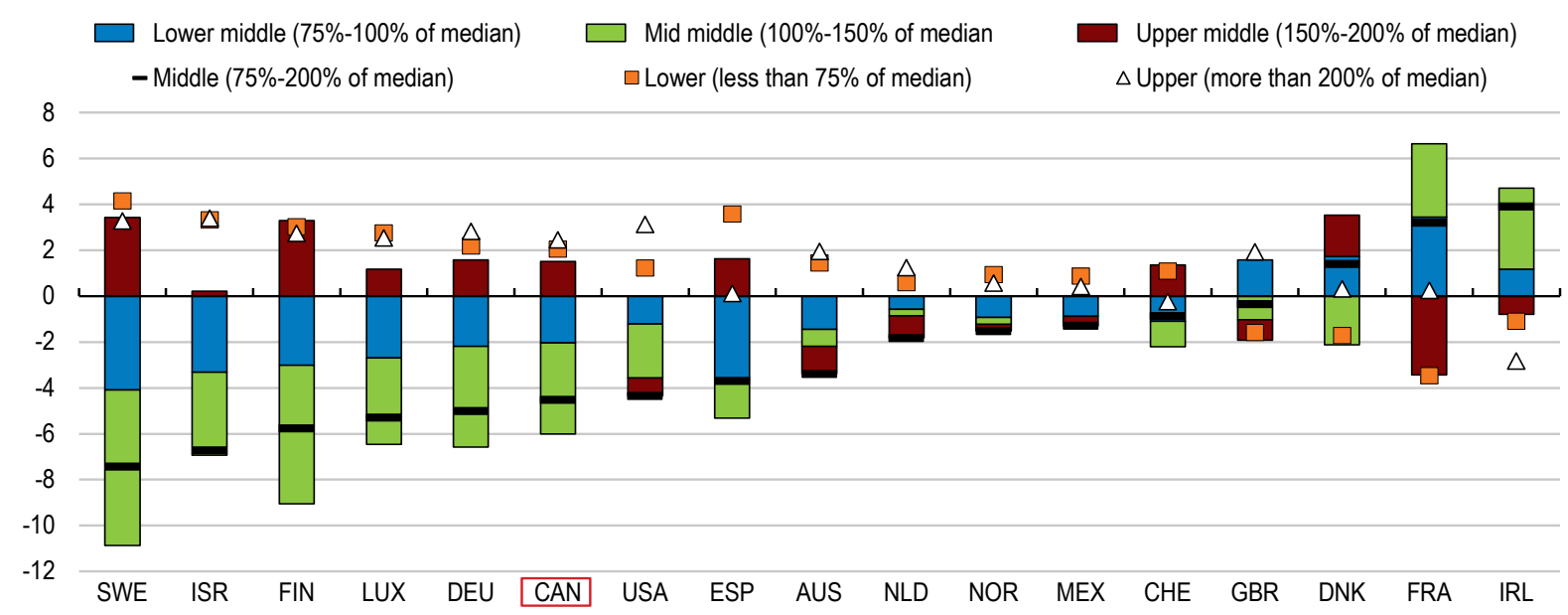

Note: "Middle income" households are defined as those with income between $75 \%$ and $200 \%$ of the national median. Source: OECD (2019), Under Pressure: The Squeezed Middle Class, https://doi.org/10.1787/689afed1-en.

StatLink त्गाड़ https://stat.link/g79rin

The effectiveness of the redistribution system is hampered to some extent by the prevalence of eligible people who fail to claim social benefits to which they are entitled. For some programmes this occurs when individuals delay the filing of tax returns or do not file at all. Some $10-12 \%$ of adults do not file tax returns and thus fail to receive refundable credits such as the Canada Child Benefit Tax Credit and the Goods and Services Tax Credit. The total amount left on the table may be as much as CAD 2 billion per year (Hosek, 2020). In September 2020 the government promised to introduce a free, automatic tax-filing system for simple returns to overcome this barrier, as 36 other countries have already done (Tax Policy Center, 2020). Another example of under-utilisation is the Registered Disability Savings Plan: for a variety of reasons, a large share of people with disabilities eligible for the programme do not participate in it, thereby missing out on as much as CAD 90000 in bonds and matching grants over their lifetimes. Yet another measure with a poor take-up is the Canada Learning Bond. It provides low-income families with support for their children's future education without requiring any personal contributions, yet in 2018 only about $38 \%$ of the 3.3 million eligible children took advantage of it.

\section{Other dimensions of inequality: life satisfaction, wealth, gender and childcare}

Almost all other measures of inequality are less severe in Canada than elsewhere in the OECD (OECD, 2020f). For example, the top quintile has $70 \%$ greater life satisfaction than the bottom quintile, compared to an average OECD premium of $110 \%$ and bettered only by Finland (Figure 7 ). Wealth inequality is also slightly less pronounced than the OECD average (Balestra and Tonkin, 2018). In that regard Canada stands out for the close alignment of its income and wealth distributions (op. cit., Figure 2.11), as well as the latter's stability since 2005 (op. cit., Table 3.2). In any case, rising wealth inequality is not a problem to the extent that it is attributable to population aging combined with saving for retirement. 
Figure 7. The dispersion of life satisfaction is relatively low

Premium in life satisfaction scores of the top $20 \%$ relative to the bottom $20 \%, 2018$

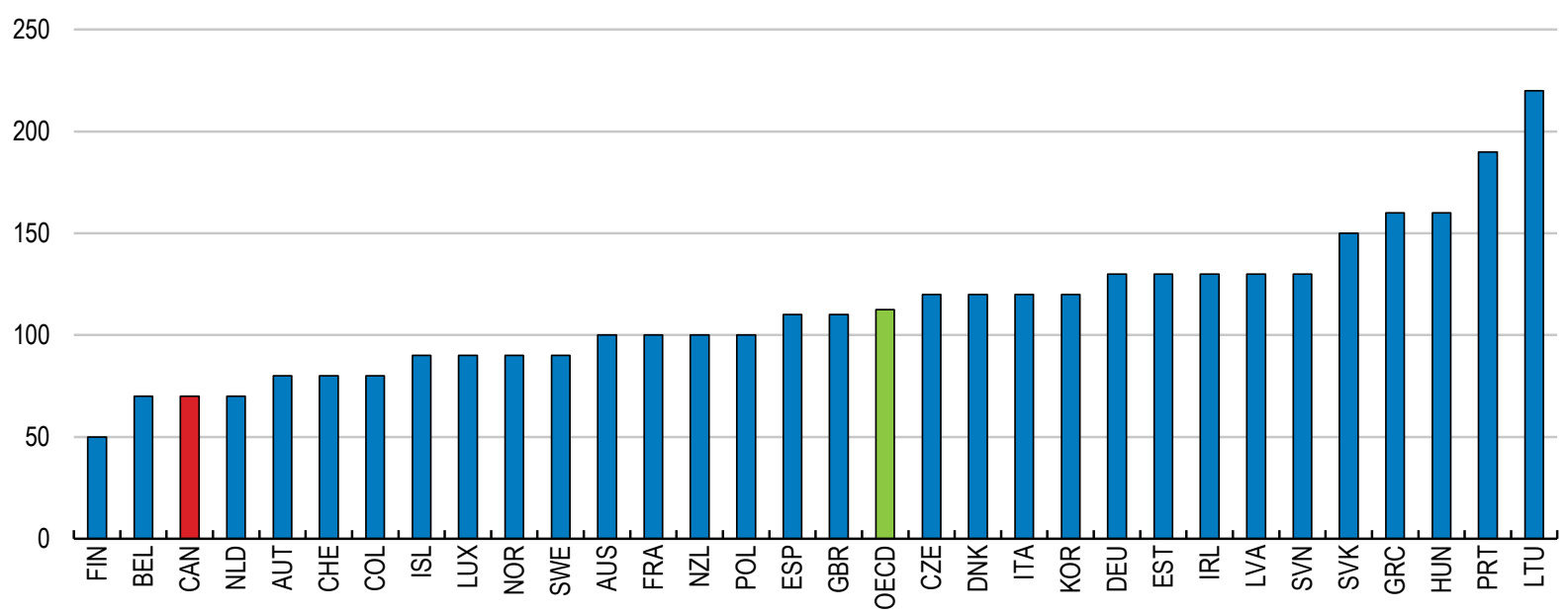

Source: Calculations based on data from OECD (2020), How's Life in Canada 2020, https://www.oecd.org/canada/Better-Life-Initiative-countrynote-Canada.pdf.

Gender inequality facing Canadian women is comparatively low, despite a large gender pay gap for fulltime workers. Women's life satisfaction is identical with that of men, as it is on average in the OECD (Figure 8). Yet, one of the largest differences between the sexes in Canada as elsewhere is in "feeling safe", which points to the problem of gender-based violence, which is most commonly domestic violence that victimises women about four times as much as men (Burczycka, 2019). And women have lower average self-rated mental health than men. Nevertheless, in several other ways (notably in terms of longterm unemployment), it seems that Canadian women are relatively better off than their counterparts abroad. Canadian men suffer from comparatively large gender disparity in long-term unemployment and large absolute gaps in deaths from homicide, suicide, alcohol and drugs, as well as long working hours. However, while the gender median hourly wage gap has shrunk gradually since 2001 from about $21 \%$ to some $15 \%$ in recent years, Canadian women seem to be in the middle of the pack of 14 countries for which employment income comparisons are possible, but are among those with the largest gaps for full-time, fullyear workers, implying comparatively small gaps for part-time workers. Work by Finance Canada shows that $20-25 \%$ of the hourly wage gap is attributable to the occupational structure of female employment, with the majority due to differences in hourly pay within occupations, as women are more often found in low-wage jobs than men. One explanation for this outcome is that women and men place different values on particular job characteristics and sort themselves across different occupations and employers according to the relevant trade-offs. Given women's greater share of unpaid work responsibilities within households, women may be choosing jobs that offer lower wages in return for more working-time flexibility. This aligns with the Finance Canada finding that the gender wage gap is especially pronounced during childbearing and childrearing ages and is almost twice as large for those with children aged under 12, pointing to the importance of flexible work arrangements and access to and affordability of childcare for women's economic well-being. With a view to continuing to shrink women's economic inequality the federal government recently committed to creating a task force to guide an Action Plan on Women in the Economy. 


\section{Figure 8. Inequalities in well-being indicators between men and women in Canada}

Gender ratios (distance from parity) for selected indicators of current well-being, 2018 or latest available year
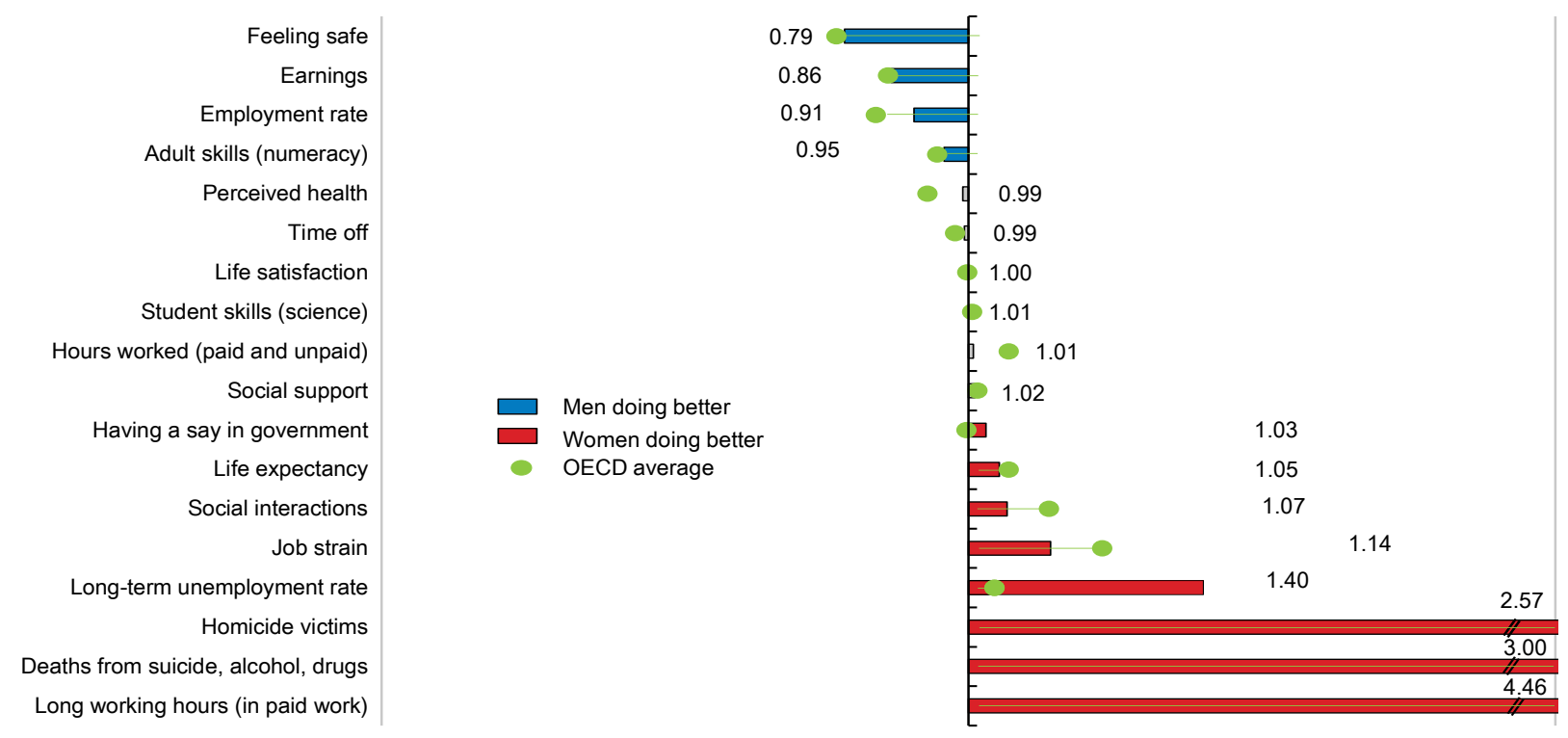

Source: OECD (2020), How's Life in Canada 2020, https://www.oecd.org/canada/Better-Life-Initiative-country-note-Canada.pdf.

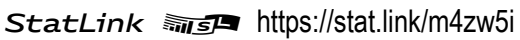

Childcare policy in Canada is a provincial/territorial responsibility. Little is known about childcare quality variations and comparisons over time or internationally, but recent data show that childcare costs for typical couples in Ontario (the only province examined by the OECD) are moderately burdensome (Figure 9, Panel A). Based in part on the fact that Québec's labour-force participation rate for prime-age women moved from 2.7 percentage points below the all-Canada average in 1997, when it adopted its generous childcare-subsidy policy, to 3.3 percentage points above it in 2019 , other provinces (notably British Columbia) and the current federal government have been giving priority to improving access to childcare with a view to encouraging employment by parents. Prior to the pandemic annual federal support amounted to CAD 2.8 billion ( $0.1 \%$ of GDP), mainly through a tax deduction for childcare expenses worth CAD 0.8 billion annually, and the Canada Social Transfer to the provinces and territories. However, taking the whole tax and benefit system into account and including childcare costs, the financial incentives to taking up full-time employment for people with young children in Ontario are the OECD's worst, with a 96\% tax rate on the extra earnings for those earning an average wage (Panel B). However, Ontario does offer a refundable tax credit for childcare expenses to focus its support on low-income parents. Some other jurisdictions offer generous means-tested subsidies that lower net childcare costs for families, and a number of provinces complement them with maximum fees, ensuring that low-income families pay little out of pocket. The federal government has also made an effort to get women back to work in the crisis, having approved an extra CAD 625 million in childcare funding in July 2020. Earlier it had financed 40000 more affordable places. However, the scarcity of spaces persists. 


\section{Figure 9. Childcare costs and their labour-market incentive effects in Canada}

A. Net childcare costs for selected family types, 2019 or latest available ${ }^{1}$

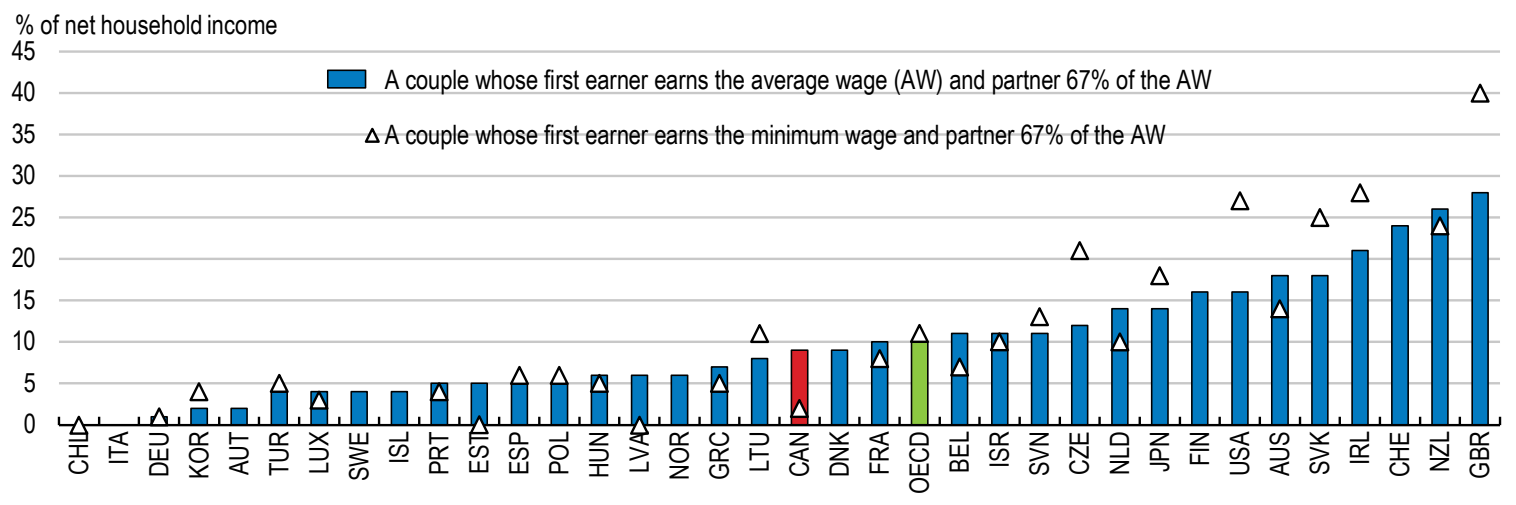

B. Financial disincentive to enter employment with childcare costs, 2019 or latest available ${ }^{2}$

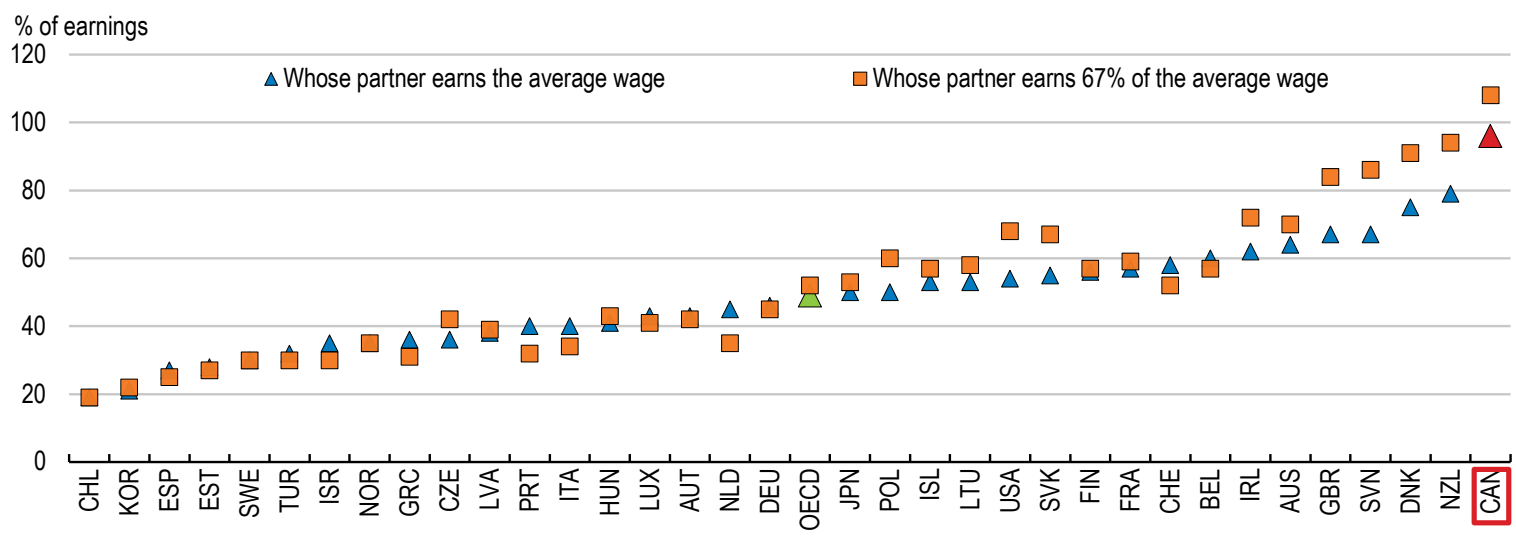

1. This chart shows the net childcare costs for parents using full-time centre-based childcare, after any benefits designed to reduce the gross childcare fees. Childcare benefits can be received in the form of childcare allowances, tax concessions, fee rebates and increases in other benefit entitlements. Net childcare costs are shown for couples assuming two children aged 2 and 3 , one parent earns $67 \%$ of the average wage whereas the other earns either the minimum wage or $100 \%$ of the average wage.

2. This chart shows the percentage of earnings lost to either higher taxes or lower benefits when a parent of two children aged 2 and 3 takes up full-time employment and uses centre-based childcare. Calculations refer to a couple where the other parent works full-time at $67 \%$ of the average wage.

Source: OECD (2020), "Benefits and wages: Net childcare cost for parents using childcare", OECD Social and Welfare Statistics (database), https://doi.org/10.1787/b0781729-en; OECD (2020), Financial disincentive to enter employment with childcare costs (indicator). https://doi.org/ 10.1787/d44eb45b-en.

StatLink त्ताs https://stat.link/smkqj8

\section{The pandemic has probably exacerbated inequality along various lines}

Data show that the disadvantaged have suffered more inequality since the advent of the pandemic (Hou et al., 2020). Racialised populations in particular were found to have suffered disproportionately from COVID-19, even if some provinces deliberately do not gather disaggregated racial and ethnic data, notably Québec (McKenzie, 2020). According to an online crowdsourced survey of 36000 people from 26 May to 8 June, $34 \%$ of White Canadians had suffered job loss or reduced hours, compared to $42 \%$ for Filipino Canadians and $47 \%$ for West Asian Canadians. This could have been due to discrimination but was no doubt also because of differences in job distribution and length of tenure. In this same survey important financial impacts were cited by $23 \%$ of White Canadians, but by at least $42 \%$ of Arab Canadians, Filipino Canadians and West Asian Canadians. However, racialised populations were also more likely to have applied for and received federal financial support. In most OECD countries women are more likely to have been more exposed to the virus because of their occupational distribution: a larger share are employed in 
jobs requiring contact with diseases and with clients and high levels of physical proximity (for example, in the health-care and social-services sectors) and are less likely to be able to work from home (Lewandowski et al., 2020). Starting in July 2020 Statistics Canada has been giving disaggregated labour market information for racialised minorities. They continue to register much higher unemployment rates than those of White Canadians, but the gaps shrank noticeably in November (led by South Asian and Southeast Asian Canadians), reaching 3.3 percentage points.

\section{What difference does a focus on poverty instead of inequality make?}

Canada's multiple public low-income and poverty measures have evolved differently over time (Box 4). Working-age adult absolute poverty rates are still largely aligned with labour-market outcomes (the number of earners in the household), thereby emphasising the importance of boosting labour-force attachment, even if increasing numbers of workers are earning below-poverty level incomes (Stapleton, 2019). Accordingly, poverty rates are highest for people with disabilities (notably those with mental-health issues), lone parents and single working-age adults. But they are especially high for Indigenous Peoples (see below), Black Canadians and Chinese Canadians (double the rate for White Canadians) and above all for West Asian Canadians, Arab Canadians and Korean Canadians (triple the rate for White Canadians) (Hou et al, 2020) (see below). Chronic low-income rates were much higher in 2016 (the latest available data) for immigrants than the Canadian born, no matter how long since they arrived in Canada (Picot and Lu, 2017). In general, poverty rates are highest in the Maritime Provinces (where traditionally unemployment has been higher than average, wages and participation lower, and employment more seasonal) and lowest in the Prairies, which conforms to the pattern of average incomes across Canada.

\section{Box 4. Canada's public measures of low income and the official measure of poverty}

Canadian low-income measures comprise the Low Income Measure, the Low Income Cut Offs and the Market Basket Measure. The first is based on those who do not receive $50 \%$ of national median income and is therefore a relative measure (like the inequality measures above). The second is based on receiving income at which families are expected to spend 20 percentage points more than the average family on essentials (food, shelter and clothing) using estimates from an expenditure survey and is therefore an absolute figure. The last sets 53 regional different thresholds based on the time-varying cost of a basket of goods and services needed to maintain a basic, modest standard of living and is therefore another absolute measure. The Low Income Cut Off rate peaked around 1997 at about $15 \%$ and declined to around $9 \%$ in recent years, while the Low Income Measure has trended up since the late-1980s, reaching $14 \%$ in 2015.

In 2018 the federal government established the Market Basket Measure as Canada's official poverty line. The threshold annual income for a two-adult, two-child family in 2018 ranged from CAD 37397 in parts of Québec to CAD 48677 in Vancouver. In 2020 the basket was reviewed through a comprehensive stakeholder engagement process, since, prior to this review, some critics had opined that it suffered from the assumption that certain important items (the cost of a cell phone in particular) are a fixed proportion of food and clothing outlays and that minimal housing costs were severely underestimated. Both criticisms were addressed, thereby boosting the threshold in some cities (notably by $24 \%$ for a four-person family in Edmonton). The national poverty rate increased from $8.7 \%$ to $11.0 \%$ for 2018 as a result of this review, which continues to reflect a substantial decrease from 2015 when it was $14.5 \%$ according to the revised measure (Djidel et al., 2020). The official statisticians responsible for the Measure are now turning to other communications technologies, child-care expenses, remoteness (though it continues not to reflect poverty for First Nations on reserve), the adjustments for family size and composition and the calculation of the "other" component for more study. But prescription drugs may also be worthy of further consideration in view of the lack of universal coverage 
(see below). And it would be useful to investigate the size of the "poverty premium" in Canada (how much the poor pay for their goods and services because they cannot afford to buy in bulk, they pay higher home insurance as they live in riskier neighbourhoods, they have to access more expensive credit, payday loans in particular, etc.). This premium was estimated at nearly a thousand Canadian dollars per year in the United Kingdom several years ago (Davies et al., 2016).

Canada's relative poverty has largely converged with the OECD average since 2015, notably with lower rates than the United States (Figure 10). That is attributable to a somewhat more redistributive tax and transfer system, although it remains considerably less so than the OECD average. One striking feature is that the level of provincial social assistance is in no jurisdiction sufficient to lift recipients over the Market Basket Measure threshold: even accounting for GST/HST tax credit and Child Benefits, it varies from 39$58 \%$ of that level for single, childless adults and from $67-86 \%$ for single adults with children (Hillel, 2020). Even though absolute poverty rates cannot be compared internationally poverty and low income among Canada's seniors' would seem to be in the middle of the G7 range: higher than the EU-country outcomes, but lower than the others'. Their Low-Income Rate has trended slightly higher since the mid-1990s but remains lower than that of other age groups in Canada. The child poverty rate has fallen moderately over the last 30 years to $10.8 \%$ (18.6\% according to the LIM), in part thanks to a series of policy measures culminating in the Canada Child Benefit (CCB). The CCB helps almost 3.7 million families and about 6.5 million children, with 367000 fewer children in poverty in 2018 than in 2015. According to Campaign 2000 End Child and Family Poverty (2020), in 20171.36 million children were in poverty using the aftertax Low Income Measure. The CCB is estimated to have reduced this by 684000 , while other public policies removed a further 0.4 million, implying that such measures reduced child poverty by $45 \%$. Yet, poverty remains much higher for those with poor access to the CCB: those with precarious immigration status, children in shelters and First Nations children.

Another aspect of financial inequality is asset poverty or asset resilience, i.e. the share of households that could not manage to maintain their well-being at a low-income threshold (half of median income) for three months in the event of a sudden income stop. Based on Statistics Canada's Surveys of Financial Security, it has been shown that the share of asset-poor households is two to three times as large as those in income poverty. Asset poverty grew from 1999 to 2012 (Rothwell and Robson, 2017). Education has similar effects on both asset and income poverty, while immigration status has an influence only on the latter. Signs of financial distress are recourse to payday loans and missing mortgage or other loan repayments, which are all closely aligned with indebtedness and housing tenure (Marshall, 2019).

\section{The recent implementation of a national Poverty Reduction Strategy}

In August 2018 the federal government released Opportunity for All - Canada's First Poverty Reduction Strategy. The Strategy established the Market Basket Measure as Canada's official poverty line. In June 2019 it followed up with the Poverty Reduction Act, which targeted a halving in thus defined poverty from its then latest (2015) value of $12.1 \%$ (since revised to $14.5 \%$ ) by 2030 . An intermediate target of a $20 \%$ decline by 2020 was reached already in 2017 . The latest figure - still for 2018 - is $11.0 \%$. The Strategy also created a National Advisory Council on Poverty to ensure accountability. It is charged with producing an annual monitoring report to the Minister of Families, Children and Social Development, the first of which was expected by the end of 2020 . That report would be given more prominence if it were presented to Parliament instead. At the same time, a dashboard of 12 poverty indicators (in addition to the Market Basket Measure itself) was created for ease of monitoring (Table 4). While a majority have been moving in the right direction, some have been deteriorating, namely unmet housing needs, food insecurity, youth not in employment, education or training, low teen literacy and numeracy, the average poverty gap and the entry rate into poverty. 
Figure 10. Relative poverty is about OECD average despite less redistributive taxes and transfers

A. Poverty rate, at line $50 \%$, after taxes and transfers

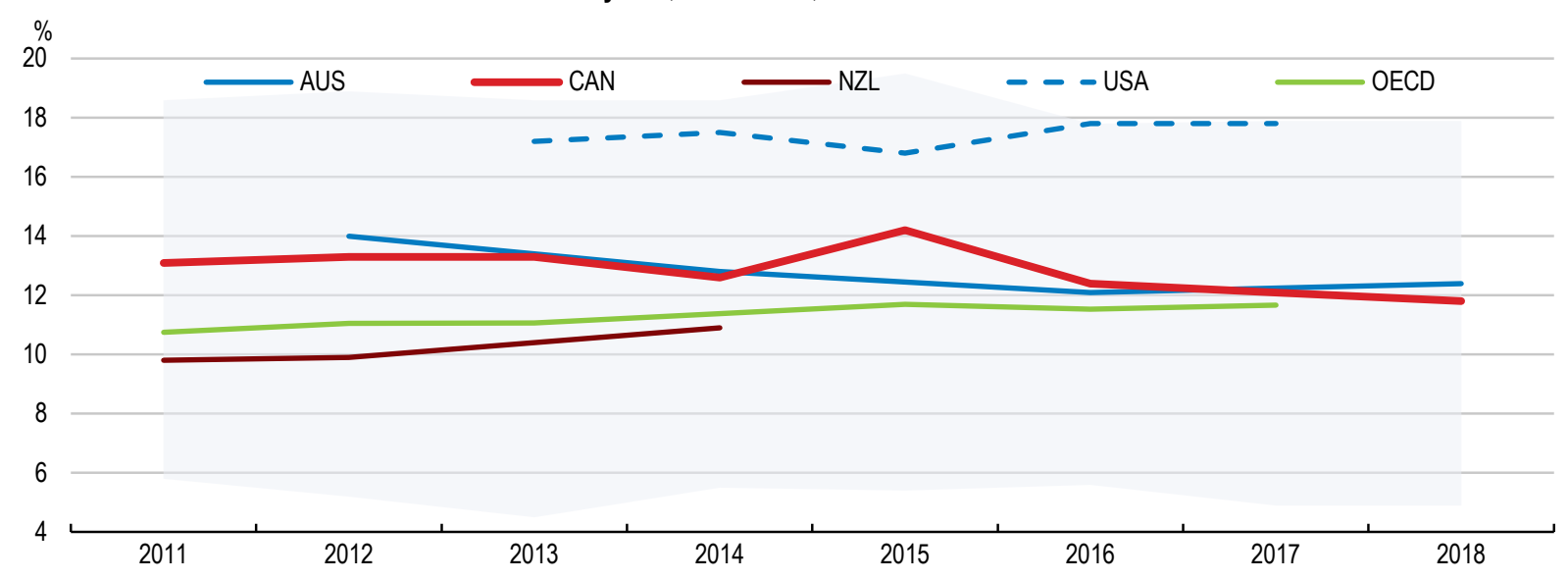

B. Difference in poverty rates before and after taxes and transfers

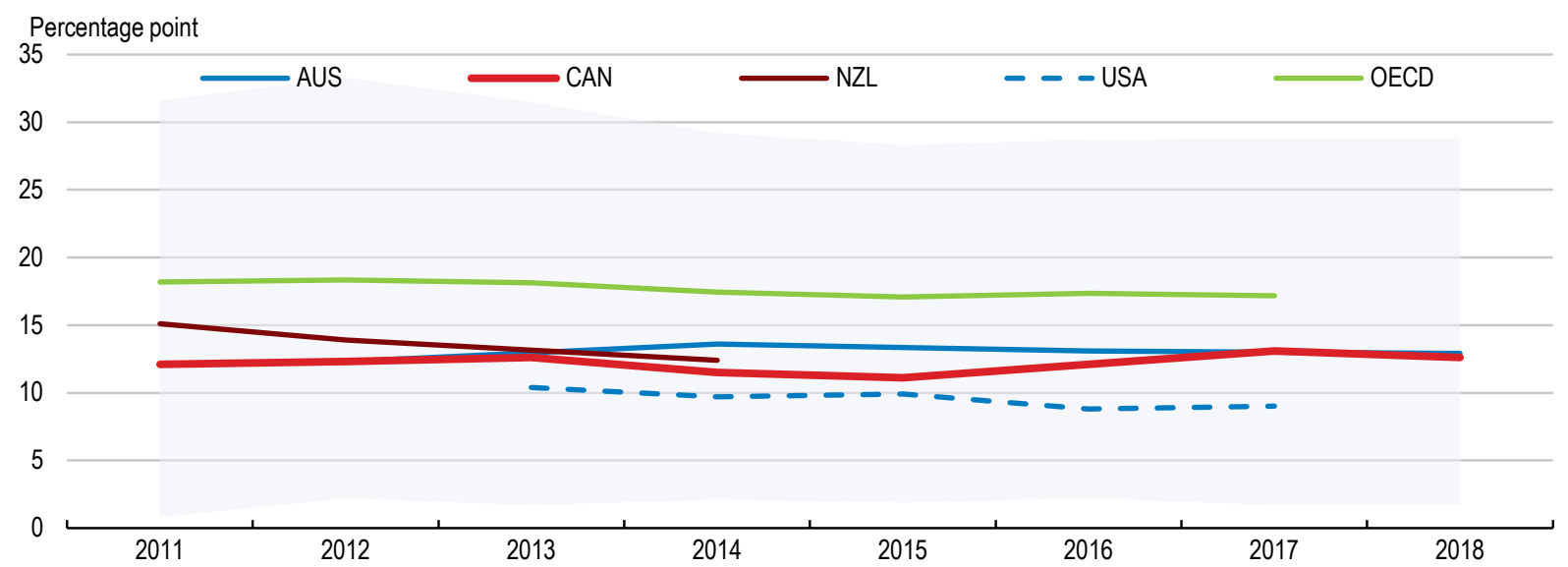

Note: The poverty threshold is set at $50 \%$ of median disposable income in each country. The shaded area shows the range in OECD countries. Source: OECD (2020), Income and Inequality Distribution database.

StatLink ज्ञाs https://stat.link/wtj08e 
Table 4. Canada's official dashboard to track progress on poverty reduction, September 2020

\begin{tabular}{|c|c|c|c|c|}
\hline Indicator & $\begin{array}{l}\text { Most } \\
\text { recent } \\
\text { value }\end{array}$ & Trend & $\begin{array}{l}\text { Percentage } \\
\text { change }\end{array}$ & Reference period \\
\hline \multicolumn{5}{|l|}{ Dignity } \\
\hline Deep income poverty & \multirow[t]{2}{*}{$5.4 \%$} & \multirow[t]{2}{*}{$\nabla$} & \multirow[t]{2}{*}{$-8.5 \%$} & \multirow[t]{2}{*}{2017 to 2018} \\
\hline (Persons with income below 75\% of Canada's Official Poverty Line) & & & & \\
\hline Unmet Housing Needs & $12.7 \%$ & $\Delta$ & $1.6 \%$ & 2011 to 2016 \\
\hline Unmet Health Needs & \multirow[t]{2}{*}{$11.2 \%$} & \multirow{2}{*}{$\nabla$} & \multirow[t]{2}{*}{$-10.4 \%$} & \multirow[t]{2}{*}{$(2000-01)$ to 2014} \\
\hline $\begin{array}{l}\text { (Persons } 12 \text { years and older reporting not receiving health care when } \\
\text { they felt they needed it) }\end{array}$ & & & & \\
\hline Food Insecurity & \multirow[t]{2}{*}{$8.7 \%$} & \multirow{2}{*}{$\triangle$} & \multirow[t]{2}{*}{$4.8 \%$} & \multirow[t]{2}{*}{$(2011-12)$ to $(2017-18)$} \\
\hline (Households reporting Food Insecurity.) & & & & \\
\hline \multicolumn{5}{|l|}{ Opportunity and Inclusion } \\
\hline Relative Low Income & \multirow[t]{2}{*}{$12.3 \%$} & \multirow[t]{2}{*}{$\nabla$} & \multirow[t]{2}{*}{$-2.4 \%$} & \multirow[t]{2}{*}{2017 to 2018} \\
\hline (Persons who had less than half the median after-tax income) & & & & \\
\hline Bottom 40 Percent Income Share & \multirow[t]{2}{*}{$20.8 \%$} & \multirow[b]{2}{*}{$\triangle$} & \multirow[t]{2}{*}{$2.0 \%$} & \multirow[t]{2}{*}{2017 to 2018} \\
\hline $\begin{array}{l}\text { (Percentage of total after-tax income that went to those in the bottom } \\
40 \% \text { of the income distribution.) }\end{array}$ & & & & \\
\hline Youth Engagement & \multirow[t]{2}{*}{$11.7 \%$} & \multirow[b]{2}{*}{$\triangle$} & \multirow[t]{2}{*}{$23.2 \%$} & \multirow[t]{2}{*}{2019 to 2020} \\
\hline $\begin{array}{l}\text { (Persons aged } 15-24 \text { who were not in employment, education or } \\
\text { training.) }\end{array}$ & & & & \\
\hline \multicolumn{5}{|l|}{ Literacy and Numeracy } \\
\hline - Low Literacy ( 15 year olds) & $13.8 \%$ & $\triangle$ & $29.0 \%$ & 2015 to 2018 \\
\hline - Low Numeracy (15 year olds) & $16.3 \%$ & $\Delta$ & $13.2 \%$ & 2015 to 2018 \\
\hline \multicolumn{5}{|l|}{ Resilience and Security } \\
\hline \multicolumn{5}{|l|}{ Median Hourly Wage } \\
\hline - All & $\$ 24.04$ & $\triangle$ & $2.2 \%$ & 2018 to 2019 \\
\hline - Women & $\$ 22.00$ & $\triangle$ & $0.4 \%$ & 2018 to 2019 \\
\hline - Men & $\$ 26.00$ & V & $2.0 \%$ & 2018 to 2019 \\
\hline Average Poverty Gap & \multirow[t]{2}{*}{$33.4 \%$} & \multirow[b]{2}{*}{$\Delta$} & \multirow[t]{2}{*}{$1.5 \%$} & 2017 to 2018 \\
\hline $\begin{array}{l}\text { (For those living below the poverty line, the poverty gap ratio is the amount } \\
\text { that the person's disposable family income is below the poverty line, } \\
\text { expressed as a percentage of the poverty line.) }\end{array}$ & & & & \\
\hline Asset Resilience & $51.2 \%$ & $\triangle$ & $10.8 \%$ & 2005 to 2012 \\
\hline (Persons who had enough savings to maintain well-being for three months.) & & & & \\
\hline Low Income Entry and Exit Rates - Entry Rates (All Canadians) & $4.1 \%$ & $\Delta$ & $5.1 \%$ & (2015-16) to $(2016-17)$ \\
\hline Low Income Entry and Exit Rates - Exit Rates (Low-income Canadians) & $27.9 \%$ & $\triangle$ & $1.1 \%$ & (2015-16) to (2016-17) \\
\hline
\end{tabular}

Source: Statistics Canada.

\section{Food insecurity as a manifestation of poverty}

Food insecurity affects one in 12 households (3.0\% are severely food insecure, $5.7 \%$ moderately so; in addition, another $4.0 \%$ are marginally insecure), including more than one in six children, and is particularly severe (afflicting more than one in four) among those identifying as Indigenous or Black or who have immigrated to Canada in the last five years (Tarasuk and Mitchell, 2020; Statistics Canada, 2020b). It is especially prevalent in the territories, above all Nunavut (57\%). Most sufferers had employment income, even if its prevalence is especially severe among those reliant on social assistance $(60 \%)$ and on Employment Insurance or Workers' Compensation (32\%). Once the COVID-19 pandemic struck, Statistics Canada data from a new web panel survey showed that $14.6 \%$ of Canadian households experienced food insecurity in May 2020. 
Food insecurity has multiple effects, notably on health. Those who are severely food-insecure in Ontario incur public health-care costs 2.5 times as much as others because of their higher rates of diabetes, hypertension and food allergies, and the premature death they experience (they die on average nine years earlier). It is reflected in the use of food banks, which has more than doubled in the past 30 years to some 900000 users per month. Before the pandemic, the federal government announced that it would spend CAD 134 million on a variety of new food and agriculture measures, including food banks, farmers markets, community kitchens and, in conjunction with the provinces and territories, a national school food programme (Agriculture and Agri-Food Canada, 2020). Special measures also exist in remote northern communities. Then, after the pandemic hit the federal government established a CAD 200 million Emergency Food Security Fund, half of which was allocated by the autumn.

Yet, as food security advocates have long noted, this issue does not merely reflect access to food and will not be solved by food banks (which rely on highly processed, shelf-stable food) alone. Food insecurity and the higher rates of chronic diseases associated with it are linked to poverty, and its eradication will require improved food access -- more convenient location of grocery stores and overcoming the abundance of low-cost, fast-food options ("food deserts") -- and adequate income and awareness to be able to afford and choose nutritious food.

\section{A basic income scheme is much discussed but would be expensive}

Basic income generally refers to a direct cash transfer to recipients with few conditions to allow them to meet their basic needs. The current system of provincial and territorial social assistance ("welfare") programmes (which had over 1.58 million beneficiaries in 2019) provides only a survival level of means and is a far cry from what is required to escape at least the monetary aspects of poverty for those ineligible for other government transfers. Recognising this is only the first step to seeing the advantages of guaranteeing citizens and permanent residents enough income to avoid not only material deprivation but also social exclusion and injustice. Advocates of basic income (such as Forget, 2020) argue that it could not only effectively tackle poverty and inequality but also address the changing nature of work, which finds more people in non-standard jobs, and promote population health and well-being. It could also enhance automatic stabilisation during economic downturns and might allow the social safety net to be streamlined and more efficient. On the other hand, critics worry about the fiscal costs and possible work disincentives and oppose payments without requirements to work or seek work. Some would prefer that governments increase pro-poor spending on social services such as prescription drug and dental coverage, childcare and affordable housing. Canadian social policy already had some minimum income guarantees for children (the Canada Child Benefit) and for retirees (the Guaranteed Income Supplement) prior to the pandemic, but the gaps in the social safety net have been brought into sharper focus by the current crisis.

Besides the 2017-18 universal basic income pilot in Finland (Kangas et al, 2020) and a number of municipal initiatives around the world (OECD, 2017b), there is a long tradition of Canada of experimentation with guaranteed minimum income schemes, the difference between the two being whether or not they include clawbacks at some point to avoid paying the transfer to the already affluent. The Mincome pilot in Dauphin, Manitoba, was conducted from 1974 to 1978 and covered about 10000 people. Another variant was the community wage in return for work - an idea disliked by some experts even if it buys political support, because of the extra administrative costs involved and the fact that it retains the stigmatisation of the poor (Boadway et al., 2016) - on locally developed projects in Cape Breton (Nova Scotia) under the Community Employment Innovation Project. It ran for several years starting in 1999 and was judged a success once the improvement in social trust was taken into account (Helliwell et al., 2020a).

Ontario also ran a project in three areas in the province from October 2017 until its cancellation was announced following a change in government in 2018 (payments continued until March 2019). Two small surveys of beneficiaries indicate a variety of benefits (Basic Income Canada Network, 2019; Ferdosi et al., 2020): improved physical and mental health following the adoption of a healthier diet, smoking or drinking alcohol less often, and more frequent physical activity; less use of food banks; greater motivation to find a 
better paying job; and higher likelihood of beginning an education or training programme. The first also found that, once the programme was cancelled, $80 \%$ of respondents reported that previous health problems returned and $61 \%$ that they had to alter future plans. Presumably, with a permanent basic income scheme in place, workers would also be able to walk away from unsafe workplaces in both pandemic and normal times, giving them more leverage when employers have the stronger bargaining position.

The political difficulties of organising a national guaranteed minimum income are substantial because of joint government jurisdiction. Otherwise, the main barriers are the huge expected fiscal cost of a programme large enough to matter in the fight against poverty with a small enough clawback rate not to constrain work incentives excessively and the need to avoid negative impacts on a large number of people, assuming existing transfers would be cancelled (OECD, 2017b). A recent costing of a particular guaranteed minimum income scheme by the Parliamentary Budget Officer (2020) that would pay the same benefits to those aged 18-64 as did the cancelled Ontario pilot (which offered $75 \%$ of the Low-Income Measure, viz. around CAD 17000 and 24000 annually tax-free for individuals and couples, respectively, plus an additional CAD 6000 for people with disabilities) pegged the annualised cost in 2021-22, without considering any behavioural reactions such as possible adverse labour-supply effects (Clavet et al., 2013) at CAD 82-184 billion (some 4-8\% of GDP), depending on the benefit's phase-out rate per dollar of employment income (ranging from 50\% down to 15\%). However, over CAD 30 billion in saving could be expected from the cancellation of other federal fiscal measures that would arguably no longer be needed, leaving a potential net cost of as little as CAD 50 billion (about 21/2 per cent of GDP). That could be further sharply reduced at a general government level if provincial income assistance spending could be shifted towards such a scheme. Assumptions in another recent study were more generous, with annual benefits of CAD 22000 and 31000 for working-age individuals and couples along with a $40 \%$ clawback rate (Pasma and Regehr, 2019). This base case was estimated to cost CAD 134 billion (5.8\% of GDP) annually. If the scheme were extended to include all adults including pensioners, the estimated gross cost would rise to CAD 187 billion ( $8 \%$ of GDP), though of course it could be offset by winding down the Guaranteed Income Supplement programme for the elderly, which will soon cost some CAD 20 billion per year.

The premise that getting people above the poverty line from just below it automatically improves their wellbeing has been challenged by Kumar et al. (2017) based on the Minimum Income for Healthy Living approach developed in the United Kingdom. For individuals to achieve a dignified life (to "thrive"), they need far more than having their basic needs met. This could cost CAD 46 000-55 000 per year for a single, non-elderly Torontonian, about double the Market Basket Measure value.

\section{Some less costly ways to confront poverty}

The least-cost solution to the problem of poverty is to make targeted increases in individual incomes via the tax and benefit system. Many observers argue that an expensive universal basic income or similar transfer programme is not needed to handle the poverty problem and that a well-designed tax-cum-socialassistance reform could suffice. In principle, in 2018 all Canadians could have been lifted above the Market Basket Measure poverty line with only CAD 18.5 billion in extra transfers (Hillel, 2020, p. 26). Details of three such proposals are provided in Box 5. Indeed, in a very recent exhaustive assessment of alternative approaches to treating the poverty problem in British Columbia Green et al. (2020) judged that a basic income programme was not the most cost-effective strategy to achieve poverty reduction with a view to moving to a more just society, judging it to be too individualistic and lacking in a spirit of community, social interactions, reciprocity and dignity. 


\section{Box 5. Three options to confront the poverty problem through tax/transfer system reforms}

Some researchers have devised hypothetical reforms where a guaranteed minimum income is financed by cuts to tax expenditures and other benefits without considering any linkage of benefits to labour market activation. Wolfson (2018) outlined a "guaranteed income/simplified tax" proposal that could provide every adult CAD 8000 and every child CAD 5000 per year with a marginal total tax rate of $38 \%$ up to CAD 125000 per year and $50.2 \%$ thereafter. Financing would be fully provided by abolishing the basic personal exemption and all refundable tax credits, capping tax benefits on contributions to retirement savings and pension plans at CAD 10000 per year and making capital gains fully taxable.

In a similar vein, using 2015 data, Stevens and Simpson (2017) argued that eliminating the basic deduction and five other tax credits could allow a refundable tax credit of CAD 6657 per adult (plus an extra CAD 1500 for people with disabilities and CAD 750 for caregivers) with only a $15 \%$ clawback rate. Replication at the provincial level would allow payments ranging from CAD 8777 per person in British Columbia to CAD 13973 in Québec. But it would still leave a net fiscal cost of CAD 8.1 billion (about $10 \%$ of the pay-outs) due to the $1.8 \%$ overall loss of earnings from the calculated workdisincentive effects. Poverty (as measured by the Low Income Cut Off) would be eradicated except for a rate of $19 \%$ for the single non-elderly and $1.8 \%$ for non-elderly childless couples; the overall poverty rate would drop from $12.0 \%$ to $5.2 \%$.

Finally, Boadway et al. (2016) favoured getting rid of all tax credits and applying a $30 \%$ clawback rate, which would allow annual payments of CAD 20000 per adult within an equivalised scale, a slightly larger earnings loss of $2.2 \%$ and a sharper fall in overall poverty (to $3.2 \%$ ) than the Stevens and Simpson proposal.

Some observers believe that the new benefits provided in the wake of the pandemic can be transformed into a guaranteed minimum income. The federal government decided to replace the Canada Emergency Response Benefit on 27 September 2020 with the Canada Recovery Benefit for those ineligible for Employment Insurance - the self-employed in particular - who have lost at least half of their earnings because of the pandemic and are looking for work, something that will raise difficult administration and enforcement issues (Boadway, 2020). The Recovery Benefit is a set amount of CAD 500 per week (CAD 450 after withholding tax) for up to 26 weeks in the following 12 months, implying only a small decline in income for those previously working full-time in a minimum-wage job. It allows recipients to earn more income (up to CAD 38000 per year) than either the Canada Emergency Response Benefit or Employment Insurance before starting to claw it back through the tax system (at a 50\% rate, meaning it is all gone only for those with annual income exceeding CAD 64 000). In that sense it has some of the features of a basic income, but costs less because it excludes those who have not been working at all and those whose earnings were lower than CAD 5000 in 2019 or 2020, which is therefore a key reason why these measures are considered to be "basic income". An unfortunate feature as far as work incentives are concerned, however, is that the effective tax rate on earnings above the threshold is very high, since personal income tax is applicable in addition to the clawback: some estimates point to marginal rates of around $80 \%$ (Boadway et al., 2020). The Canada Recovery Benefit will run for a year at a budgetary cost of CAD 9.7 billion. At the same time the federal government established a floor for Employment Insurance payments (which replace $55 \%$ of wages) also of CAD 500 per week and temporarily cut the number of insured hours needed to qualify to 120 for regular benefits and offered additional support for those ill with COVID-19 as well as caregivers; in total these changes are estimated to cost CAD 33 billion over two years. At this point the Canada Recovery Benefit has not been integrated with other social spending measures, which will no doubt generate inefficiencies.

In sum, Canadians seem to have moved a fair distance since the advent of the pandemic to endorsing the idea of providing more financial support for the poor and unfortunate in society. This is a praiseworthy goal and could be achieved at least cost by means of enhancing existing social assistance schemes or by a carefully designed tax reform. 


\section{The challenges relating to housing affordability and homelessness}

\section{Affordability problems are widespread and concentrated among those on low incomes}

Housing is obviously a key direct driver of overall individual and social well-being (OECD, 2019, p.156) and a bulwark for public health. In some form it figures in almost all the major composite indexes and dashboards of well-being in Canada and abroad. Canadians are by and large satisfied with their homes: in a 2018-19 survey of 65000 Canadian households Statistics Canada (2019) found that $82.6 \%$ of respondents were either satisfied or very satisfied with their dwellings and $85.6 \%$ with their neighbourhoods. Energy efficiency was cited as the characteristic garnering the least satisfaction (62\%) (Fonberg and Schellenberg, 2019). Affordability was also seen as a problem, with $30 \%$ less than satisfied, led by Toronto renters (48\%) and Vancouver owners (58\%). Homeowners seem to be happier than renters (Hardoon, 2020; Shi et al., 2019; Lemyre et al., 2018), especially if they are mortgage-free (Fonberg and Schellenberg, 2019). And those happiness outcomes extend to their health, with those having difficulty paying their housing costs reporting poor self-rated health more frequently (Pollack et al., 2010). One major exception to the predominance of satisfaction is in the North where the need for more and better housing is chronic, affordability problems abound, and homeownership rates are lower than elsewhere (Canada Mortgage and Housing Corporation, 2020).

Canada's major social inclusiveness challenges with regard to housing are: first, poor affordability mainly among lower-income groups, especially in major cities, notably Vancouver and Toronto (Figure 11, Panel A); and second, homelessness among the at-risk populations who suffer from incomebased poverty but also from mental- and physical-health and substance-use and discrimination problems. Besides inclusiveness, housing markets should ideally be efficient and environmentally sustainable (OECD, 2020a). In general, Canada's housing market performs well along the first of these dimensions, less so along the second.

\section{Figure 11. House price developments}
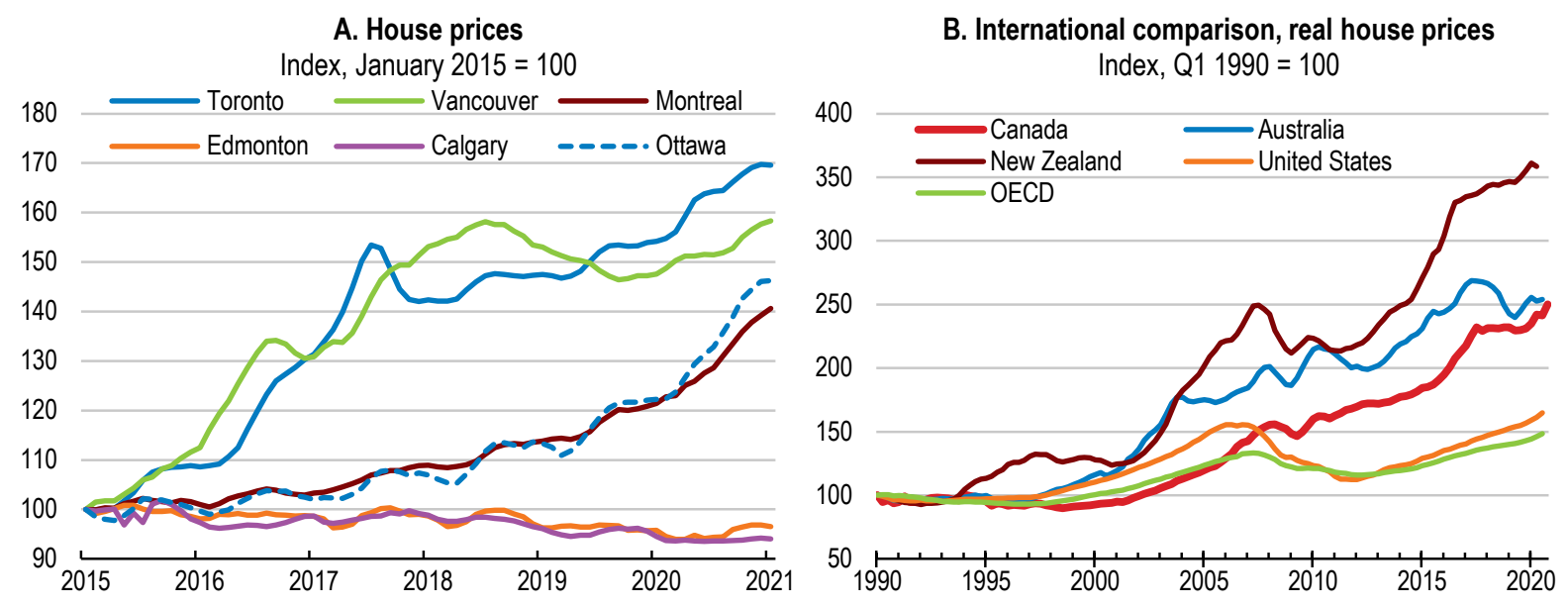

Source: Teranet-National Bank of Canada House Price Index (housepriceindex.ca); OECD Economic Outlook database. 
Canadian housing prices have not undergone any obvious national downturns for a very long time, even if regional markets have had bouts of weakness, such as Alberta's since the 2014 oil-price decline. Many observers had expected some weakness to emerge during the pandemic, but exactly the opposite has occurred, with strong price appreciation taking place in numerous local markets for single-family dwellings, despite an extremely robust supply response. The share of total consumption for the average household spending on own living quarters rose from $21.0 \%$ in 2010 to $22.5 \%$ in 2017 , a trend that is common among OECD countries (OECD, 2020a, Figure 1.4). In 2016 it took about 10 years of disposable income for an average household to afford a typical 100-squre metre dwelling, up from only about seven years of income in 2000 (op. cit., Figure 3.1). At that point the spread of shelter spending by pre-tax income quintile ranged from $34.8 \%$ for the poorest to $27.4 \%$ for the most affluent; the gap of 7.4 percentage points compares to only 2.1 percentage points for food. Clearly, even if low mortgage rates have eased the debt-service burden for most homeowners, housing affordability has worsened for the poorest Canadians whose incomes have not kept pace with the rise in house prices that followed the downtrend in interest rates.

Prolonged strong growth in house prices is also generating inter-generational inequities: younger generations have had to delay moving out of the parental home (that is, fewer households have been formed; Leon and Iveniuk, 2020) and/or have been renters longer than earlier cohorts in order to build up enough savings for a down payment that in 2018 reached almost eight months of income for a first-time buyer with median income in Vancouver (Finance Canada, 2018). There has also been a sizable shift from single-family houses to multi-family apartments occupied by those in the 20 to 34 age bracket. Most obviously, overall household indebtedness has continued to rise (Figure 12), which stands out as one of Canada's few black marks among the indicators in the OECD's Better Life Index (OECD, 2020f). While insolvencies have plunged during the pandemic, a sharp reversal is expected once government support is withdrawn (Cision, 2020). Involving non-profit credit counselling services alongside government support measures would surely yield sizable benefits, even if Canadian youth outperform most others in financial literacy in the OECD's Programme for International Student Assessment, as do adults in other contexts (Klapper et al., 2015).

Canadians allocate an average of about $24 \%$ of their final consumption to housing (including water, electricity and fuels), almost two percentage points over the OECD average, but about five less than the leading Finns. A similar story pertains for imputed rents for homeowners. One study argued that the situation is especially acute in Nova Scotia whose average household allocated $47 \%$ of net income to housing in 2014, about 10 points more than 20 years earlier and eight more than the Canada-wide average (Engage Nova Scotia and the Canadian Index of Wellbeing, 2018). But, on the other hand, Canadians enjoy much more living space than most other OECD residents: Canada is the OECD's top country in terms of the number of rooms per person (OECD, 2020f), and the overcrowding rate among even lowincome households in 2018 was only $1.1 \%$, compared to a Member-country average of $16.2 \%$. What is crucial is the number of people who cannot afford to live in a small but decent dwelling and of low-income households in dwellings that are not properly maintained, resulting in outstanding needs for major repairs (6.5\% of all private households lived in such dwellings in $2016: 5.6 \%$ of owners and $8.0 \%$ of renters). 
Figure 12. Household indebtedness

$\%$ of disposable income

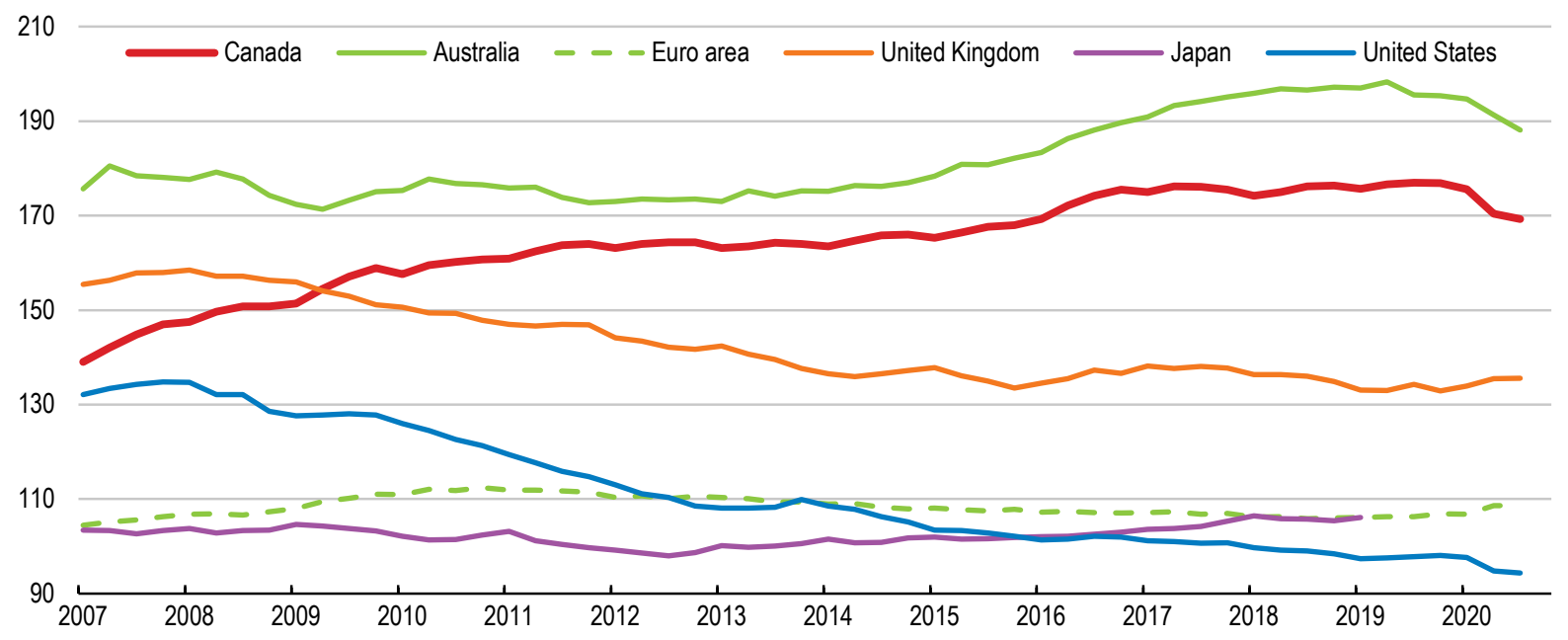

Source: OECD, National Accounts - Household Dashboard database.

StatLink त्ञाs https://stat.link/bg512v

Canada's homeownership rate of $68.5 \%$ is just slightly above the OECD average of $67.8 \%$, but the share of homeowners without a mortgage is much smaller. Homeownership is much more skewed by income than for most Member countries, however, as about $90 \%$ of those in the top income quintile were homeowners in 2016 , compared to less than $30 \%$ of those in the bottom quintile (Figure 13).

Figure 13. The homeownership rate is near the OECD average but skewed towards the affluent Share of homeowners across the income distribution, 2016

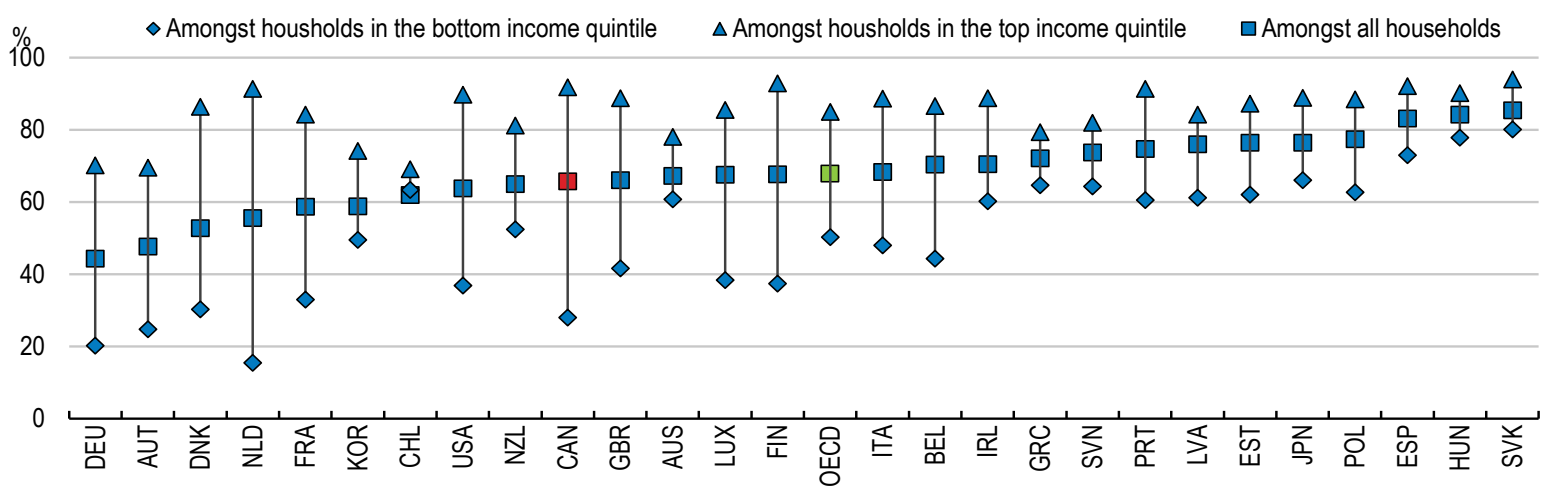

Note: Homeownership among households in the bottom net wealth quintile can be higher than among all households (e.g. in the case of the Netherlands). This is the result of composition effects in the bottom net wealth quintile. Net wealth is equal to total assets minus total liabilities, the bottom net wealth quintile can thus be composed either of low asset households, or of highly-leveraged households. Countries that experienced sharp declines in house prices in the period before 2014 (such as Ireland and the Netherlands) display high homeownership in the bottom net wealth quintile because many homeowners experienced shrinking net wealth and even negative equity due to high leverage in combination with asset depreciation. This shifted the composition of the bottom net wealth quintile towards more homeowners with a mortgage. Source: OECD Wealth Distribution Database (oe.cd/wealth). Household Economic Survey database for New Zealand. 
High spending on housing is an issue mainly for those on low incomes. The so-called "cost overburden rate" - the share of households spending more than $40 \%$ of their gross income on housing - was $34.7 \%$ among renters in Canada in 2016, just above the OECD average figure (but for low-income owners with a mortgage it was $39 \%$, well above the OECD average of $25.4 \%$ ). Canadians consider housing to be affordable when it costs less than $30 \%$ of their gross income and in "core (or severe) housing need" when their housing costs more than $30 \%(50 \%)$. For a small number of extreme cases ( $8.1 \%$ of all renters), housing costs reach over $80 \%$ of income (Rech, 2019). However, the problem is one of distribution, since for all owners and private-market renters together the shares in core and severe housing need are only $5.2 \%$ and $15.3 \%$, respectively, lower than the corresponding US figures of $6.5 \%$ and $19.7 \%$, for example. Not surprisingly, affordability is an especially difficult problem in Vancouver and Toronto, which are ranked second and sixth least affordable of the 92 major markets in the countries covered by Demographia (2020) based on their multiples of median house prices over median gross pre-tax household incomes (11.2 and 8.6, respectively). Over the past decade these price pressures have spread outwards into nearby parts of British Columbia and southern Ontario.

A larger-than-OECD-average share of renters is in private-market rentals, as social housing (governmentowned housing, which is the primary form of affordable housing) now represents less than $4 \%$ of the total housing stock (about half the OECD average share: Figure 14), the bulk of which was built in the 1960s and 1970 s and is reaching the end of its useful life (without refurbishment). Since the presence of social housing exerts a moderating influence on nearby private rents, the shrinkage of the social stock has also been a boon to private landlords. Real government spending to fight housing poverty began to shrink already in the mid-1980s. The federal government essentially withdrew from financing affordable housing in the early 1990s. By 1996 new social housing construction had almost completely dried up. The shortage of social and affordable housing remains. While there were 629000 households who reported living in social and affordable housing in late 2018, 284000 reported having at least one member on a waiting list (although about a fifth of such households were already in a subsidised unit), 61\% of which had been waiting for two years or more (Statistics Canada, 2019). A disproportionate share of the wait listed are in Ontario (3.4\% of its population), Toronto in particular (Auditor General of Ontario, 2017). There, only 20000 of the 285000 below-market-rental units were built after 1996, compared to 1.36 million other dwellings.

Figure 14. The size of the social housing stock is relatively low in Canada

Social rental dwellings, as a \% of the total housing stock, 2018 or nearest year

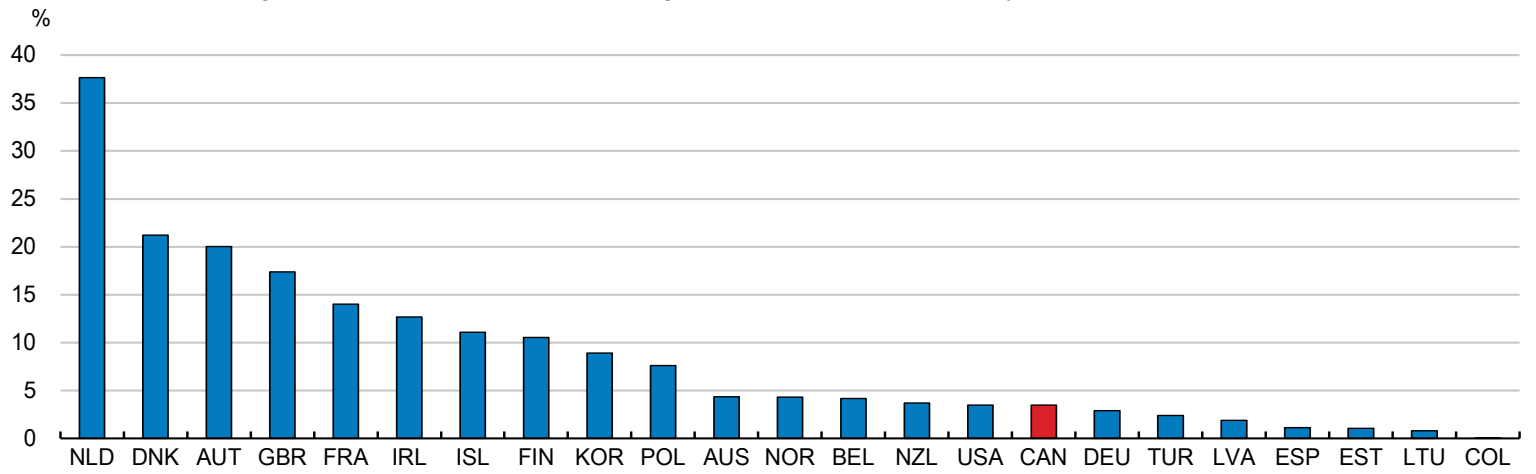

Note: For New Zealand, data refer to the number of social housing places (public housing) that are funded through central government and do not include social housing provided by local authorities. For the United States, the social housing stock includes public housing, subsidised units developed through specific programmes targeting the elderly (section 202) and people with disabilities (section 811), as well as income-restricted units created through the Low-Income Housing Tax Credit (LIHTC) programme; the number of public housing units as well as section 202 and 811 dwellings financed through the LIHTC programme have been adjusted to avoid double-counting, following OECD correspondence with the U.S. Department of Housing and Urban Development. For Canada, data exclude units managed by the Société d'habitation du Québec (SHQ) for the Province of Québec. Turkish data includes only social housing produced between 2002 and 2020 by the Housing Development Administration (TOKI) and exclude those provided by local governments. For Spain, the figures may also contain other types of reduced rent housing, e.g. employer-provided dwellings. For Colombia, data refers only to social rental housing produced since 2019 in the semillero de propietarios programme.

Source: OECD, Housing Synthesis Report (forthcoming). 


\section{The federal government has implemented a National Housing Strategy}

The then newly elected federal government developed the first National Housing Strategy (A Place to Call Home) in 2017. The ten-year, initially CAD 40 billion plan (an average of $0.2 \%$ of current GDP; since expanded to over CAD 55 billion in the 2018 and 2019 Budgets) is designed to reduce or eliminate housing need for some 530000 households of the 1.7 million judged to be in core housing need in 2016 and reduce chronic homelessness by half by 2027-2028. Through a combination of CAD 16.1 billion in extra federal funds, pre-existing federal budgets and matching funds from provinces and territories it will: 1) finance up to 125000 new homes (over four times the number in the decade ending in 2015); 2) repair and renew a further 300000 units (three times as many as in the previous decade) to catch up on deferred maintenance and improve energy efficiency; 3) provide CAD 1.74 billion for several Indigenous-led housing measures; and, 4) (as of April 2020) provide a new Canada Housing Benefit directly to an estimated 300000 recipient households in need, worth an average of CAD 2500 per year by the end of the decade. Such housing allowances avoid disincentives to mobility and may be more equitable than affordable housing, yet they may also perversely raise rental prices (Salvi del Pero et al., 2016). In 2020 the federal government also launched the Rapid Housing Initiative, a CAD 1 billion dollar measure for the rapid construction of as many as 3000 permanent affordable housing units.

\section{Options for improving housing affordability}

Increasing the supply of housing would help to improve housing affordability. While Canada's estimated long-run housing supply elasticity seems to vary substantially across the country (from less than 0.5 in Toronto and Vancouver to about 2.0 in Edmonton) due to different geographic constraints and regulatory settings (Canada Mortgage and Housing Corporation, 2018), its national housing supply elasticity is only average by OECD standards (Cavalleri et al., 2019). It could have been expected to be greater than that because of its extensive land availability (even if most people live in a narrow strip of land near the US border). Raising it would ease the housing cost burden (Cavalleri et al., 2019). This could be done in Canada by ensuring a competitive construction sector, reducing rent controls and relaxing strict zoning and land-use regulations and urban containment policies, which serve to raise land values, generate greater urban sprawl and slow local growth (Demographia, 2020; Green et al., 2016). The authorities have recognised the importance of encouraging more supply and in August 2020 announced a five-year CAD 300 million Housing Supply Challenge, with CAD 25 million in a first round focusing on data gaps and future rounds related to other aspects of supply including northern housing.

Demand factors could also play a crucial role in rising house prices and increasing affordability problems (Gordon, 2020a). Declining (real) mortgage rates have been the most important factor in boosting demand and improving affordability for buyers. Tax considerations are also important. Even if tax relief for homeowners is comparatively limited and residential property taxes are heavy, the system is by no means neutral between owning and renting. Property taxes could conceivably be made progressive and landvalue-capture taxes/fees for capital appreciation due to publicly provided infrastructure could be instituted, as in New Zealand. Gordon (2020b) argues that non-residents, mainly from China, have a tax advantage over those paying income tax in Canada in using their cumulated wealth to purchase Canadian property and shows that the non-resident share of purchases is a significant determinant of housing price-to-income ratios in Vancouver and Toronto. One solution is to tax foreign purchases, as British Columbia and Ontario have done (even if these taxes may be skirted by using proxy buyers not subject to the tax or by opaque corporate ownership structures). Another is to tax foreign speculators who leave their properties vacant, as British Columbia started to do at end-2018 with its Speculation and Vacancy Tax (Gordon, 2020b). These policies seem to have had some limited success, though disentangling the effects from those of actions by the Chinese authorities to discourage such capital outflows to avoid excessive risk-taking is difficult. Finally, in principle of course, non-residents could be made liable for a penalty rate of local property tax as well. 
Policies could also focus to a greater extent on keeping rents affordable. To that end the federal government just announced its intent to boost the existing Rental Construction Financing Initiative by CAD 12 billion over seven years. It allows the Canada Mortgage and Housing Corporation to provide lowinterest loans and mortgage insurance for developers of purpose-built rental housing. The extra funds should allow the construction of some 28500 units. Some call for a sizeable increase in the existing CAD 13.2 billion National Housing Co-Investment Fund (Campaign 2000 End Child and Family Poverty, 2020; CCPA, 2020), which supports new construction and renovation of existing units and requires applicants to keep rents for at least $30 \%$ of units in supported projects below $80 \%$ of the area's median market rental rate for 20 years. The generosity of the Canada Housing Benefit could also be further boosted (CCPA, 2020), though some of the benefit will leak into rents and therefore accrue to landlords, especially in tight local housing markets where supply is inelastic. In addition, governments could prioritise social and affordable housing when disposing of surplus land, as was begun on a modest scale under the Federal Lands Initiative in 2019 with five sales in four cities.

Some of the features of Ontario's affordable-housing system need to be reconsidered. First, municipal providers should require those who no longer qualify for such housing to leave, as all four western provinces allow for, although there are trade-offs to incentivising better-off tenants to move out ("throughfare") (OECD, 2020k). Second, providers should be required to prioritise more generally those in greatest need of housing, not just victims of family violence. All providers should implement maximum asset tests so as to preclude those having over a million dollars in assets being eligible. Third, the province should examine ways of avoiding the apparent poverty trap that discourages people from getting a job if they lose their rights to such housing and end up worse off.

Innovative forms of housing and its financing should be piloted and encouraged so as to encourage a faster shift away from the idealised single-family home, whose predominance has led to excessive use of cars, with their costly externalities in terms of congestion, air pollution and carbon emissions. Besides changing urban planning so as to increase urban density that would justify greater investments in public transit. In addition, more emphasis could be given to general "co-living" arrangements (with small private bedrooms and large communal social spaces) for single-person households and to mixing housing of different kinds (such as combining seniors' with either student housing or childcare, as Japan has done in its yoro shisetsu) (OECD, 2020l). Redundant office space from increased teleworking and hotels and motels bankrupted during the current economic crisis could be turned into affordable housing. More lowcost modular housing could be built. A larger financial boost in the form of seed capital (Hunsley, 2020), could be provided for housing co-operatives or trusts (also called associations), which in Canada currently comprise about 93000 households with about a quarter of a million people. Co-operatives play a substantial role in the market in Australia, Austria, Denmark, Germany, the Netherlands and Sweden (OECD, 2020a, Boxes 8.3 and 10.1; Caturianas et al., 2020, Tables 3 and 6) and were estimated in 2003 to be $14 \%$ more cost efficient than other forms of multi-unit housing (Auditor General of Ontario, 2017). Similarly, the First-time Home Buyer Incentive shared-equity programme could be expanded (Temkin et al., 2011); it allows purchasers to have less mortgage debt and share symmetrically in the price risk, while US experience shows that they perform just as well in terms of mortgage delinquencies (Theodos et al., 2019). To this point uptake has been low.

\section{Homelessness is a chronic problem with heavy well-being costs}

Observers have called Canada's homelessness problem a crisis for at least a decade now (Gaetz, 2010). Primary homelessness includes those sleeping rough or in emergency shelters. But there are many others in precarious situations, including those who "couch surf" with friends or family, often termed the "hidden homeless" (OECD, 2020j). Some people experience homelessness over a long period, while for others the condition is transitional. Many are employed, but their wages are so low that they cannot afford food and shelter cost increases. Stakeholders believe that $85 \%$ experience homelessness solely because of affordability issues (Employment and Social Development Canada, 2018b). Increases in homelessness are driven by structural factors (such as tight housing markets, gentrification, the entry of financial investors into the sector, labour market changes and a shrinking social safety net), institutional and systemic failures (when people exit from foster care, the criminal justice system, the military, hospitals and mental-health 
facilities), often in combination with individual circumstances. People experiencing homelessness have clearly suffered even greater deprivation during the ongoing pandemic (CCPA, 2020), which has underscored the cracks in Canada's social safety net, given how difficult social distancing is for those without stable housing and how isolating life is for them. Homelessness often begins with an eviction. OECD data show that Ontario has a very high rate of initiated eviction, surpassed only by the United States. A recent paper by Leon and Iveniuk (2020) examines eviction applications in Toronto neighbourhoods and concludes that they are related to the local poverty rate, the share of Black households and the amount of subsidised housing (negatively).

Canadians experiencing chronic homelessness live as many as 25 fewer years than others (in France the gap is up to 35 fewer years) and (although causality is hard to determine) suffer from higher risks of mental illness (one-third of the homeless suffer from it, especially women (Rech, 2019)), food insecurity (Fafard St. Germain and Tarasuk, 2020), substance-use problems and sexually transmitted diseases. Homelessness also multiplies the costs of other societal ills such as family strife and unemployment (Laird, 2007; OECD, 2020j). It imposes heavy fiscal costs even without explicit policy treatment: people experiencing homelessness require counselling and extra medical and emergency room services and sometimes additional criminal-justice spending. Those costs have been estimated at CAD 55000 per person annually. Indeed, every dollar spent on affordable housing and support for the chronically homeless is said to save CAD 2.20 in public spending for health, social services and justice (Gaetz et al., 2014).

How widespread is homelessness in Canada? The COVID-19 pandemic has had a profound impact on homelessness. During the pandemic, government aid has prevented many of the poorest from losing their homes, and evictions have been curtailed, but there is not yet evidence on increases in its prevalence beyond visible encampments in cities such as Victoria, Toronto and Edmonton. The latest figures (from the March-April 2018 nationally coordinated Point-in-Time count) show that across 61 communities there were about 32000 individuals experiencing homelessness on a single night, of which $65 \%$ were in shelters, $21 \%$ in transitional housing and $14 \%$ sleeping rough, (Employment and Social Development Canada, 2019a). In 2016129127 people (0.36\% of the population) used the nation's 400 or so emergency shelters, including victims of family and gender-based violence. This was down moderately from about 156000 in 2005 and 142000 in 2010. Putting these figures into international context is difficult because of a number of measurement issues (Table 5).

The province of Alberta has managed the steepest decline over time, thanks to its adoption of policies - a long-term strategy involving a multi-level political commitment to end homelessness and a shared, collaborative approach in policy and services - emulating Finland, which has recorded a sharp drop over the last decade, along with only three other EU countries (Baptista and Marlier, 2019). Youth homelessness has also diminished, but the numbers have been increasing for seniors (Employment and Social Development Canada, 2019b). Trends have been disparate: as mentioned, various Albertan cities have made substantial progress in lowering their numbers by adopting more innovative, integrated and cooperative approaches to the problem, but Toronto's situation has grown more severe, as efforts made by the city have been unable to achieve an inclusive regime open to civil society (Doberstein, 2016), and the city has reduced community-based crisis services. Nationally, about $70 \%$ of those accessing shelters are men, $31 \%$ Indigenous (far beyond their $4.9 \%$ population share), $17 \%$ youth and $6 \%$ immigrants/refugees (Baker, 2019). In addition, approximately $20 \%$ experience chronic homelessness (defined as: individuals who have experienced homelessness for at least six months over the past year or have had recurrent experiences of homelessness over the past three years, with a cumulative duration of at least 18 months. Length of stay at shelters has increased in recent years, thus, while overall numbers have declined, nightly occupancy of the approximately 15000 emergency shelter beds available is still over 90\% (Employment and Social Development Canada, 2019b). 


\section{Policies to deal with homelessness}

In principle, policies to address homelessness fall into categories of preventive measures, emergency actions or ways of encouraging people to transition into some form of acceptable and sustainable housing (OECD, 2020j). All three are part of an optimal strategy, but for a long time many countries, including Canada, put too much emphasis on the emergency-measures component, what some have termed "managing the crisis" (Gaetz, 2010). Although responsibility for social and welfare services rests with the provinces and territories, the federal government has made significant investments to support those serving the homeless, including through Reaching Home: Canada's Homelessness Strategy (see below), mainly for health and other services at the community level (Doberstein and Smith, 2016; Gaetz, 2010). On average, approximately CAD 13 was invested in addressing community homelessness issues for every dollar spent by the federal homelessness programme in 2015-16 (Employment and Social Development Canada, 2018a).

Table 5. Homelessness in an international perspective

\begin{tabular}{|c|c|c|c|c|}
\hline & Year & $\begin{array}{l}\text { Number of } \\
\text { homeless }\end{array}$ & $\begin{array}{l}\text { Homeless as } \% \text { of } \\
\text { total population }\end{array}$ & $\begin{array}{l}\text { Figures include more than persons } \\
\text { living rough, in emergency accommodation and in } \\
\text { accommodation for the homeless? }\end{array}$ \\
\hline Australia & 2016 & 116427 & $0.48 \%$ & Yes \\
\hline Austria & 2017 & 21567 & $0.25 \%$ & No \\
\hline Brazil & 2015 & 101854 & $0.05 \%$ & Not provided \\
\hline Canada $^{3}$ & 2016 & 129127 & $0.36 \%$ & No \\
\hline Canada $^{3}$ & 2018 & 32000 & $0.09 \%$ & Yes \\
\hline Chile & 2019 & 14013 & $0.07 \%$ & No \\
\hline Croatia & 2013 & 462 & $0.01 \%$ & No \\
\hline Czech Republic & 2019 & 23900 & $0.22 \%$ & Yes \\
\hline Denmark & 2019 & 6431 & $0.11 \%$ & Yes \\
\hline Estonia & 2011 & 864 & $0.06 \%$ & Yes \\
\hline Finland & 2018 & 5482 & $0.10 \%$ & Yes \\
\hline France & 2012 & 141500 & $0.22 \%$ & No \\
\hline Germany & 2018 & 337000 & $0.41 \%$ & Yes \\
\hline Greece & 2009 & 21216 & $0.19 \%$ & Yes \\
\hline Hungary & 2014 & 10068 & $0.10 \%$ & No \\
\hline Iceland & 2017 & 349 & $0.10 \%$ & Yes \\
\hline Ireland & 2018 & 6194 & $0.13 \%$ & No \\
\hline Israel & 2018 & 1825 & $0.02 \%$ & No \\
\hline Italy & 2014 & 50724 & $0.08 \%$ & No \\
\hline Japan & 2019 & 4555 & $0.00 \%$ & No \\
\hline Latvia & 2017 & 6877 & $0.35 \%$ & Yes \\
\hline Lithuania & 2011 & 857 & $0.03 \%$ & No \\
\hline Luxembourg & 2014 & 2059 & $0.37 \%$ & Yes \\
\hline Mexico & 2010 & 40911 & $0.04 \%$ & Yes \\
\hline Netherlands & 2016 & 30500 & $0.18 \%$ & Yes \\
\hline New Zealand & 2013 & 41207 & $0.94 \%$ & Yes \\
\hline Norway & 2016 & 3909 & $0.07 \%$ & Yes \\
\hline Poland & 2019 & 30330 & $0.08 \%$ & Yes \\
\hline Portugal & 2017 & 4414 & $0.04 \%$ & No \\
\hline Slovenia & 2015 & 2700 & $0.13 \%$ & No \\
\hline Slovak Republic & 2011 & 23483 & $0.44 \%$ & Yes \\
\hline Spain & 2012 & 22938 & $0.05 \%$ & No \\
\hline Sweden & 2017 & 33250 & $0.33 \%$ & Yes \\
\hline United States & 2018 & 552830 & $0.17 \%$ & Yes \\
\hline UK: England & 2017 & (57 890 households) & (0.26\% households) & Yes, but limited to certain priority categories \\
\hline $\begin{array}{l}\text { UK: Northern } \\
\text { Ireland }\end{array}$ & 2018 & (9673 households) & (1.23\% households) & $\begin{array}{l}\text { Yes, but limited to certain priority categories; includes } \\
\text { those threatened with homelessness }\end{array}$ \\
\hline UK: Wales & 2018 & (10 737 households) & (0.80\% households) & $\begin{array}{l}\text { Yes, but limited to certain priority categories; includes } \\
\text { those threatened with homelessness }\end{array}$ \\
\hline UK: Scotland & 2018 & (36 465 households) & (1.50\% households) & Yes; includes households threatened with homelessness \\
\hline
\end{tabular}

1. Methodologies differ across countries for calculating the homeless population, so the counts are not comparable across countries. In particular, since many people cycle in and out of homelessness throughout a year, period prevalence rates are several times larger than point-in-time counts, which measure homelessness on a single night.

2. Refers to population on 1 January of the year of reference, see OECD Population database.

3. Canada: the first, higher figure is a period prevalence figure for the number of emergency shelter users; the lower figure is for a point in time but includes those in transitional housing and sleeping rough.

Source: OECD Policy Brief on Affordable Housing (2020), Indicator HC3.1.1, except for Canada's point-in-time estimate. 
Gradually Canada has joined a large number of other OECD countries in adopting the principle of Housing First, which is based on securing permanent housing as rapidly as possible for those experiencing homelessness and only then dealing with their other problems. At least for highly vulnerable groups, its success has been clearly demonstrated (Stergiopoulos et al., 2015), most remarkably in Medicine Hat (Alberta) where chronic homelessness has been eradicated.

To prevent individuals and families from becoming homeless, more could be done to avoid evictions beyond the current moratoria and other measures taken during the pandemic, such as by focusing interventions at that stage (through better coordination with substance-use and mental-health supports and anti-poverty measures, and improved mediation and strengthened legal aid) and of course by boosting rental supply by the various means discussed in the previous section.

Preventing and reducing homelessness is a key component of Canada's National Housing Strategy, which includes funding of CAD 2.2 billion over 10 years to expand and extend federal homelessness programming. Launched in April 2019, Reaching Home: Canada's Homelessness Strategy is intended to support the most vulnerable Canadians in maintaining safe, stable and affordable housing and to reduce chronic homelessness by half by 2027-2028. It is a community-based programme that provides direct financial support to urban, Indigenous, rural and remote communities to help them address their local homelessness needs, including those of seniors, the LGBTQ2 community, victims of family violence, racialised people, Indigenous peoples, youth, veterans and those with disabilities, mental health and addiction issues. Cumulative additional funding of almost CAD 700 million was announced during 2020 to help the sector manage the impacts of the pandemic and lower the risk of COVID-19 transmission amongst people experiencing homelessness by reducing overcrowding in shelters, establishing isolation spaces and securing additional accommodation, notably over the winter months, as well as by delivering more permanent housing solutions and other prevention activities to stem the inflow into homelessness caused by the economic downturn. A National Housing Council was announced in November 2020, including the yet-to-be-named Federal Housing Advocate. That should be resourced adequately. Annual monitoring reports are to begin soon, outcomes will be analysed and results will help to inform future federal homelessness policy and programme design. Looking forward, the importance of system coordination and governance in tackling homelessness has been emphasised (Doberstein, 2016), and some observers have called for an enhanced federal-provincial partnership on housing issues (CCPA, 2020).

\section{The role of physical and mental health status in determining well-being}

\section{The relative importance of health outcomes in well-being determination}

Health is the dimension of life where there is the strongest consensus across OECD countries about its centrality to people's well-being. In a recent assessment of 20 well-being dashboards developed by Member governments all but one (which focused on environmental sustainability) featured health, and there is also a fairly high degree of alignment among them as to what indicators to use to reflect this dimension (Exton and Fleischer, 2020). Health outcomes - whether measured by objective or subjective indicators - are also important determinants of life satisfaction. Together they explain some $20 \%$ of crosscountry differences, exceeded only by per capita incomes at $49 \%$. In Canada, the life-satisfaction penalty for poor or fair subjectively assessed mental health is even greater than its counterpart for physical health (Shi et al., 2019). Some experts believe that these figures may be biased by common mood effects and so prefer to use objective health indicators (Clark, 2018). The two can give quite different readings at the aggregate level: according to the Canadian Institute for Health Information, in 2015-17 Newfoundland and Labrador has the second best self-reported overall health among Canadian provinces but is among the worst for objective measures like life expectancy at birth or at age 65 .

The most commonly used objective health indicator is life expectancy, though usually there is some sort of adjustment for the person's health status. Canadians have a life expectancy at birth of around 82 years, up around five years since 1990. This places them in the middle of nations at a similar level of income. A 
recently released survey from the Conference Board covering 11 high-income OECD countries in a recent survey by the Commonwealth Fund that shows that Canadians are more likely to have multiple chronic conditions and mental health conditions and an avoidable emergency-room visit in the past two years than most others (Doty et al., 2021).

Income has a large impact on Canadians' life expectancy, as it does on a variety of health-related outcomes including mental illness and suicide rates, with people in top-quintile neighbourhoods enjoying a four-year advantage in life expectancy and about half as many cases of mental illness and suicide as those in a bottom-quintile district (Table 6); unfortunately, no comparable data exist for other countries. Income makes a significant difference to the share of Canadians having multiple health conditions or mental health conditions, as well as in various access measures such as having to skip health care (especially dental care) because of cost, lacking a regular provider or place of care and experiencing difficulties in getting after-hours care (Doty et al., 2021). But it makes no difference in the ability to make an appointment for primary care within a day, no doubt because of the anti-queue-jumping provisions of the Canada Health Act. Differences in education also have a significant impact on health outcomes, as do other measures of socio-economic status; indeed, a few years ago it was estimated that health inequalities led to CAD 6.2 billion in extra annual health-care spending (Public Health Agency of Canada, 2016). Once adjusted for health status the impacts of income and education on life expectancy are much larger: the shortfall is over 11 (adjusted) years for the lowest quintiles in each case. As well, Indigenous people have lower average life expectancy, by about a decade; they also have much more mental illness and higher attempted suicide rates (see section below).

\section{Table 6. Inequalities in life expectancy and hospitalisations for mental illness and suicide}

Comparisons with reference group (male, non-Indigenous identity, high foreign-born population area, large urban centre other than Toronto, Montréal and Vancouver, highest income/education and least deprived quintile areas)

\begin{tabular}{l|c|c|c}
\hline & $\begin{array}{c}\text { Life expectancy: } \\
\text { differences in years }\end{array}$ & $\begin{array}{c}\text { Hospitalisations for } \\
\text { mental illness: rate ratio }\end{array}$ & $\begin{array}{c}\text { Hospitalisations for } \\
\text { attempted suicide: rate ratio }\end{array}$ \\
\hline Female gender & +4.5 & 1.2 & -3.3 \\
\hline Indigenous identity & -10.5 & N.A & 3.7 \\
\hline Area with predominance of First Nations & -11.2 & 3.0 & 2.7 \\
\hline Area with predominance of Métis & -6.9 & 2.1 & 6.5 \\
\hline Area with predominance of Inuit & -12.0 & 2.2 & 1.7 \\
\hline Low foreign-born population area & -2.9 & 1.3 & 1.3 \\
\hline Medium foreign-born population area & -1.0 & 1.1 & 1.9 \\
\hline Remote area & -3.7 & 2.0 & 1.3 \\
\hline Rural area & -1.1 & 0.9 & 1.1 \\
\hline Small urban centres & -1.0 & 1.5 & 0.8 \\
\hline Toronto, Montréal, Vancouver & +1.5 & 0.9 & 1.8 \\
\hline Lowest income quintile area & -4.1 & 2.2 & 1.6 \\
\hline Lowest education quintile area & -3.1 & 1.5 & 1.6 \\
\hline Most materially deprived quintile area & -3.8 & 2.2 & 1.7 \\
\hline Most socially deprived quintile area & -2.8 & 2.9 & 2.7 \\
\hline Highest combined deprivation quintile area & -5.9 & 5.5 & \\
\hline
\end{tabular}

Source: Pan-Canadian Health Inequalities Reporting Initiative (2018), Key Health Inequalities in Canada: A National Portrait, Annexes 1 and 2.

Health inequality in Canada is generally low- to-middle ranking. OECD (2019d) looked at 14 healthinequality indicators in terms of exposure to risk factors and access to health care for 33 countries and found Canada to be in the low-inequality group for five and the intermediate group for smoking, general practitioner and specialist visits and breast-cancer screening (data were lacking for the other indicators). In comparative terms Canada's penalty in terms of self-assessed health for low educational attainment is smaller than the OECD average (OECD, 2020f), and utilisation of health-care services is unequal in a 
variety of dimensions, but especially for dentistry (a finding confirmed by the Commonwealth Fund), no doubt because of its poor insurance coverage (OECD, 2019d; Doty et al., 2021). In addition, specific groups are at a considerable disadvantage. Canada maintains a database of over 100 health indicators disaggregated by 14 social stratifiers and produces a monitoring report every four or five years. Findings of interest are that those identifying as bisexual suffer from noteworthy health inequality (e.g. self-rated mental health, suicide attempts, arthritis and asthma; see (Table 7 below), and otherwise such inequality is highest for Indigenous people and racialised populations.

Canada spends $11.6 \%$ of its GDP on health care, much less than the United States, but well above the OECD average of $8.8 \%$. That share is very likely to rise steadily in coming years, even without any future pandemic (Drummond and Sinclair, 2020), mainly because of population aging and new medical technologies, notably in the form of innovative drugs and those to treat rare diseases.

With provincial/territorial responsibility for the delivery of health care, Canada can compare outcomes regionally and draw the appropriate conclusions from any systematic differences. However, for that potential to be properly exploited, health information systems need to be consolidated (Drummond and Sinclair, 2020), and data quality and timeliness improved. One example is cause-of-death statistics in the current pandemic, which have been gathered and transmitted from the provinces to the relevant central authorities very slowly, encumbering the analysis needed for an optimal policy response. Scotland manages that in merely four days. The role of data and digital technology in achieving health policy objectives has been examined in OECD $(2019 \mathrm{~g})$.

\section{Waiting times have been a longstanding concern}

One longstanding concern in Canada has been waiting times for many different health services (including for mental health, discussed below), notably non-emergency treatments. Survey data published by the Fraser Institute show they reached a median of 21 weeks in 2019 but varied from 16 to 49 weeks across provinces (Barua and Moir, 2019). An estimated $2.9 \%$ of the population was waiting for some procedure at that point in time, leading $1.5 \%$ of the population to seek treatment outside the country during the year. The economic cost of these waiting times aggregated to an estimated CAD 1.9 billion in 2017, counting only lost working time (Barua and Hasan, 2018). No research has looked at how large is the negative wellbeing impact of having to wait for treatment. Official data tell a similar story. Despite governmentrecommended waiting-times ceilings, nearly $30 \%$ of patients do not receive treatment for joint replacements and cataracts within those time frames. There has been clear deterioration in recent years (Canadian Institute for Health Information, 2020), in spite of greater resources, due to demand-increasing population ageing and, for joint replacements, rising incidence of osteoarthritis and obesity. Postponement of interventions due to the COVID-19 pandemic is likely to have worsened the waiting-times problem.

Compared to other countries Canada's waiting times are around the OECD median, but much longer than in the best performing countries like Denmark and Italy (Table 7). In the recent Conference Board survey only Sweden had a worse outcome than Canada for the share of people unable to make a primary-care appointment within a day among the 11 countries included (Doty et al., 2021). The Canadian authorities recognise that waiting times are an issue in all types of health services recently surveyed by the OECD, as is the case for only five other countries out of 24 (OECD, 2020d). Other countries have managed to make progress, notably Denmark, England and Finland.

\section{The primacy of mental health in determining well-being}

According to the World Health Organisation, good mental health is a state of well-being in which the individual realises their abilities, can cope with the normal stresses of life, can work productively and is able to make a contribution to their community. According to the Institute of Health Metrics and Evaluation, mental disorders afflict up to about one in eight adults in the world at any one time - many more at some point in their lifetime: the Public Health Agency of Canada believes it to be one in three in Canada if one 
includes substance use/dependency problems as well. Recent OECD/WHO data (which admittedly suffer from some comparability problems) show that its treatment cost CAD 9.6 billion in 2010 , some $10.6 \%$ of total health expenditures, a share exceeded only by France, Norway and Germany (Figure 15). Its total economic burden for Canada was pegged at close to 3\% of GDP in 2012 (Mental Health Commission of Canada, 2012) but over $4 \%$ of OECD GDP once indirect costs are included. Those who suffer also tend to be exposed to poverty, low skills and joblessness (or at least job insecurity). The risks of hospitalisation for mental illness and of suicide are significantly higher for those who are materially and/or socially deprived, poorly educated, on low income or Indigenous (Table 6 above). It is likely that, as for physical illhealth, more effort should be devoted to prevention of mental illness. But the treatment of mental ill-health beyond the obviously required long-term support for those with severe psychoses is thought to be particularly cost effective, because it saves on physical health-care services and generates large productivity gains (Global Happiness and Wellbeing Policy Report 2019, Chapter 3). Layard (2019) argues that it is cheaper in well-being terms to treat more people for depression and anxiety than to improve physical health or implement pro-poor income redistribution and even, by a narrow margin, than to lower unemployment through active labour-market policies. Also, more needs to be done to ensure that patients are treated respectfully by health-care professionals (OECD, 2019h) and to integrate mental health and employment policy, an area where Canada does relatively well but has nonetheless scope for further progress.

\section{Table 7. A cross-country comparison of waiting times}

Median waiting times for selected elective surgeries (days), 2018

\begin{tabular}{l|c|c|c|c|c}
\hline & Cataract surgery & Hip replacement & Knee replacement & Prostatectomy & Coronary bypass \\
\hline Australia & 84 & 119 & 209 & 44 & 17 \\
\hline Canada & 66 & 105 & 122 & 40 & 6 \\
\hline Chile & 97 & 240 & 839 & 69 & 26 \\
\hline Denmark & 36 & 35 & 44 & 36 & 10 \\
\hline Estonia & 187 & 282 & 461 & 39 & 15 \\
\hline Finland & 97 & 77 & 99 & 10 & 22 \\
\hline Hungary & 36 & 43 & 85 & 36 & 5 \\
\hline Israel & 77 & 56 & 45 & 36 & 62 \\
\hline Italy & 24 & 50 & 89 & 66 & 62 \\
\hline New Zealand & 82 & 81 & 152 & & \\
\hline Norway1 & 132 & 123 & 253 & 81 & 5 \\
\hline Poland & 246 & 179 & 204 & 75 & 37 \\
\hline Portugal & 119 & 126 & 147 & 45 & 7 \\
\hline Spain & 74 & 118 & 90 & 35 & 55 \\
\hline Sweden & 51 & 75 & 98 & 42 & 16 \\
\hline United Kingdom & 65 & 92 & 111 & & \\
\hline Country median & 76 & 99 & & & \\
\hline
\end{tabular}

1. Waiting times for Norway are over-estimated because they start from the date when a doctor refers a patient for specialist assessment, whereas elsewhere they start only when a specialist has assessed the patient and puts them on the waiting list for treatment.

Source: OECD Health Statistics. 


\section{Figure 15. Spending on mental health}

Mental health spending as percentage of total health spending, 2018 (or latest year)

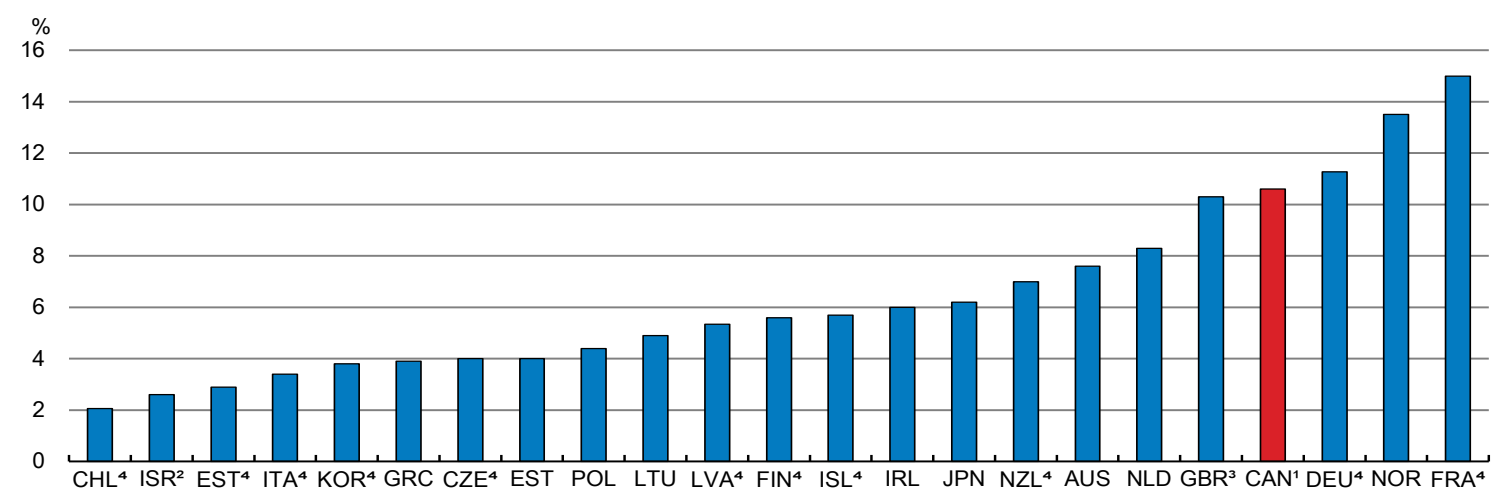

1. Includes dementia.

2. Covers only inpatient (mental health hospital) care.

3. Data for England.

4. Covers only public health spending.

Source: World Health Organisation (2018), World Health Atlas 2017; OECD (2020), OECD Mental Health Performance Benchmarking Data and Policy Questionnaires, OECD Publishing, Paris.

StatLink त्ञाजा https://stat.link/vnfxy9

In 2015 the Mental Health Commission of Canada (2015) published a dashboard of 55 mental-health indicators, which they graded according to a traffic light system: only 6 were coded green, 28 yellow and fully 21 red. The Public Health Agency of Canada has since developed a helpful Positive Mental Health Surveillance Indicator Framework covering a wide variety of dimensions (notably emphasising "positive" mental health) and separating adults from youth, a useful distinction since their situations are often different. However, the latest (2019) version contains a majority of data that are rather out of date and nothing newer than from 2017, limiting its effectiveness. In August 2020 data from the 2019 Canadian Community Health Survey were released, showing that $67 \%$ of Canadians over 12 living in the ten provinces rated their mental health as very good or excellent, down from $72 \%$ in 2015 (Statistics Canada, 2020a) (Table 8). Declines were widespread regionally as well as by age group (except for seniors), gender, Indigenous or visible minority status and sexual orientation. There was a parallel increase in the share of the population 12 years old and over reporting a diagnosed mood or anxiety disorder (from $12 \%$ to $14 \%$ ), with an especially pronounced jump for those aged 18 to 34 (13\% to $17 \%$ ). 
Table 8. How Canadian adults and youth assessed their mental health in 2019

Share of Canadians (excluding the territories) reporting very good or excellent mental health, 2015 and 2019, \%

\begin{tabular}{l|l|l}
\hline & $\mathbf{2 0 1 5}$ & $\mathbf{2 0 1 9}$ \\
\hline Canada, excluding the territories & 72 & $67^{\star}$ \\
\hline Sex & & 70 \\
\hline Males & 74 & 64 \\
\hline Females & 70 & $7^{\star}$ \\
\hline Age group & 78 & $61^{\star}$ \\
\hline 12 to 17 & 72 & $67^{\star}$ \\
\hline 18 to 34 & 72 & $70^{\star}$ \\
\hline 35 to 49 & 72 & 71 \\
\hline 50 to 64 & 71 & $54^{\star}$ \\
\hline 65 and older & 63 & $47^{\star}$ \\
\hline Indigenous, all ages ${ }^{*}$ & 59 & $68^{\star}$ \\
\hline Indigenous, aged 18 to 34 & 73 & $68^{\star}$ \\
\hline Non-Indigenous, all ages & & $58^{\star}$ \\
\hline Sexual orientation & & \\
\hline Heterosexual & 73 & $37^{\star}$ \\
\hline Gay or lesbian & 70 & 67 \\
\hline Bisexual & 43 & 66 \\
\hline Canadians designated as visible minorities & 73 & \\
\hline Black Canadians & 74 & \\
\hline
\end{tabular}

* Significantly different from 2015.

1. Indigenous includes First Nations off reserve (but excludes those in remote northern areas in the provinces), Métis and Inuit outside Inuit Nunangat.

2. The question on sexual orientation is posed to respondents aged 15 and older.

Source: Canadian Community Health Survey, 2015 and 2019.

The COVID-19 pandemic and the resulting economic downturn - like other downturns - has worsened the public's mental health (Findlay and Arim, 2020). Some groups have suffered more, notably women and especially, according to a crowdsourcing survey, gender-diverse individuals (Moyser, 2020b), recent immigrants (Evra and Mongrain, 2020), youth, health-care workers, Indigenous people and those from racialised populations (see below). In June 2020 the Mental Health Commission of Canada and the Conference Board of Canada (2020) reported that $84 \%$ of 1800 people surveyed had heightened mentalhealth concerns (based on 15 indicators) during the lockdown, although other surveys show lower figures. But Canada is not alone in this regard: in Europe, the life-satisfaction effects of degraded mental health in April 2020 as compared to the 2019 average were estimated at 3.5 times the loss in GDP per capita in well-being terms, and the share of respondents who self-reported good or very good health fell from $69 \%$ to $63 \%$, while those reporting being depressed (lonely) rose from $6 \%(6 \%)$ to $13 \%$ (17\%) (Allas et al., 2020). Canadians, however, reported better physical health in the pandemic (Findlay and Arim, 2020), and those who became more physically active did much better in well-being terms than those who became less active (Lesser and Nienhuis, 2020).

In order to improve access to mental health care then Canada should implement maximum waiting times for adult mental-health services as many other OECD countries have done, among them Australia and England. To be effective, however, this would probably require adequate resources to provide increased service volumes. As well, it should adopt even more stringent ceilings for children and adolescents, given the long and growing waiting lists in evidence in Ontario, for example (OECD, 2020d). 


\section{The role of health behaviours, especially problematic substance use}

Health behaviours, including substance-related harms, lower life expectancy and harm well-being. For example, the well-being benefit of not smoking has been estimated to have been worth CAD 563/week (which cumulates to around 62\% of per capita GDP) in 2009-10 (Shi et al., 2019). Obesity (and thus the risk of diabetes and dying from COVID-19) (Holly et al., 2020), smoking and harmful alcohol consumption all vary socio-economically in Canada, as in other countries (OECD, 2019d) (Table 9). Gender, income, educational attainment, sexual orientation and Indigenous and ethnic status all have clear associations. Problematic substance-related harms are arguably the most serious health behaviour. The latest data show that altogether almost 76000 Canadians died of substance-related causes in 2017, which cost the Canadian economy CAD 46 billion (2.9\% of GDP), up 6\% in the previous two years (Canadian Centre on Substance Use Costs and Harms Scientific Working Group, 2020).

\section{Table 9. Inequalities in obesity, high alcohol consumption and smoking}

Prevalence ratios compared to the reference category (female, non-Indigenous, white, heterosexual, non-immigrant, large urban centres other than Montréal, Toronto and Vancouver, highest income quintile, university graduate)

\begin{tabular}{l|c|c|c}
\hline & Self-reported obesity & High alcohol consumption & Smoking \\
\hline Male & 1.1 & 2.3 & 1.3 \\
\hline First Nations & 1.6 & 1.3 & 1.9 \\
\hline Métis & 1.4 & 1.4 & 1.7 \\
\hline Inuit & 1.6 & 1.3 & 2.4 \\
\hline Black & 1.0 & 0.3 & 0.5 \\
\hline East/Southeast Asian & 0.3 & 0.3 & 0.5 \\
\hline South Asian & 0.6 & 0.3 & 0.3 \\
\hline Arab/West Asian & 0.8 & 0.3 & 0.8 \\
\hline Bisexual & 0.9 & 1.2 & 1.6 \\
\hline Lesbian/gay & 0.9 & 1.3 & 1.4 \\
\hline Recent immigrant & 0.6 & 0.3 & 0.5 \\
\hline Non-recent immigrant & 0.7 & 0.5 & 0.6 \\
\hline Remote areas & 1.3 & 1.1 & 1.3 \\
\hline Rural areas & 1.2 & 1.0 & 1.2 \\
\hline Small urban centres & 1.2 & 1.0 & 0.9 \\
\hline Toronto, Montréal, Vancouver & 0.8 & 0.7 & 1.9 \\
\hline Lowest income quintile & 1.2 & 0.6 & 3.9 \\
\hline Less than high-school education & 2.0 & 1.4 & 2.6 \\
\hline High school graduate & 1.6 & 1.3 & \\
\hline
\end{tabular}

Source: Pan-Canadian Health Inequalities Reporting Initiative (2018), Key Health Inequalities in Canada: A National Portrait, Annexes 1 and 2.

Canada has also been suffering from a comparatively severe epidemic of opioid-related deaths in recent years (more than triple the OECD average), albeit less widespread than in the United States (OECD, 2019e) (Figure 16). Fentanyl, a powerful synthetic opioid that has infiltrated the illegal drug supply, or one of its analogues was involved in $77 \%$ of the deaths in the first quarter of 2020 . Canadian deaths relating to opioid use reached 5084 in 2017 (Canadian Centre on Substance Use Costs and Harms Scientific Working Group, 2020), including not only deaths from poisoning but also from partially attributable infectious conditions such as opioid-attributable infectious diseases and motor vehicle collisions. Even higher numbers, based on official data for poisoning alone, were reported for 2018 (OECD, 2019e). Opioidrelated deaths resulted in 100000 lost years of potential productive life in 2017 (Canadian Centre on Substance Use Costs and Harms Scientific Working Group, 2020, p.31) -- one type of what were termed "deaths of despair" by Case and Deaton (2020), with a considerable impact on life expectancy in both the United States and Canada (in 2017 opioids cost Canadian men 0.11 years in lost life expectancy and 
women 0.02 years) -- especially in certain regions and among younger and middle-aged adults. The COVID-19 outbreak has compounded Canada's ongoing overdose crisis with dramatically higher opioidrelated harms. In 2020 in British Columbia alone 1716 people died from an overdose, a greater toll than in any other year and about double the number who died of COVID-19 in the province in the year. Opioid use cost the national economy around CAD 6 billion in 2017 and looks likely to have continued to rise since then, given the rising number of related deaths (Canadian Centre on Substance Use Costs and Harms Scientific Working Group, 2020). Those costs take the form of health-system costs, lost productivity (mainly premature death, but also long-term disability, short-term absenteeism and impaired job performance) and extra costs of criminal justice.

To respond to the disturbing trends in opioid-related harms and deaths in evidence since the pandemic began the federal government has increased its support for community-level harm reduction and safer supply interventions and provided guidance on prescribing, dispensing and delivering opioids and other narcotics. However, further increasing the availability of harm reduction and safe supply, improving access to evidence-based treatments, reducing reliance on the criminal-justice system and enhancing data and surveillance capacity are all options that should be explored.

\section{Figure 16. Opioid availability and related deaths in OECD countries}

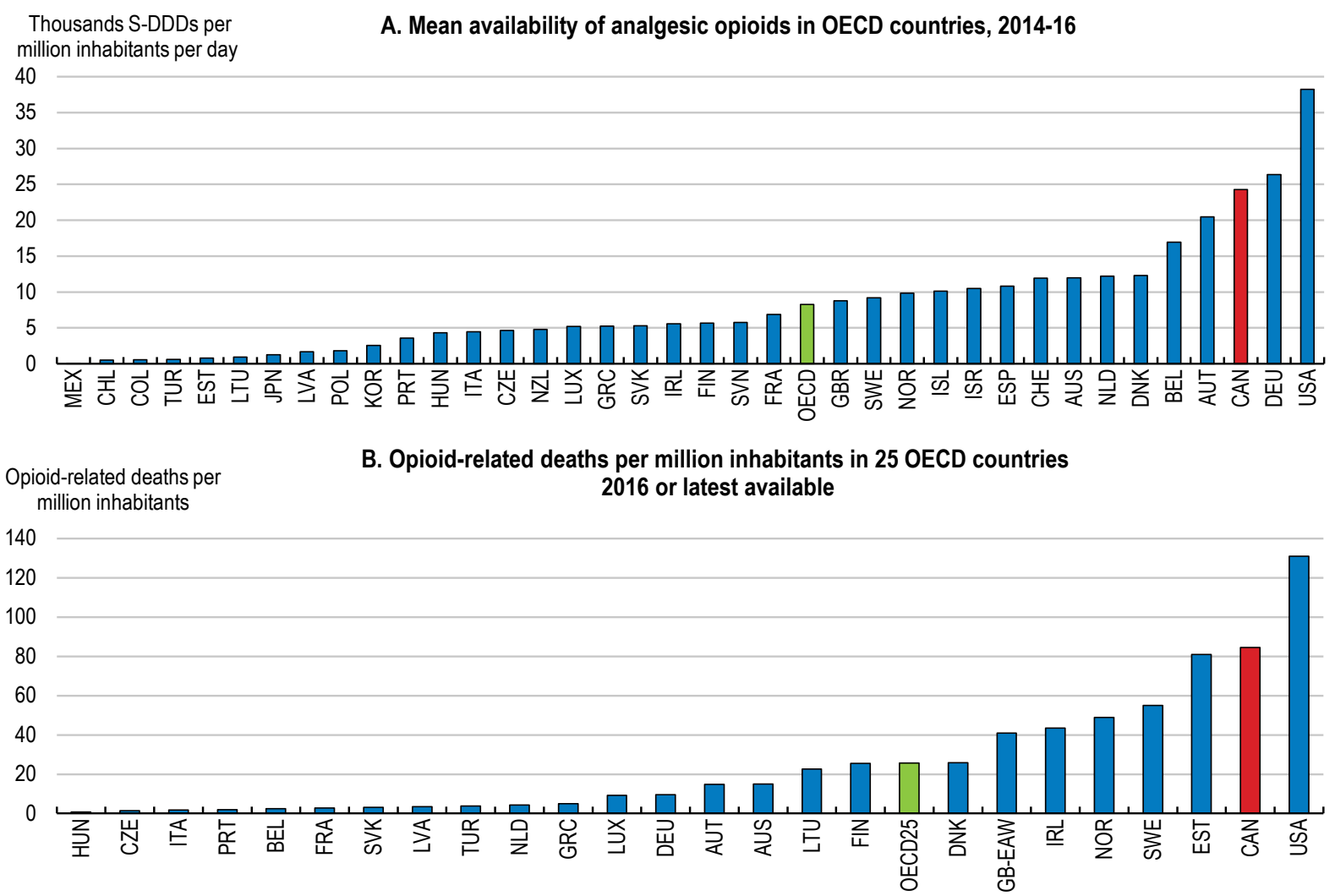

Notes: This does NOT include illicit opioids. S-DDD: Defined daily doses for statistical purposes. GB-EAW: England and Wales.

Source: OECD (2019), Addressing Problematic Opioid Use in OECD Countries, OECD Health Policy Studies, OECD Publishing, Paris, https://doi.org/10.1787/a18286f0-en.

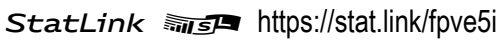




\section{Policy options for improving the health and well-being of Canadians}

What should be done to ensure the health-care system is working to improve the health and well-being of Canadians? First, health-care spending should be refocused initially on a broader definition of health outcomes including their physical, mental and social dimensions, but ultimately on well-being more generally, possibly through the adoption of multi-disciplinary health teams to manage funding to achieve optimal well-being outcomes (Drummond and Sinclair, 2020). Ontario is moving in this direction with its "accountable care" approach. The impact of spending on carers and family members should also be considered (Global Happiness and Wellbeing Policy Report 2019, Chapter 3). In that regard, a greater policy spotlight should be placed on mental health, even if Canada already seems to spend more than many other countries. Already in 2012 the Mental Health Commission of Canada argued for a rise in the mental-health share of the government's health-care spending dollar from $7 \%$ to $9 \%$, but there has been no progress since then. If extra funding were provided during lockdowns, more treatments and services could be digitally delivered and guided meditations made widely available. Emotional skills teaching and relationship coaching for high-risk groups could be provided (Frijters et al., 2020). The recent decisions to bolster distress centres and provide more remote mental health care certainly go in the right direction. Yet, the crucial role of upstream determinants of mental health must be recognised: policymakers need to focus on social factors such as wealth inequality, inadequate housing, dysfunctional neighbourhoods and systemic racism, notably involving Indigenous peoples (Boyer, 2017), if they hope to make more significant progress among the less fortunate in this dimension (Shim and Compton, 2018).

Second, several features of health-care delivery should be adjusted to reduce waiting times, lower longrun costs and improve quality and safety. For example, any remaining remuneration and coverage uncertainties for telemedicine need to be quickly resolved, so that a maximum amount of all forms of health care can thus continue to be delivered without exposing health-care workers unnecessarily and available efficiencies achieved (Wyonch and Maharishi, 2020). There should also be a faster shift to team-based care through enhanced inter-professional collaboration, allowing a more holistic approach to care. Canadian health authorities could do more to alleviate lengthy waiting times throughout the system by: following Australia, New Zealand and Norway and implementing patient prioritisation procedures; adopting technologies allowing patients to easily find available doctors; rolling out more widely existing processes to improve co-ordination between primary-care providers and both specialists and hospitals; allowing nurses and other health-care professionals to take over some tasks from physicians such as immunisations (as in the majority of other OECD countries (OECD, 2020d); and ensuring that primary-care patients can be seen outside working hours (where Canada does comparatively poorly, according to very recent evidence from the Commonwealth Fund (Doty et al., 2021).

Third, more funding should be directed to public- and community-based interventions and other prevention measures, as they have proven high cost effectiveness (Masters et al., 2017). One example of this that is gaining recognition internationally is Iceland's Planet Youth model. OECD Health Accounts show public health to be only around $6 \%$ of Canada's total health-care outlays.

Fourth, policy environments could be used to provide more structured support for healthy lifestyle choices. As regards alcohol-related policies, availability is no doubt a key issue, but taxes should probably be raised further for distributional reasons as well. Physicians should receive better training in pain management so as to avoid unnecessary use of opioids and in ways to support people with substance-use disorders (addictions). And the health-care, social and criminal-justice systems should better coordinate their efforts in that area. While the use of cannabis was legalised in Canada in 2018 (it was only the second country in the world after Uruguay to do so), it is noteworthy that 13 OECD countries (plus parts of Australia) have decriminalised narcotics for possession and consumption for personal use, and two more have depenalised it, and there has been no sign of increased use, for example, in Portugal since its decriminalisation in 2001 (OECD, 2019e, Table 4.3 and Box 4.4). 


\section{The need to expand public insurance coverage to include pharmaceuticals}

Canada is the world's only country out of the 67 with a public universal health-insurance regime that excludes drug coverage at the national level (Quebec, for example, has had mandatory drug coverage since the 1990s). Instead, it has a fragmented patchwork of over 100 different public payers and over 100000 private, mainly employer-managed plans (each with their associated administrative costs), which still leaves an estimated $20 \%$ of the population lacking effective coverage (including those who have only coverage for chronic conditions entailing extreme costs). Various attempts have been made to expand Medicare to overcome this coverage problem over the years, notably with the recent report of the Advisory Council on the Implementation of National Pharmacare (Health Canada, 2019). It made a powerful case for completing Medicare by pointing out that: 1) Canadians spend more on prescription drugs per capita than anybody else other than Americans and Swiss, mainly because of high prices (though, following a lengthy consultative process, new regulations will take effect at mid-year 2021 governing patented medicines whose prices will be compared with those in 11 other advanced OECD Member countries); 2) three million Canadians fail to have their prescriptions filled because of affordability challenges, while a further million cut back on food and heating and yet another million borrow to do so; and 3) many suffer needlessly and/or die prematurely. It cited evidence that if out-of-pocket expenses were removed for just diabetes, cardiovascular disease and chronic respiratory conditions, there would be 220000 fewer emergency-room visits and 90000 fewer hospitalisations, saving CAD 1.2 billion a year.

The Council's plan was to create a national drug agency in 2021 charged with establishing an initial essential formulary of 100-200 drugs covering about half of all prescriptions and negotiating their prices, then to launch the system in 2022 and continue to phase-in new drugs over the following five years. Currently some public payers have excessive numbers of drugs on their formularies - Ontario has over 3800 , for example - which may boost prices and make shortages and physician errors more likely (Persaud and Ahmad, 2017). They could easily follow more closely the WHO's model approved list, the most recent version of which (April 2019) contains 460 medicines, an approach used by 155 countries. The Council recommended very modest co-payments with exemptions for those on low incomes and an annual ceiling of CAD 100 per family, as well as separate arrangements for expensive drugs to treat rare diseases. But coverage for dentistry, vision and mental health would still remain job-related.

While incremental fiscal costs would be heavy (CAD 3.5 billion in 2022, rising to CAD 15.3 billion in 2027), overall national drug spending would fall by CAD 0.3 billion in 2022 and CAD 5.0 billion in 2027, as average prices would fall through the exercise of greater bargaining power. Other efficiencies would arise. Those employers who currently offer drug plans would save an annual CAD 750 per employee or CAD 6 billion in total, their workers about CAD 100 each or CAD 4 billion in total, and $95 \%$ of households would gain, by an average of CAD 350/year. In addition, job-switching costs ("job lock") would be reduced, yielding gains in labour-market efficiency.

However, momentum for Pharmacare has been lost due to its budgetary costs (no matter the extent to which they fall on the federal or provincial/territorial governments) and the complexity of negotiating a deal with the provinces/territories as well as opposition from the health-insurance industry and retail pharmacies (commissions from generic-drug producers would decline). Nevertheless, before the pandemic, Health Canada planned on moving ahead with Pharmacare. But, even if no final decisions have been taken, it may go ahead only with so-called "foundational issues": implementing a programme for covering expensive drugs for rare diseases, agreeing a national formulary and setting up a joint procurement agency, assuming the provinces and territories agree. If providing Pharmacare is deemed too fiscally costly in the current context, at a minimum efforts should be made to fill current coverage gaps in the interest of social inclusion in this time of COVID-19. 


\section{The lack of paid sick leave for most workers is unfair and risky}

Another gap in the social safety net is the lack of paid sick leave for the majority of Canadian employees. Currently, such leave is a voluntary employer-provided fringe benefit that is valid until Employment Insurance benefits kick in (if applicable). In 2016, 58\% of workers had no paid sick days, the figure rising to $74 \%$ for those earning less than CAD 25000 per year (Decent Work and Health Network, 2020). That explains why the problem is more severe for women, immigrants, Indigenous peoples and racialised populations, all of whom are more concentrated in low-paid jobs. It is also more prevalent for non-unionised workers. Only workers in Québec, Prince Edward Island and federally regulated sectors (who number about 915000 ) get any mandated paid sick days. The federal government recognised the risks of discouraging those with COVID-19 from staying home so as to avoid spreading the virus and recently implemented a ten-day scheme, but it was explicitly for COVID-19 (and not for other illnesses) and thus temporary. However, the same arguments apply more generally, which would explain why 17 of 22 advanced economies and 19 of 34 OECD Members had such mandates (Decent Work and Health Network, 2020). It would therefore seem to make good sense to universalise the applicability of this benefit.

\section{The quality of long-term care can be improved}

With an aging population - the share of those over 65 is projected to rise from a sixth to a quarter by 2041 - demand for long-term care for the elderly is rising and will continue to do so. This can be provided at home (by paid or informal carers, notably family members), in community settings or in long-term care facilities such as nursing homes (which currently house about $42 \%$ of those over 80 needing constant care, compared to an OECD average of about 30\%). Institutionalised care for the elderly is a difficult problem to manage. And it is getting ever more challenging thanks to chronic diseases and health conditions and the rising prevalence of dementia (from which two-thirds of residents of long-term care homes suffer), and old and often rundown infrastructure, which sometimes leads to overcrowding. According to the 2016 Census, about $1.2 \%$ of Canadians were residents of such homes, with similar numbers in nursing homes and in other seniors' residences, excluding the $0.2 \%$ who were in facilities for disabilities and addictions. Waiting lists exist for both types. In Ontario, they are an average of five months for those in the community and 100 days for those currently in acute-care institutions (Royal Society of Canada, 2020). OECD data (OECD.Stat) show that Canada devotes spending by government and compulsory schemes of about $1.5 \%$ of GDP on long-term care, less than some European countries at around $2 \%$. Some relief was provided in the 2017 federal budget when CAD 6 billion over a decade in extra funding was provided to help the provinces and territories supply home care. Nevertheless, the quality of care provided in long-term care institutions is often poor, and the situation came to a head when the COVID-19 pandemic hit. Virus outbreaks appeared in multiple long-term care institutions throughout the country, but especially in Nova Scotia, Québec and Ontario. One recent study compared outcomes in Ontario and British Columbia and concluded that the considerable difference in performance was attributable to: better coordination between the system, hospitals and public health authorities; greater funding (CAD 222 per resident per day rather than CAD 203), allowing for more carer hours per resident and fewer shared rooms ( $24 \%$ compared to $63 \%$ ); more non-profits; and more comprehensive inspections (Liu et al., 2020). Overall, by mid-year, about $80 \%$ of the nation's fatalities had been residents of such homes, probably a higher share than anywhere else in the OECD (Grant, 2020) and double the average. The latest data show that that cumulative share has fallen only marginally to below three-quarters.

While initial responses to the pandemic were dictated by the system's capacity, the federal government acted to increase the wages of low-income essential workers the definition of which was left to the provinces and territories, but the result was that in some places poorly paid workers were left without protection against wage losses. Most provinces/territories also implemented orders for long-term care workers to work at only a single site (to prevent transmission) either on a mandatory or voluntary basis.

The current problems in Canada's 2039 care homes reflect long recognised deficiencies that were highlighted by the pandemic (Royal Society of Canada, 2020). These shortcomings relate to infection 
prevention and control, workforce issues and aging infrastructure, all in a context of the patchwork of often light regulatory standards. According to the Canadian Institute for Health Information, while $46 \%$ of these institutions are publicly owned, $28 \%$ are profit-driven (the rest are private, but not-for-profit); on average, for-profit homes have worse conditions, and their for-profit status is associated with the extent of outbreaks and the number of resident deaths, but not with the likelihood of outbreaks (Stall et al., 2020). Many homes, especially those in the for-profit sector, have too few staff who are often low paid, poorly trained, part-time and casual and with higher turnover (Box 6). In general, countries with centralised regulation and organisation of long-term care have had better outcomes during the pandemic (Grant, 2020).

\section{Box 6. Indicators of staff shortages and low pay in Canadian long-term care institutions}

Throughout the sector in Canada staff are lacking and thus overworked and subject to burnout, chronically badly paid (average pay is $35 \%$ lower than in the hospital sector for the same occupation (OECD, 2020g, Figure 1.6) and without the right to hazard pay or sick leave) and poorly trained and thus subject to heavier injury risk. Up to $35 \%$ have only part-time hours, which requires many of them to move from one residence to another, thereby also boosting the risk of spreading contamination in a pandemic. Canada has fewer nurses and personal support workers in long-term care institutions per resident than most other OECD countries, for example half what the Netherlands and Norway have. Only seven provinces require that a registered nurse be on duty at all times. There has also been a shift away from registered nurses to unlicensed care aides (Royal Society of Canada, 2020). Canada lacks about $20 \%$ of the required number of daily nursing-care hours per resident. Without comprehensive care, residents often rely on family members to fill in services gaps, a solution that is becoming increasingly difficult due to family composition and distance (Royal Society of Canada, 2020). Merely to keep the ratio of care workers to the elderly population constant their numbers will have to rise by $80 \%$ by 2040 , a much larger increase than in the average OECD country.

The solutions are also multiple but politically difficult, given provincial and territorial responsibility in this area. The most radical would be to alleviate the burden of seniors' care by modifying the Canada Health Act and putting all such services (not just hospital and physician services) into Medicare. Costs could be covered by dedicated taxes (possibly only on those over a certain age threshold), as in the United States, Japan, Israel and several EU countries.

In any case, there should be more support for people to remain at home, as a majority of them clearly prefer, as long as possible ("ageing in place") through encouragement of healthy ageing and use of innovative technologies. Even though Canada had been one of the leading countries in deinstitutionalising its elderly care, with a $12.2 \%$ fall in the number of beds per senior in the decade to 2015 (OECD, 2020i), the number of beds per senior was still above the OECD average (Figure 17,Panel A), the share of nurses and personal carers working in home care remained the smallest among 17 OECD countries in 2016, and its public spending on home care was lower than the OECD average, having shifted away from such care in recent years (Panel B). Only Ontario spends more than half its budget for elderly care on care in the community as opposed to specialised institutions; that must surely change. When institutionalisation is unavoidable, the standards applied must be improved and inspections more frequent and rigorous: in 2019 Ontario inspected only nine of its 626 long-term care institutions.

Long-term care workers must be better paid and trained, both to enter the profession and through continuing education, even when they are agency provided. Long-term care workers and residents should be given priority for vaccinations in the impending roll-out and for protective equipment and test-and-trace efforts in any future waves of this pandemic, and multi-site work practices must be at least temporarily banned. The federal government should establish national standards for staffing and infectious disease control (Royal Society of Canada, 2020; Canadian Medical Association et al., 2020), even in the face of opposition from some provinces/territories who want only untied increases in federal transfers (which the 
government just agreed to, but only once the pandemic is over). In its recent Fall Economic Statement it reiterated its intention to seek such national standards and provided CAD 1 billion in new funding for protecting these facilities from COVID-19 and future pandemics. Finally, data collection must be intensified and used in the accreditation process, especially in the for-profit sector.

Figure 17. Long-term care: number of beds, spending and staffing

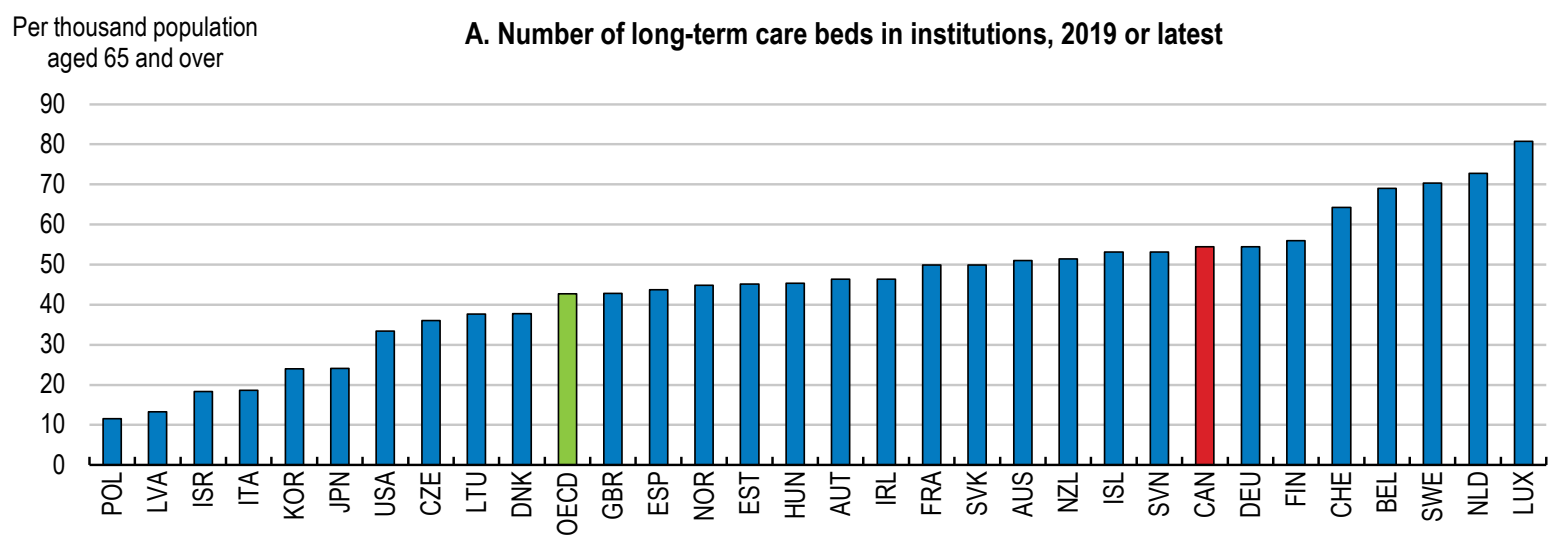

B. Share of public spending on long-term care allocated to home-based and inpatient long-term care, 2019 or latest

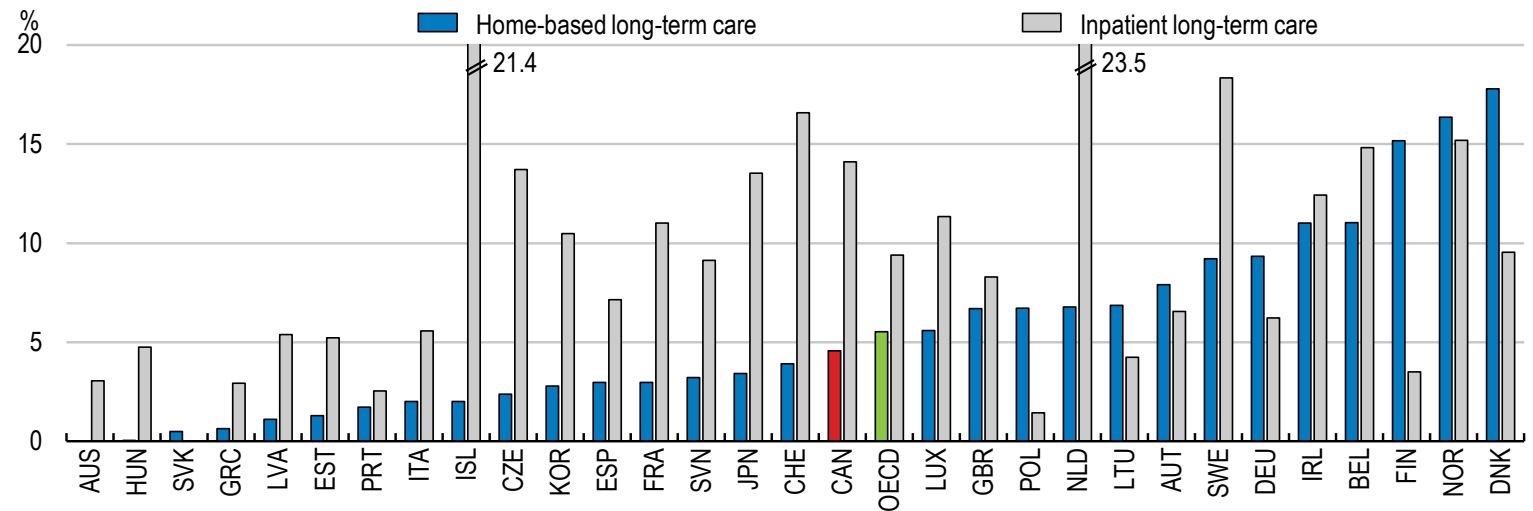

C. Composition of the long-term care workforce, 2019 or latest ${ }^{1}$

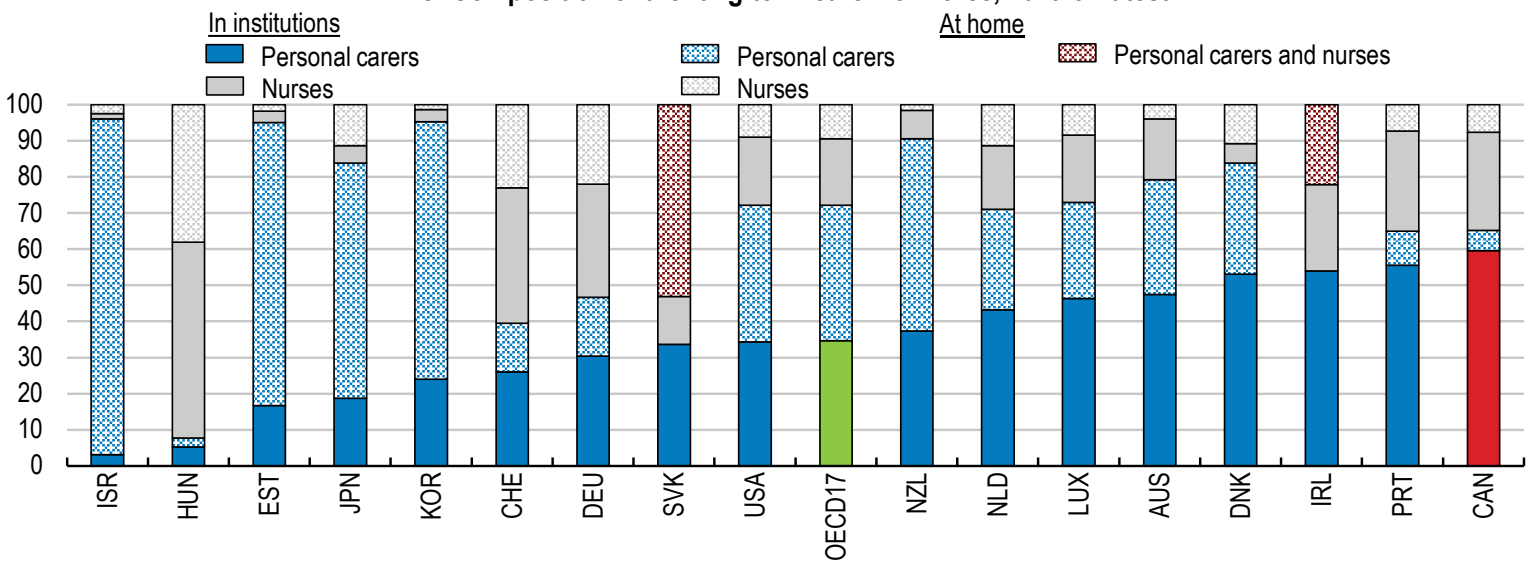

Note: For each panel, OECD unweighted average is computed using the OECD countries shown in the chart.

1. For Ireland and the Slovak Republic, the break-down by occupation of long-term care workers at home is not available.

Source: OECD (2020), Health statistics database, https://doi.org/10.1787/health-data-en.

StatLink त्ञाज https://stat.link/ih2b9z 


\section{The role of environmental factors in the quality of life}

Various aspects of environmental quality also appear among the dashboard of well-being indicators used by nearly all countries. The literature on the determinants of subjective well-being shows that people are indeed sensitive to their immediate surroundings, notably the quality of the air they breathe (as 4.2 million premature deaths are attributable to it every year according to the World Health Organization). Connectedness with nature is significantly associated with "eudaimonic" well-being (living a good and meaningful life) and personal growth (Pritchard et al., 2020). However, the relationship between well-being and longer-term sustainability considerations seems less clear (Box 7). Greener environments closer to nature encourage physical activity that generates physical- and mental-health benefits and social interaction. This may be especially true for older people for whom active aging provides physical and mental health benefits; this has led to an "ecological model of aging" and the development of "age-friendly communities" (Zheng and Yang, 2019). The same social environments favouring current happiness are likely to support social behaviours necessary to improve the quality and security of the environment for future generations (Barrington-Leigh, 2017; Helliwell et al., 2020b).

\section{Box 7. The environmentalist's paradox: improving well-being despite a worsening ecosystem}

It has been argued that most people who respond to surveys about their well-being are not very forwardlooking (Benjamin et al., 2020). For example, human well-being has been rising over time, despite a degradation of the ecosystem in a number of domains (the "environmentalist's paradox"). RaudseppHearne et al. (2010) point to three possible explanations: 1) well-being seems to be mainly dependent on food services (which alone have improved), as opposed to those from forests, for example; 2) technological innovation has allowed some decoupling of well-being from nature (reducing environmental stress); and 3) time lags may lead to future declines in well-being resulting from this degradation. Sachs, in his Introduction to the Global Council for Happiness and Wellbeing Policy Report (2019), advocates supplementing current well-being indicators with stocks of natural capital, as is done by the OECD's How's Life? reports. Qasim and Grimes (2018) use the concept of Adjusted Net Saving (as calculated by the World Bank as net national saving plus education expenditure less energy, mineral and forest depletion less air-quality damage from $\mathrm{CO}_{2}$ and particulates). They show that the impact of Adjusted Net Saving on subjective well-being is negative for 10-15 years but turns around and becomes positive and sometimes significant after 20 years. Barrington-Leigh (2020) calls for quantitative limits on resource use and waste streams for sustainability considerations ("ecological precaution").

The list of proven environmental drivers of subjective well-being is long and growing. People in urban contexts are less happy than their rural counterparts beyond a certain point of environmental stress, despite the income gains resulting from agglomeration economies, because of:

- The associated water and air pollution (Luechinger, 2009; Levinson, 2012). OECD countries with low levels of particulate pollution also have greater average subjective well-being (Krekel and MacKerron, 2020). Happiness Research Institute and Leaps by Bayer (2020) calculates that inhabitants of Krakow, the European city with the worst air pollution, experience a loss of wellbeing equivalent to about $15 \%$ of their annual income.

- Noise pollution (Rehdanz and Maddison, 2008). The UK Treasury's Green Book (2018, pp.63-64) gives suggested values for the costs of these externalities according to day versus night, decibel levels of 45-75 and whether the noise is road-, rail- or aircraft-sourced.

- A lack of green space (Krekel et al., 2016) and traffic congestion/longer commutes that are typical of city life (Burger et al., 2020).

In a larger sample of 130 countries De Neve and Sachs (2020) investigate the connection between subjective well-being and the United Nations Sustainable Development Goals. Their results point to a 
significant, positive impact of only some of the environmental Goals on well-being: numbers 6 (Clean Water and Sanitation), 7 (Affordable and Clean Energy) and 11 (Sustainable Cities and Communities), in particular. Perhaps surprisingly, Goals 12 (Responsible Consumption and Production) and 13 (Climate Action) have significantly negative coefficients. When they aggregate the Goals into five groups and decompose the cross-country variance of well-being, they find those associated with the environment account for $8 \%$ of the total explained, economic factors are responsible for $31 \%$, health $24 \%$, social $20 \%$ and legal $17 \%$.

\section{How does Canada rank according to these environmental indicators?}

Canada scores relatively well on environmental indicators with a close link with well-being, and often worse for greenhouse gas emissions and other longer term indicators. Canada is ranked $20^{\text {th }}$ behind Australia, immediately behind New Zealand but ahead of the United States in the Environmental Performance Index (see Table 1 above), which covers 11 domains and includes 32 indicators for 180 countries (Wendling et al., 2020). It scores highly for indoor air pollution, lead exposure, biodiversity habitat (terrestrial ecological diversity) and growth rates of both sulphur dioxide and nitrogen oxides. But it scores very badly for greenhouse gas emissions per capita $\left(168^{\text {th }}\right)$, ecosystem services $\left(110^{\text {th }}\right)$, species habitat (suitable habitat changes since 2001$)\left(101^{\text {st }}\right)$, protected areas $\left(91^{\text {st }}\right)$, fisheries $\left(89^{\text {th }}\right)$, greenhouse gas intensity trend $\left(77^{\text {th }}\right)$ and ozone exposure $\left(55^{\text {th }}\right)$.

Other sources show sub-standard Canadian outcomes for the share of renewable energy, the amount of fine particle pollution and water quality (tentatively, because, while monitored across the country, the data are not strictly comparable). Ontario raised its drinking-water standards and inspection resources in the wake of the 2000 Walkerton water disaster; now the issue is rather on takings (withdrawals) and toxic bluegreen algae blooms. Alberta has water-quality and -quantity frameworks but only in the north-east where oilsands producers are located and need to know the system's carrying capacity. But there are fears that tailings ponds are leaking into groundwater in that region (Commission for Environmental Cooperation, 2020). There is also water stress in some regions, such as southern Alberta. Canada's share of wastewater undergoing primary treatment - which had been a focus of the latest OECD Environmental Performance Review (2017) because charges for such services were too low to recover costs - can be substantially improved (Canada ranks $28^{\text {th }}$ in the OECD). Indeed, there was no sign of improvement in the latest OECD data: the share being treated had fallen from $87.2 \%$ in 2004 to $84 \%$ in 2017 .

Other concerns include disturbing trends in the Red List Index of threatened species (especially for monitored mammals and fish, while some bird species have improved) (World Wildlife Fund, 2020) and in Canada's overall material footprint thanks to steadily declining biocapacity since 1961 (Global Footprint Network, 2020). The lack of environmentally related taxation, which is lower as a share of GDP only in Mexico and the United States among OECD countries and has fallen since 2000, is also notable (Figure 1.20 in Chapter 1), although the use of cap-and-trade systems lowers the share all else equal. Raising this share could have a large well-being payoff in terms of aligning prices with external costs and also generating useful revenues, which could be used for spending on other social programmes.

\section{Government policies to deal with these major environmental challenges}

Ever since 2008 the federal government has had a Sustainable Development Strategy, defined for successive three-year terms, with the current version lasting until 2022 (Environment and Climate Change Canada, 2019). It includes aspirational, long-term goals in 13 dimensions with 25 indicators that directly support 12 of the 17 SDGs. The latest edition strengthened targets in six areas, added objectives for zeroemission vehicles (notably 100\% market share by 2040 ) and clean-tech exports, reworked the Sustainable Food Strategy and expanded the suite of indicators to measure progress. In terms of levels areas of concern include: electronic waste, sulphur dioxide embodied in imports, production-based nitrogen, nitrogen embodied in imports, energy-related carbon emissions, carbon dioxide embodied in imports and the effective price of carbon. For trends those judged unsatisfactory are: sustainable nitrogen management, safely managed sanitation services and the renewables share of energy production. 


\section{The special case of Canada's Indigenous peoples and racialised populations}

\section{Indigenous peoples have long had poor well-being outcomes}

Canada has had a long history of policy failure in addressing challenges faced by its Indigenous peoples whose socio-economic outcomes have been harmed by the history of colonialism and the intergenerational trauma it has caused. It was only in 2007 that Canada signed the UN Declaration on the Rights of Indigenous Peoples (and introduced legislation to implement it in December 2020). This historical process culminated in official apologies for the century-long system of residential schools (see Kim (2019) for a summary), the Truth and Reconciliation process, the recent National Inquiry into Missing and Murdered Indigenous Women and Girls and a notable acceleration in negotiating land claims settlements. These outcomes have led to or at least coincided with a cultural resurgence and a feeling of revitalisation in many Indigenous communities.

The importance of achieving secure land tenure and overcoming the long-term barrier of the 1876 Indian $A c t$, which leaves reserve land by default under federal government control, was recently emphasised by OECD (2020h). While it took Canada more than 40 years to negotiate 40 Indigenous land and rights agreements prior to 2015 , new processes aim to achieve faster results in terms of empowering Indigenous governments. These include more than 75 new Recognition of Indigenous Rights and Self-Determination discussions that were underway by the time of the March 2019 federal budget, 29 of which had resulted in signed preliminary accords (Budget Chapter 3). Nevertheless, further improvements in governance practises that would empower Indigenous governments are possible (OECD, 2020h).

Indigenous peoples are approaching 5\% of the total Canadian population, a share that is likely to rise in the medium term (Drummond et al., 2017). There are three distinct groups of Indigenous peoples, each with different histories, identities and challenges: First Nations, Métis and Inuit. The differences between them (and among First Nations) are large, which has led to the mutual agreement to adopt a "distinctionsbased approach" to all relevant policymaking. However, knowledge about the socio-economic situation of First Nations people living on reserves is often lacking because some do not take part in Statistics Canada surveys, including the census. The importance of collecting better data for all Indigenous peoples was recently emphasised by OECD (2020h). But it is clear that, despite significant and rising funding for education and health care (especially in remote communities) and to provide those on reserve with income assistance, they remain a distinctly disadvantaged group.

This is highlighted by two recent publications. The National Indigenous Economic Development Board (2019) examined 31 measures covering employment, income, community well-being, education, business development, governance, resources and infrastructure. It concluded that, while progress is being made on some indicators since its initial report in 2012, most gaps remain large, and a few are moving in the wrong direction. This implies a substantial likelihood that the target of economic parity in 2022 will be missed without accelerated policy and programme supports, especially for the First Nations on reserve populations where gaps are largest.

The second is a report from the First Nations Information Governance Centre (2020), which recently published a useful summary of the situation in 2015-16 based on Regional Health Surveys. It focuses on chronic health conditions, which afflict nearly $60 \%$ of First Nations adults (even more for females). Almost one in ten claimed they did not get all the health care they needed because of waiting lists, the lack of available providers or affordability or coverage factors. Yet it should be mentioned that there has been measureable improvement in the area of long-term drinking water advisories on public on-reserve systems whose number has fallen from 105 in November 2015 to 59 in December 2020. The target was to eliminate the problem by the middle of 2021 thanks to massive Federal budget spending that began with Budget 2016 and was reinforced in Budget 2019. But that target will be missed, despite the recent announcement of a further CAD 1.5 billion in additional investments including CAD 114 million in annual operating funding by $2025-26$ to ensure clean drinking water for First Nations communities. 
The Indigenous peoples have a number of other dimensions of well-being in which their outcomes are much worse than those of their non-Indigenous counterparts (Table 10; note that these data exclude First Nations on reserve and Inuit living in Inuit Nunangat)). They have a greater incidence of poor self-reported mental health, especially for women (who are much more frequently victims of family and other genderbased violence (Native Women's Association of Canada, no date) and even forced sterilisation), those aged 18-34 and First Nations, along with a greater deterioration since 2015 (Statistics Canada, 2020a). The share reporting a diagnosed mood or anxiety disorder tells a similar story. They also suffer much more from substance-use-related harms, and deaths by homicide and suicide, especially among the Inuit: for the entire Indigenous population, the homicide rate is about five times that of the rest of the population, a difference of over 100 deaths per year. Given that suicide rates are about ten times higher in Inuit communities than the national average, Inuit leaders have helped to develop a suicide prevention strategy to help individuals in crisis to access appropriate services.

\section{Table 10. Selected indicators of comparative well-being of Canada's Indigenous peoples}

\begin{tabular}{|c|c|c|c|c|c|c|}
\hline & \multicolumn{3}{|c|}{ Indigenous } & \multicolumn{3}{|c|}{ Non-Indigenous } \\
\hline \multicolumn{7}{|l|}{ A. Mental health outcomes, 2019} \\
\hline \multicolumn{7}{|l|}{ 1. Perceived mental health } \\
\hline$\%$ Share very good or excellent & \multicolumn{3}{|c|}{54} & \multicolumn{3}{|c|}{68} \\
\hline \multicolumn{7}{|l|}{ Of which: } \\
\hline Women & \multicolumn{3}{|c|}{49} & \multicolumn{3}{|c|}{$?$} \\
\hline Men & \multicolumn{3}{|c|}{59} & \multicolumn{3}{|c|}{ ? } \\
\hline Those aged $18-34$ & \multicolumn{3}{|c|}{47} & \multicolumn{3}{|c|}{ ? } \\
\hline First Nations & \multicolumn{3}{|c|}{49} & \multicolumn{3}{|c|}{--} \\
\hline Change since $2015, \%$ points & \multicolumn{3}{|c|}{-9} & \multicolumn{3}{|c|}{-5} \\
\hline \multicolumn{7}{|c|}{ 2. \% With diagnosed mood/anxiety disorder } \\
\hline Total & \multicolumn{3}{|c|}{27} & \multicolumn{3}{|c|}{13} \\
\hline \multicolumn{7}{|l|}{ Of which: } \\
\hline Women & \multicolumn{3}{|c|}{35} & \multicolumn{3}{|c|}{16} \\
\hline Men & \multicolumn{3}{|c|}{19} & & & \\
\hline First Nations & \multicolumn{3}{|c|}{31} & \multicolumn{3}{|c|}{--} \\
\hline Change since $2015, \%$ points & \multicolumn{3}{|c|}{+5} & \multicolumn{3}{|c|}{+2} \\
\hline B. Poverty indicators, $\%$ & & & & \\
\hline$\%$ With income below MBM pove & & & & & & \\
\hline Total & & 24 & & & 13 & \\
\hline Of which: & & & & & & \\
\hline Those aged below 18 & & 30 & & & $?$ & \\
\hline First Nations off reserve & & 30 & & & -- & \\
\hline 1. \% Living in food insecure hous & & & & & & \\
\hline Adults & & 38 & & & $?$ & \\
\hline Of which: & & & & & $?$ & \\
\hline Men & & 34 & & & ? & \\
\hline First Nations off reserve & & 43 & & & -- & \\
\hline Inuit & & 53 & & & -- & \\
\hline C. Recent unemployment outc & & & & & & \\
\hline & Total & Women & Men & Total & Women & Men \\
\hline Dec. 2019-Feb. 2020 & 10.0 & 7.3 & 12.6 & 5.5 & 4.9 & 6.0 \\
\hline Mar. 2020-May 2020 & 16.6 & 13.6 & 19.5 & 11.7 & 11.7 & 11.7 \\
\hline June 2020-Aug. 2020 & 16.8 & 16.8 & 16.7 & 11.2 & 11.9 & 10.6 \\
\hline
\end{tabular}

Source: Canadian Community Health Survey 2019; P. Arriagada, T. Hahmann and V. O'Donnell (2020a), "Indigenous people and mental health during the COVID-19 pandemic", Statistics Canada, 23 June; A. Bleakney, H. Masoud and H. Robertson (2020), "Labour market impacts of COVID-19 in Indigenous people: March to August 2020", Statistics Canada, 2 November. 
Poverty is also much more widespread for First Nations off reserve than non-Indigenous, less so for Métis and Inuit (Canada Without Poverty, n.d.). The same pattern of much higher poverty rates also applies to children, especially for Status First Nations on and off reserve (Beedie, 2019; Campaign 2000, 2020). In 2016 fully 297 of the 367 (81\%) First Nations reserves for which census data are available had povertylevel average incomes per capita, and 27 had average annual incomes below CAD 10000 . Not surprisingly their disadvantage extends to food insecurity as well. This contributes to poor physical and mental health, worse educational outcomes and added family stress. COVID-19 had a larger impact on their ability to meet their financial obligations or essential needs, self-reported as strong or moderate by $36 \%$ compared to $25 \%$ for others (Arriagada et al., 2020b). This is consistent with the more persistent rise in unemployment during the crisis, especially for women (Table 10, Panel C).

Overcrowding, poor-quality housing as well as outright homelessness are also much more serious problems for Indigenous peoples than others. The probability of a person needing to use a homeless shelter is 11 times greater for an Indigenous man and 15 times greater for an Indigenous woman than for their non-Indigenous counterparts. But the Indigenous peoples consider homelessness to be much broader than merely lacking a roof over one's head. It is the loss of "All My Relations", i.e. the sense of belonging and mental balance that goes with one's connections to kin, the community and the land (Thistle, 2017). No doubt all these conditions have led to a particularly severe hit to their well-being during the ongoing pandemic, given the large role of cultural traditions, pride, self-respect and self-determination for Indigenous people than for the mainstream population and their lack of buffers to fall back on. In recognition of their greater vulnerability the federal COVID-19 Economic Response Plan provided a number of new supports and beefed up some existing programmes to support Indigenous communities, enhance public health and mental wellness services, expand the number of shelters for women and children fleeing violence and boost income support, notably to post-secondary students (worth CAD 72.5 million).

At least well-being gaps seem to have stopped their structural widening. Based on an unweighted index devised by the federal government comprising per capita income, labour market participation, housing and educational outcomes using census data, First Nations, Inuit and non-Indigenous communities have all experienced similar-sized improvements since 1981 (Richards, 2020), leaving a fairly constant gap of 19 percentage points (58.4 vs. 77.5 ) in 2016. But the key to overcoming their well-being shortfall may lie in labour-market outcomes - Indigenous peoples' average unemployment rate in the 25-year period was $15.3 \%$ as against $7.4 \%$ for others (the gap is especially pronounced in rural areas (OECD, 2020h)); that is related to the lack of employment opportunities on First Nations reserves. To put these outcomes into context one can compare Canada with other countries that also have similar Indigenous populations (Figure 18). These data show it in the middle of this group when it comes to comparative outcomes for life expectancy, per capita incomes, and employment and unemployment rates. Outcomes also appear fairly comparable to those of Roma in Central and Eastern Europe, notably the Slovak Republic, as well as Arab Israelis (see OECD, 2019f, Chapter 1).

To achieve improved labour market outcomes, better results in primary and secondary education and more post-secondary skills training are needed. Employment and skills gaps mutually interact over time, as poorly trained labour discourages job creation and the lack of jobs ultimately discourages skills acquisition (Mahboubi and Busby, 2017). In 2019 the federal government changed the funding framework for First Nations K-12 education, gave additional support for full-time kindergarten and language and cultural programming and boosted capital spending on new schools, as well as adopting a distinctions-based approach to post-secondary education strategies. Yet providing more job opportunities in remote Indigenous communities may be a prerequisite for an improvement in labour market outcomes. Similarly, the disproportionate share of Indigenous people incarcerated also harms their employment opportunities. Furthermore, one third of Indigenous people are at high risk from being automated out of jobs by digitalisation, slightly more than non-Indigenous, because they are more heavily located in low-wage sectors, given the preponderance of people lacking a diploma or degree $(25.6 \%$ among non-elderly adult Indigenous versus $10.8 \%$ for non-Indigenous) (Diversity Institute et al., 2020). In an in-depth look at labour- 
market outcomes of Canada's Indigenous people, OECD (2018a) recommended: 1) greater flexibility in programme management; 2) better alignment of federal with provincial and territorial programming; 3 ) leveraging the role of cities in addressing the needs of urban Indigenous people; 4) improved collection and use of labour-market information (a pilot labour market information programme was launched in 2019); $5)$ using targeted work-experience programmes; 6) expanded Indigenous access to post-secondary education; 7) increased use of mentorship; and 8) exploring the use of social enterprises.

\section{Figure 18. Indigenous groups elsewhere face similar well-being challenges to those in Canada}

Values show Indigenous levels as a percentage of non-Indigenous levels

A. Life expectancy

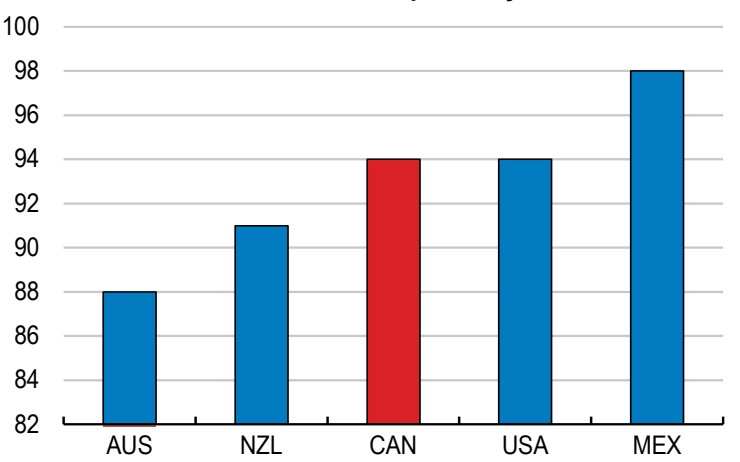

C. Employment

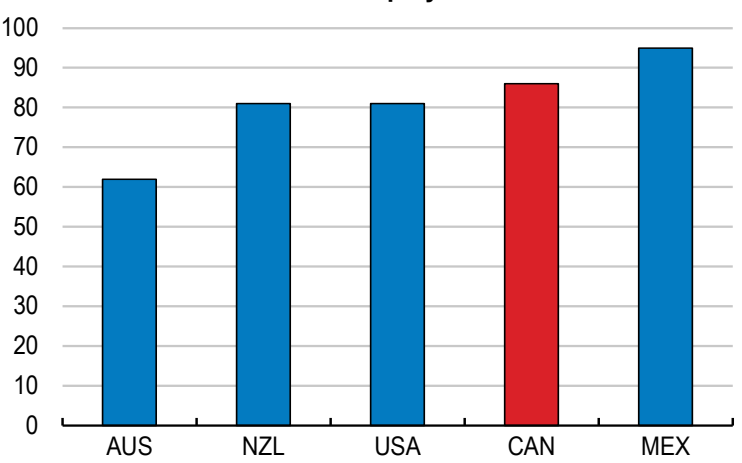

B. Income

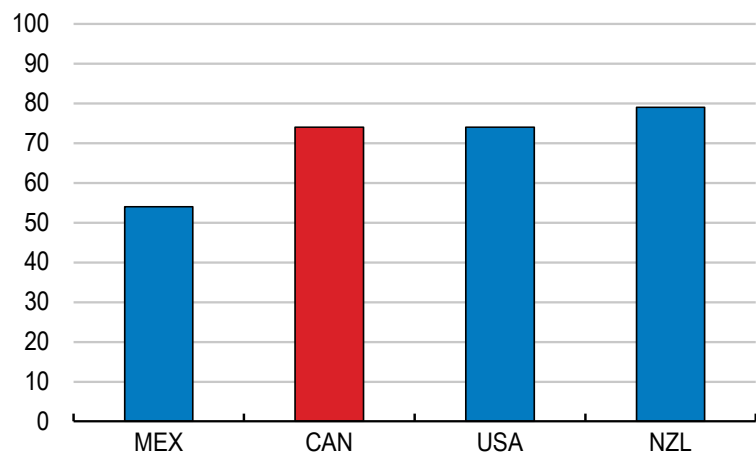

D. Unemployment

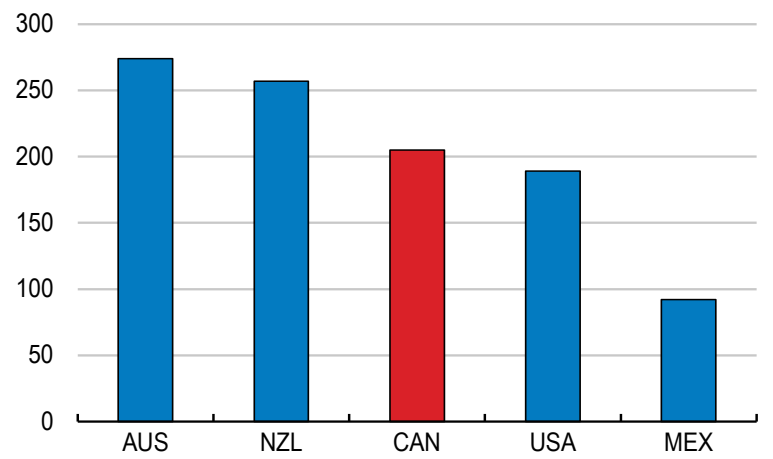

Note: The life expectancy rate of Indigenous Canadians is the weighted average of First Nations, Métis and Inuit women and men. Median income refers to total personal income for Canada; median household income for Mexico; median personal income for New Zealand; and median earnings for the United States. Non-Indigenous peoples' income corresponds to the median earnings of the total population for the United States. Employment and unemployment refer to people aged 15-64, as a percentage of the population of the same age, except for Canada where it refers to populations aged 15 and over.

Source: Adapted from OECD (2019), Linking Indigenous Communities to Regional Development, https://doi.org/10.1787/3203c082-en.

StatLink 페s] https://stat.link/u8xiy6

Indigenous entrepreneurship and business success has long been stunted not only because of a lack of relevant education and training, but also because of the barriers of rurality, small scale, lack of infrastructure and poor access to credit (OECD, 2020h). The federal government could do more to favour Indigenous businesses in its public procurement and make greater efforts to bolster the 59 Aboriginal financial institutions who are members of the National Aboriginal Capital Corporations Association. It could also offer more entrepreneurship training and advisory support. But this is not to deny the importance of economic development led by Indigenous governments, including resolving land claims and resource rights and developing their own revenue sources for achieving sustained improvement in Indigenous socioeconomic outcomes. 
Another major issue facing both Indigenous households and firms because of their strong concentration in remote northern communities is their poor access to broadband. The latest comparative data available (for 2018) show that households on First Nations reserves fared worse than not only the Canadian average but than typical rural households (Table 11). In its connectivity strategy (High-Speed Access for All) the federal government committed to working with Indigenous communities to implement connectivity projects and meet their needs, but their goal of ensuring fast and reliable access to this critical infrastructure only by 2030 is not sufficiently ambitious. It should ensure that these gaps are more quickly overcome.

Table 11. Broadband access by First Nations households by speed in Mbps, \%, 2018

\begin{tabular}{l|c|c|c}
\hline \multicolumn{1}{c|}{ Speed } & Canada & Rural communities & First Nations reserves \\
\hline $1.5+$ & 98.8 & 94.2 & 92.6 \\
\hline $5+$ & 97.9 & 90.5 & 85.8 \\
\hline $10+$ & 96.6 & 84.2 & 71.4 \\
\hline $16+$ & 94.1 & 73.8 & 55.8 \\
\hline $25+$ & 93.7 & 72.1 & 54.0 \\
\hline $50+$ & 86.5 & 43.0 & 32.3 \\
\hline $50 / 10 /$ Unlimited & 85.7 & 40.8 & 31.3 \\
\hline $100+$ & 84.9 & 37.9 & 29.3 \\
\hline
\end{tabular}

Source: CRTC (2019), CMR 2019-Retail Fixed Internet Sector and Broadband Availability, Figure 9.24.

One worthy recent innovation is the way the federal government funds First Nations communities with various flexible funding instruments that came out of negotiations with First Nations governments designed to achieve a new fiscal relationship with sufficient, predictable and sustained funding. For example, instead of providing annual appropriations, with all the uncertainty that entails, some years ago it began to offer ten-year grants, which afford their governments a lower administrative and reporting burden and considerable additional discretion in how to allocate available resources over time and across programmes, as carryovers are then permitted. Unfortunately, many have thus far not taken up the option because of feelings of distrust and of inconsistency with the decolonisation process, as well as, in some cases, a lack of governance capacity and an ability to meet eligibility requirements. Nevertheless, as of 2019, 84 First Nations (out of some 600) are in the 10-year funding system, and that number is rising fast. Other notable examples of devolution and self-determination include: the recognition of five Indigenous organisations by the government of Canada, federal Indigenous Labour Market Programming, health-care provision in British Columbia and various First Nations public services in Northern Ontario.

\section{Racialised populations are also severely disadvantaged in well-being terms}

There were 7.7 million Canadians belonging to visible minorities (22.3\% of the population) in 2016 (double that in Toronto), up from $16 \%$ a decade earlier thanks to Canada's ethnically diverse sourcing of immigrants. While many were not born in Canada and suffer economically from their immigrant status, native-born Canadians that are non-White have an extra source of disadvantage. For example, in 2016 their poverty rate varied by group but for most was more than double the $9.6 \%$ recorded for White Canadians (Hou et al., 2020) and reached around 30\% for some groups; only Filipino Canadians had a lower rate than White Canadians (8\%). Similar disparities were noted for Black and other non-White single young adults in Toronto in 2016 (Duah-Kessie et al., n.d.). Racialised populations have suffered an unemployment rate gap of nearly two percentage points, almost all of which was for women (3.2 points) (Block et al., 2019). But men from racialised populations suffer a $22 \%$ earnings penalty, pointing to the increasing prevalence of working poor, especially among Black and South Asian Canadians (Stapleton, 2019). Both genders declared smaller and less frequent capital gains and investment income on their tax returns, implying relevant wealth differences. Black Canadians also suffer from less access to nutritious 
food, more frequent housing problems (Leon and Iveniuk, 2020) and greater dissatisfaction with their neighbourhoods (Claveau, 2019).

Crowd-sourced data show that during the COVID-19 pandemic, Canadians from racialised populations experienced job loss or reduced working hours to a greater extent than their White Canadian counterparts, resulting in a larger share reporting a heavy financial impact $(25.0 \%$ versus $22.1 \%)$. They also reported that their mental health in the spring of 2020 was only fair or poor somewhat more frequently than did White Canadians ( $27.8 \%$ versus $22.9 \%$ ) and that they had moderate or severe anxiety ( $30 \%$ versus $24.2 \%$ ) (Moyser, 2020a); however, these gaps did not seem to have widened since the pandemic started. In recognition of the specific mental health problems of Black Canadians the federal government recently committed funds to local youth-at-risk culturally focused mental health programmes. 


\section{Main findings and recommendations}

\begin{tabular}{l|l}
\hline \multicolumn{1}{c|}{ MAIN POLICY FINDINGS } & \multicolumn{1}{c}{ RECOMMENDATIONS (Key recommendations in bold) } \\
\hline \multicolumn{1}{c}{ Bringing well-being to the fore in the wake of the pandemic } \\
\hline $\begin{array}{l}\text { Canada is one of a shrinking minority of OECD countries that has no } \\
\text { official well-being framework. The federal government tasked a }\end{array}$ & $\begin{array}{l}\text { Develop a dashboard of well-being indicators for use in government } \\
\text { decision making that covers current and future well-being, } \\
\text { Minister with devising one in 2019, and work is underway. }\end{array}$ \\
$\begin{array}{l}\text { Use the dashboard to identify policy challenges and to measure } \\
\text { progress in outcomes. }\end{array}$ \\
\hline
\end{tabular}

Strengthening social welfare

Canada's middle-income group has shrunk more than in most countries. Its tax-transfer system does less than most to offset what the market has wrought.

The current gender wage gap is among the OECD's largest, especially for women with school-age children. Childcare access is heavily income-constrained.

Poverty in Canada is especially high for Indigenous peoples and racialised populations. Social assistance leaves most recipients in poverty and suffering from food insecurity. Governments have given extra support to food banks during the pandemic.

\section{Creating more affordable housing}

Housing affordability is a localised problem concentrated at the bottom of the income distribution. Social and affordable housing is limited, and waiting lists are long. The federal government has had a National Housing Strategy since 2017.

Homelessness is another manifestation of poverty, closely aligned with poor health, especially mental illness, as well as food insecurity and substance abuse. It has heavy fiscal costs. The length of time people spend in shelters is increasing.

\section{Improving health and long-term care}

Having different health-care systems across the provinces and territories should provide a wealth of data to determine optimal policies, for example in dealing with the chronic problem of waiting times.

Mental health plays a key role in well-being and its dispersion. Mental illnesses are widespread and extremely costly, yet treatment is very cost effective. Even before the pandemic fewer people than in 2015 rated their mental health highly, and "deaths from despair" were increasing for most female age groups. Public health receives a small share of total health-care spending.

Problematic substance use contributed to about 76000 deaths in Canada in 2017 and cost the economy dearly. About 5000 persons died from opioids.

Canada is unusual in having a public universal health-care system that excludes drug coverage at the national level. The current patchwork imposes heavy administrative costs, leaves $19 \%$ of people in Canada without effective coverage and generates high drug prices (because of the failure to exploit collective buying power) and "job lock".

Another gap in the social safety net is the lack of paid sick days for over half of all employees, including as many as three-quarters of the lowest paid. A temporary scheme has been implemented but only for those suffering from COVID-19.
Ensure that tax returns are filed automatically, as the government has recently promised, so that all eligible people receive the benefits to which they are entitled.

Boost childcare provision through increased subsidies of services, tougher quality control and more support for working parents to pay for these services.

Consider combating poverty through more generous social benefits and taxbased measures, preferably without increasing the overall size of the budget and avoiding deleterious labour-supply effects.

Improve housing supply by ensuring a competitive construction sector, reducing rent controls and relaxing strict zoning and land-use regulations and urban containment policies.

Put more resources into social housing, and encourage alternative ownership arrangements.

Provide the new National Housing Council with adequate initial resources, and adjust funding to developing needs. Quickly name the promised federal Housing Advocate.

Seek efficiency gains and reduced waiting times through better patient prioritisation, improved co-ordination between primary-care providers and specialists, greater use of telemedicine and the reallocation of some tasks from physicians to nurses.

Exploit systemic differences across different provincial and territorial healthcare systems to define best practises.

Provide more resources for mental health and public health

Adopt maximum waiting times for adults' mental health, and make those for children and youths more stringent, even if this implies more public spending.

Enhance public health efforts to reduce and prevent substance-related harms. Ensure that the health-care, social and criminal-justice systems better coordinate their efforts in the area.

Follow through with the plan to negotiate with the provinces and territories the gradual adoption of universal drug coverage ("Pharmacare").

Negotiate a pan-Canadian plan with the provinces and territories to mandate a reasonable number of paid sick days for all workers. 


\begin{tabular}{|c|c|}
\hline MAIN POLICY FINDINGS & RECOMMENDATIONS (Key recommendations in bold) \\
\hline $\begin{array}{l}\text { The poor situation in the long-term care sector came to the fore in } \\
2020 \text { when the COVID-19 pandemic first hit: nearly three-quarters of } \\
\text { the fatalities have been among elderly residents of long-term care } \\
\text { institutions. }\end{array}$ & $\begin{array}{l}\text { Increase support for high-quality institutional and home-based long- } \\
\text { term care. } \\
\text { Tighten standards, make inspections more frequent and rigorous, and } \\
\text { intensify data collection for use in the accreditation process. } \\
\text { Improve training and pay for long-term care workers. } \\
\text { Encourage aging in place. }\end{array}$ \\
\hline \multicolumn{2}{|c|}{ Building a more sustainable environment } \\
\hline $\begin{array}{l}\text { Well-being is also influenced by environmental factors. Canada's } \\
\text { environmental performance is diverse but middling overall. } \\
\text { Environmentally related taxation is among the lowest in the OECD, } \\
\text { and it has been falling in relation to GDP, though some of the gap is } \\
\text { due to the use of cap-and-trade systems rather than carbon taxes to } \\
\text { fight climate change. }\end{array}$ & $\begin{array}{l}\text { Follow through with the recent plan to accelerate the increases in } \\
\text { carbon pricing and taxation through } 2030 \text { while protecting the poorest } \\
\text { from the impact on their living standards. } \\
\text { Make greater use of taxation and charges to tackle environmental } \\
\text { externalities, including from vehicle fuels, waste water treatment and } \\
\text { solid waste disposal. }\end{array}$ \\
\hline \multicolumn{2}{|c|}{ Supporting the well-being of Indigenous peoples and racialised populations } \\
\hline $\begin{array}{l}\text { Canada's Indigenous peoples have long suffered from a number of } \\
\text { disadvantages, despite rising public funding. Progress has recently } \\
\text { been made in renewing government-to-government relationships } \\
\text { through achieving self-determination, specifically by resolving land } \\
\text { claims cases and offering ten-year funding, so far taken up only by a } \\
\text { minority of groups. }\end{array}$ & $\begin{array}{l}\text { Enhance self-determination among Indigenous peoples. } \\
\text { Maintain the distinctions-based approach to policy, and ensure } \\
\text { adequate funding to achieve policy goals. } \\
\text { Ensure fast and reliable access to high-speed broadband sooner than by } \\
2030 \text {. }\end{array}$ \\
\hline $\begin{array}{l}\text { Racialised populations are over a fifth of the national total and rising } \\
\text { fast. They suffer from higher unemployment, especially for women, } \\
\text { lower earnings, particularly among men, and, for most groups, much } \\
\text { higher poverty rates. Economic and social pressures they face have } \\
\text { increased with the pandemic. }\end{array}$ & $\begin{array}{l}\text { Implement those reforms to the social assistance and/or tax systems, } \\
\text { Pharmacare and paid sick leave recommended above, as a good first step } \\
\text { to deal with the social injustices confronting these minority groups. }\end{array}$ \\
\hline
\end{tabular}




\section{Bibliography}

Agriculture and Agri-Food Canada (2020), Food Policy for Canada: Everyone at the Table, 11 March, Ottawa.

Allas, T., D. Chinn, P.E. Sjatil and W. Zimmerman (2020), "Addressing the high cost of COVID-19 on life satisfaction", McKinsey, June.

Arriagada, P. T. Hahmann and V. O'Donnell (2020a), "Indigenous people and mental health during the COVID-19 pandemic", Statistics Canada, 23 June.

Arriagada, P., T. Hahmann and V. O'Donnell (2020b), "Indigenous people in urban areas: Vulnerabilities to the socioeconomic impacts of COVID-19", Statistics Canada, 26 May.

Auditor General of Ontario (2017), Annual Report, 6 December.

Balestra, C. and G. Cohen (2021, forthcoming), "Income inequality through people's eyes: Evidence from the OECD's Compare your income web tool", Working Paper, OECD Publishing, Paris.

Balestra, C. and R. Tonkin (2018), "Inequalities in household wealth across OECD countries: Evidence from the OECD Wealth Distribution Database", OECD Statistics Working Paper, 2018-01, OECD Publishing, June.

Baptista, I. and Eric Marlier (2019), Fighting homelessness and housing exclusion in Europe: A Study of national policies, European Social Policy Network, European Commission, Brussels.

Barrington-Leigh, C. (2020), "Reframing policy around life satisfaction and sustainability: a quantitative framework for wellbeing", unpublished, July.

Barrington-Leigh, C. (2017), "Sustainability and Well-Being: A Happy Synergy", Development, 59, July, pp. 292-98.

Barrington-Leigh, C. (2013), "The Quebec Convergence and Canadian Life Satisfaction, 1985-2008”, Canadian Public Policy, 39, 2, June, pp. 193-219.

Barua, B. and M. Moir (2019), Waiting Your Turn: Wait Times for Health Care in Canada, 2019 Report, Fraser Institute, Vancouver, 10 December.

Barua, B. and S. Hasan (2018), "The Private Cost of Public Queues for Medically Necessary Care, 2018”, Fraser Research Bulletin, May.

Basic Income Canada Network (2019), Signposts to Success: Report of a BICN Survey of Ontario Basis Income Recipients, March.

Beedie, N., D. Macdonald and D. Wilson (2019), Towards Justice: Tackling Indigenous Child Poverty in Canada, Upstream, July.

Benjamin, D.J., J. Debnam, M. Fleurbaey, O. Heffetz and M. Kimball (2020), "What Do Happiness Data Mean? Evidence from a Survey of Happiness Respondents", unpublished draft, 7 March.

Bleakney, A., H. Masoud and H. Robertson (2020), "Labour market impacts of COVID-19 on Indigenous people: March to August 2020", Statistics Canada, 2 November.

Block, S., G.E. Galabuzi and R. Tranjan (2019), "Canada's Colour-Coded Income Inequality”, Canadian Centre for Policy Alternatives, Ottawa, December.

Boadway, R., L. Godbout and M. Smart (2020), "Marginal Tax Rates under the Canada Recovery Benefit", Finances of the Nation, 30 October.

Boadway, R., K. Cuff and K. Koebel (2016), "Designing a Basic Income Guarantee for Canada”, Working Paper, No. 1371, Queens University Economics Department.

Boarini, R., F. Murtin, P. Schreyer and M. Fleurbaey (2016), "Multi-dimensional Living Standards: A Welfare Measure Based on Preferences", OECD Statistics Working Paper, No. 2016/05, 7 September.

Boyer, Y. (2017), "Healing racism in Canadian health care", CMAJ, 189, 46, 20 November. 
Burczycka, M. (2019), "Section 2: Police-reported intimate partner violence in Canada, 2018", in Statistics Canada, Family violence in Canada: A statistical Profile, 2018, 12 December.

Burger, M.J., P.S. Morrison, M. Hendriks and M.M. Hoogerbrugge (2020), "Urban-Rural Happiness Differentials across the World", Chapter 4 in J.F. Helliwell et al. (eds.), World Happiness Report 2020.

Campaign 2000 End Child and Family Poverty (2020), 2020 Setting the Stage for a Poverty-Free Canada, Report Card on Child and Family Poverty in Canada, 14 January.

Canada Mortgage and Housing Corporation (2020), Northern Housing Report, Ottawa, October.

Canada Mortgage and Housing Corporation (2018), Examining Escalating House Prices in Large Canadian Metropolitan Centres, Ottawa, 24 May.

Canada Without Poverty (no date), "Just the Facts", Ottawa.

Canadian Centre on Substance Use Costs and Harms Scientific Working Group (2020), Canadian Substance Use Costs and Harms 2015-2017.

Canadian Index of Wellbeing (2016), How are Canadians Really Doing? The 2016 CIW National Report, University of Waterloo, November.

Canadian Institute for Health Information (2020), "Wait Times for Priority Procedures in Canada, 2020", 9 July.

Canadian Medical Association, Canadian Nurses Association, Canadian Society for Long-Term Care Medicine and Canadian Support Workers Association (2020), "National Standards for Long-Term Care: The Art of the Possible?", 8 December.

Case, A. and A. Deaton (2020), Deaths of Despair and the Future of Capitalism, Princeton University Press, Princeton.

Caturianas, D., P. Lewandowski, J. Sokolowski, Z. Kowalik and E. Barcevičius (2020), Policies to Ensure Access to Affordable Housing, Directorate General for Internal Policies, European Parliament, Brussels, August.

Cavalleri, M.C., B. Cournède and E. Özsöğüt (2019), "How Responsive are Housing Markets in the OECD? National Level Estimates", OECD Economics Department Working Papers, No. 1589, December, OECD Publishing, Paris.

Cision (2020), "Bromwich and Smith: Bracing for a personal bankruptcy boom amid business closures", 6 August.

Clark, A.E. (2018), "Four Decades of the Economics of Happiness: Where Next?", Review of Income and Wealth, 64, 2, June, pp. 245-69.

Clark, A.E., S. Flèche, R. Layard, N. Powdthavee and G. Ward (2018), The Origins of Happiness: The Science of Well-Being over the Life Course, Princeton University Press

Claveau, J. (2019), "Satisfaction of Canadian households with their neighbourhood: Highlights from the 2018 Canadian Housing Survey", Statistics Canada, 22 November.

Clavet, N.-J., J.-Y. Duclos and G. Lacroix (2013), "Fighting Poverty: Assessing the Effect of Guaranteed Minimum Income Proposals in Québec", Canadian Public Policy, 39, 4, pp. 491-516.

Connolly, M., C. Haeck and D. Lapierre (2019), "Social Mobility Trends in Canada: Going Up the Great Gatsby Curve", Research Group on Human Capital, University of Quebec in Montreal's School of Management, Working Paper, No. 19-03, 27 May.

Corak, M. (2016), "'Inequality is the root of social evil' or Maybe Not: Two Stories about Inequality and Public Policy", Canadian Public Policy, 42, 4, December, pp. 367-414.

Corak. M. (2013), "Income Inequality, Equality of Opportunity and Intergenerational Mobility", Journal of Economic Perspectives, 27, 3, Summer, pp. 79-102.

Davies, S., A. Finney and Y. Hartfree (2016), "The Poverty Premium - When low-income households pay more for essential goods and services", University of Bristol, School of Geographical Sciences, November. 
Decent Work and Health Network (2020), Before It's Too Late: How to Close the Paid Sick Days Gap During COVID-19 and Beyond, 19 August.

Demographia and Performance Urban Planning (2020), 16th Annual Demographia International Housing Affordability Survey: 2020 Rating Middle-Income Housing Affordability, St. Louis and Christchurch.

De Neve, J.-E. and J.D. Sachs (2020), "Sustainable Development and Human Well-Being", Chapter 6 in J.F Helliwell et al. (eds.), (2020), World Happiness Report 2020, Sustainable Development Solutions Network, New York, 20 March.

Diversity Institute, Canadian Council for Aboriginal Business and Future Skills Centre (2020), "Digital differences: the impact of automation on the Indigenous economy in Canada", July.

Djidel, S., B. Gustajtis, A. Heisz, K. Lam, I. Marchand and S. McDermott (2020), Report on the Second Comprehensive Review of the Market Basket Measure, Statistics Canada, 24 February.

Doberstein, C. (2016), Building a Collaborative Advantage: Network Governance and Homelessness Policy-Making in Canada, UBC Press, Vancouver and Toronto.

Doberstein, C. and A. Smith (2015), "Housing first, but affordable housing last: the Harper government and homelessness", in T. Healy and S. Trew (eds.), The Harper Record 2008-2015, Canadian Centre for Policy Alternatives, Ottawa.

Doty, M.M., R.S. Tikkanen, M. FitzGerald, K. Fields and R.D. Williams II (2021), "Income-Related Inequality in Affordability and Access to Primary Care in Eleven High-Income Countries", Health Affairs, 40, 1, pp. 113-20.

Drummond, D. and D. Sinclair (2020), "COVID-19: A Catalyst for Change in Health and Healthcare", Verbatim, CD Howe Institute, Toronto, 15 October.

Drummond, D., A. Murray, N. Mask and A. Sharpe (2017), "The Contribution of Aboriginal People to Future Labour Force Growth in Canada", Centre for the Study of Living Standards, Ottawa, 2 October.

Duah-Kessie, I., A. Siddiqi, J. Iveniuk and K. McKenzie (n.d.), "No one left behind: Exploring thriving income among the Black population in the City of Toronto", Wellesley Institute, Toronto.

Durand, M. and C. Exton (2019), "Adopting a well-being approach in central government: Policy mechanisms and practical tools", Chapter 8 in Global Happiness and Wellbeing Policy Report, Global Council for Happiness and Wellbeing, United Arab Emirates.

Easterlin, R. A. (1974), "Does economic growth improve the human lot? Some empirical evidence", in P. David and M. Reder (eds.), Nations and Households in Economic Growth, Academic Press, New York, pp. 89-125.

Edelman Trust Barometer (2020), Spring Update: Trust and the COVID-19 Pandemic: Canada Findings.

Employment and Social Development Canada (2019a), Everyone Counts 2018: Highlights, Gatineau.

Employment and Social Development Canada (2019b), Highlights of the National Shelter Study 2005 to 2016, Gatineau.

Employment and Social Development Canada (2018a), Final Report on the Evaluation of the Homelessness Partnering Strategy, Gatineau, 11 May.

Employment and Social Development Canada (2018b), Final Report of the Advisory Committee on Homelessness on the Homelessness Partnering Strategy, Gatineau.

Engage Nova Scotia and the Canadian Index of Wellbeing (2018), Nova Scotia Quality of Life Index 1994-2014, Waterloo (Ontario), draft version.

Environment and Climate Change Canada (2019), Achieving a Sustainable Future, A Federal Sustainable Development Strategy for Canada 2019 to 2022, Gatineau.

Evra, R. and E. Mongrain (2020), "Mental Health Status of Canadian Immigrants During the COVID-19 Pandemic", Statistics Canada, 14 July. 
Exton, C. and L. Fleischer (2020), "The Future of the OECD Well-being Dashboard: Discussion Paper", draft paper.

Exton. C. and M. Shinwell (2018), "Policy Use of well-being metrics: Describing countries' experiences", OECD Statistics Working Papers, No. 2018/07, OECD Publishing, Paris, November.

Fafard St. Germain, A.-A. and V. Tarasuk (2020), "Homeownership status and risk of food insecurity: examining the role of housing debt, housing expenditure and housing asset [sic] using a crosssectional survey of Canadian households", International Journal for Equity in Health, 19, 5.

Ferdosi, M., T. McDowell, W. Lewchuk and S. Ross (2020), Southern Ontario's Basic Income Experience, Hamilton Roundtable for Poverty Reduction, McMaster University Labour Studies and Hamilton Community Foundation, March.

Finance Canada (2018), "Measuring Housing Affordability for Potential Homebuyers".

Findlay, L. and R. Arim (2020), "Canadians report lower self-perceived mental health during the COVID19 pandemic", Statistics Canada, 24 April.

First Nations Information Governance Centre (2020), "Regional Health Survey Statistics for Shaping a Response to COVID-19 in First Nations Communities", May, Ottawa.

Fonberg, J.D. and G. Schellenberg (2019), "Canadians' satisfaction with their housing: Highlights from the 2018 Canadian Housing Survey", 22 November.

Forget, E.L. (2020), Basic Income for Canadians: From the COVID-19 Emergency to Financial Security for All, Lorimer Books, Toronto, October.

Frijters, P., A. E. Clark, C. Krekel and R. Layard (2020), "A Happy Choice: Wellbeing as the Goal of Government", Behavioural Public Policy, 4, 2, pp. 126-65.

Gaetz, S., E. Dej, T., Richter and M. Redman (2014), The State of Homelessness in Canada 2014, Canadian Observatory on Homelessness Press, Toronto.

Gaetz, S. (2014), "Can Housing First Work for Youth?", European Journal of Homelessness, 8, 2, pp. $159-75$.

Gaetz, S. (2010), "The Struggle to End Homelessness in Canada: How We Created the Crisis and How We Can End It", Editorial, The Open Health Services and Policy Journal, 3, pp. 21-26.

Global Footprint Network (2020), National Footprint and Biocapacity Accounts.

Global Happiness and Wellbeing Policy Report 2019 (2019), Global Council for Happiness and Wellbeing, United Arab Emirates.

Goff, L., J.F. Helliwell and G. Mayraz (2018), "Inequality of Subjective Well-Being as a Comprehensive Measure of Inequality", Economic Inquiry, 56, 4, October, pp. 277-94.

Gordon, J. (2020a), "The 'supply crisis' in Canada's housing market isn't backed up by the evidence”, Globe and Mail, 13 September.

Gordon, J. (2020b), "Reconnecting the Housing Market to the Labour Market: Foreign Ownership and Housing Affordability in Canada", Canadian Public Policy, 46, 1, March, pp. 1-22.

Grant, K. (2020), " $81 \%$ of COVID-19 deaths in Canada were in long-term care - nearly double OECD average", Globe and Mail, 25 June.

Green, D.A., J.R. Kesselman and L.M. Tedds (2020), Covering All the Basics: Reforms for a More Just Society, Final Report of the British Columbia Expert Panel on Basic Income, 28 December.

Green, K.P, J. Filipowicz, S. Lafleur and I. Herzog (2016), "The Impact of Land-Use Regulation on Housing Supply in Canada", Fraser Institute, Vancouver.

Greenwood, M.L. and S.N. de Leeuw (2012), "Social determinants of health and the future well-being of Aboriginal children in Canada", Paediatric Child Health, 17, 7, August-September, pp. 381-84.

Happiness Research Institute and Leaps by Bayer (2020), Wellbeing Adjusted Life Years, Berlin. 
Hardoon, D. with N. Hey and S. Brunetti (2020), "Wellbeing evidence at the heart of policy", What Works Wellbeing, London, February.

Hashiguchi, T.C.O. and A. Llena-Nozal (2020), "The Effectiveness of Social Protection for Long-Term Care in Old Age", OECD Health Working Papers, No. 117, April, OECD Publishing, Paris.

Health Canada (2019), A Prescription for Canada: Achieving Pharmacare for All, Final Report of the Advisory Council on the Implementation of National Pharmacare, June ("Hoskins Commission").

Helliwell, J.F., D. Gyarmati, C. Joyce and H. Orpana (2020a), "Building an Epidemiology of Happiness", NBER Working Papers, No; 28095, November.

Helliwell, J.F., R. Layard, J.D. Sachs and J.-E. De Neve (eds.) (2020b), World Happiness Report 2020, Sustainable Development Solutions Network, New York, 20 March.

Helliwell, J.F. (2019), "Measuring and Using Happiness to Support Public Policies", NBER Working Paper, No. 26529, December.

Helliwell, J.F., H. Shiplett and C.P. Barrington-Leigh (2019), "How happy are your neighbours? Variation in life satisfaction among 1200 Canadian neighbourhoods", PLOS ONE, 14, 1.

Helliwell. J.F. and H. Huang (2013), "Comparing the Happiness Effects of Real and On-line Friends", PLOS ONE, 8, 9.

Hicks, P. (2020), "Really? Social Statistics in the Throne Speech?", Social Canada.

Hillel, I. (2019), "Holes in the Social Safety Net: Poverty, Inequality and Social Assistance in Canada", Centre for the Study of Living Standards, Research Report 2020-06, Ottawa, August.

HM Treasury (2018), The Green Book: Central Government Guidance on Appraisal and Evaluation, London.

Holly, J.M.P., K. Biernacka, N. Maskell and C.M.Perks (2020), "Obesity, Diabetes and COVID_19: An Infectious Disease Spreading From the East Collides with the Consequences of an Unhealthy Lifestyle", Frontiers in Endocrinology, 11, 17 September,

Hosek, C., J. Weisstub and E. Waitzer (2020), "The pandemic has exposed the precarious economic situation of many Canadians", Globe and Mail, 14 June.

Hou, F., K. Frank and C. Schimmele (2020), "Economic impact of COVID-19 among visible minority groups", Statistics Canada, 6 July.

Hunsley, T. (2020), "The Throne Speech and Community Housing Trusts", Social Canada.

Kangas, O., S. Flour, M. Simanainen and M. Ylikanno (2020), "Evaluation of the Finnish basic income experiment", Ministry of Social Affairs and Health, Helsinki, 6 May.

Kim, P.J. (2019), "Social Determinants of Health Inequities in Indigenous Canadians Through a Life Course Approach to Colonialism and the Residential School System", Health Equity, 31, pp. 378-81.

Klapper, L., A. Lusardi and P. van Oudheusden (2015), Financial Literacy Around the World: Insights from the Standard and Poor's Rating Services Global Financial Literacy Survey.

Krekel, C. and G. MacKerron (2020), How Environmental Quality Affects Our Happiness", Ch. 5 in J.F. Helliwell et al. (eds), World Happiness Report 2020.

Krekel, C., J. Kolbe and H. Wüstemann (2016), "The Greener the Happier? The Effect of Urban Land Use on Residential Well-Being”, Ecological Economics, 121, 1, pp. 117-27.

Kumar, N., K. McKenzie and S.-g. Um (2017), "Thriving in the City: What does it cost to live a healthy life?", Wellesley Institute, Toronto, September.

Laird, G. (2007), "Homelessness in a Growth Economy: Canada's 21 $1^{\text {st }}$ Century Paradox", A Report for the Sheldon Chumir Foundation for Ethics in Leadership, Calgary.

Layard, R. (2019), "Evaluating Wellbeing in the Policy Toolkit", Powerpoint presentation to the OECD Conference on Putting Well-Being Metrics into Policy Action, 3-4 October, Paris. 
Lemyre, X., J. Mader and M. Ambard (2018), "Quantifying and Valuing the Wellbeing Impacts of Arts, Culture and Sports in Canada", Canadian Heritage, Gatineau, January.

Leon, S. and J. Iveniuk (2020), "Forced Out: Evictions, Race, and Poverty in Toronto", Wellesley Institute, Toronto, August.

Lesser, I. and C. Nienhuis (2020), "The Impact of COVID-19 on Physical Activity Behavior and WellBeing of Canadians", International Journal of Environmental Research and Public Health, 17, 11, June, p. 3899.

Levinson, A. (2012), "Valuing Public Goods Using Happiness Data: The Case of Air Quality", Journal of Public Economics, 96, 9-10, pp. 869-80.

Lewandowski, P., K. Lipowska and I. Magda (2020), "The Gender Dimension to Occupational Exposure to Contagion", IBS Working Paper, No. 05/2020, Warsaw, June.

Liu, M. et al. (2020), "COVID-19 in long-term care homes in Ontario and British Columbia", CMAJ, 192, 47, 23 November, pp. E1540-46.

Luechinger, S. (2009), "Valuing Air Quality Using the Life Satisfaction Approach", Economic Journal, 119, 536, March, pp. 482-515.

Maddison, P., K. Rehdanz and H. Welsch (2020), "Introduction" to Handbook on Wellbeing, Happiness and the Environment, Edward Elgar, Cheltenham, pp. 1-11.

Mahboubi, P. And C. Busby (2018), "Closing the Divide: Progress and Challenges in Adult Skills Development Among Indigenous Peoples", C.D. Howe Ebrief, No. 264, Toronto, 6 September.

Marshall, G. (2019), "Debt and financial distress among Canadian families", Statistics Canada, 26 June.

Masters, R., E. Anwar, B. Collins, R. Cookson and S. Capewell (2017), "Return on investment of public health interventions: a systematic review", Journal of Epidemiology and Community Health, 71, pp. 827-34.

McKenzie, K. (2020), "The new normal: moving from surviving to thriving", Wellesley Institute, Toronto, 16 June.

Mental Health Commission of Canada and Conference Board of Canada (2020), "New survey finds employment status, income, key factors impacting mental health of Canadians during COVID-19", Ottawa, 23 June.

Mental Health Commission of Canada (2015), Informing the Future: Mental Health Indicators for Canada, Ottawa.

Mental Health Commission of Canada (2012), Changing Directions, Changing Lives: The Mental Health Strategy for Canada, Ottawa, 29 June.

Moir, M. and B. Barua (2020), "The Private Cost of Public Queues for Medically Necessary Care, 2020", Fraser Research Bulletin, Fraser Institute, Vancouver, May.

Moyser, M. (2020a), "The mental health of population groups designated as visible minorities in Canada during the COVID-19 pandemic", Statistics Canada, 2 September.

Moyser, M. (2020b), "Gender differences in mental health during the COVID-19 pandemic", Statistics Canada, 9 July.

National Indigenous Economic Development Board (2019), The Indigenous Economic Progress Report 2019, Gatineau, Quebec.

Native Women's Association of Canada (no date), Drag.

OECD (2020a), "Housing Synthesis Report: Preliminary Version”, unpublished.

OECD (2020b), "Mental Health Performance Benchmarking - Progress and Key Findings", $27^{\text {th }}$ session of the Health Committee, 11-12 June.

OECD (2020d), Waiting Times for Health Service: Next in Line, 28 May, OECD Publishing, Paris. 
OECD (2020e), How's Life? 2020: Measuring Well-Being, OECD Publishing, Paris.

OECD (2020f), How's Life in Canada?, OECD Better Life Initiative, OECD Publishing, Paris.

OECD (2020g), Long-term Care and Health Care Insurance in OECD and Other Countries, February, OECD Publishing, Paris.

OECD (2020h), Linking Indigenous Communities With Regional Development in Canada, OECD Rural Policy Reviews, OECD Publishing, Paris, 21 January.

OECD (2020i), Who Cares? Attracting and Retaining Care Workers for the Elderly, OECD Publishing, Paris, 22 June.

OECD (2020j), "Better data and policies to fight homelessness in the OECD", Policy Brief on Affordable Housing, OECD Publishing, Paris.

OECD (2020k), "Social housing: A key part of past and future housing policy", Employment, Labour and Social Affairs Policy Briefs, OECD Publishing, Paris.

OECD (2020I), Housing and Inclusive Growth, OECD Publishing, Paris.

OECD (2019a), Putting Well-being Metrics into Policy Action, conference, 3-4 October, Paris.

OECD (2019b), OECD Economic Surveys: New Zealand, OECD Publishing, Paris, June.

OECD (2019c), Under Pressure: The Squeezed Middle Class, OECD Publishing, Paris.

OECD (2019d), Health For Everyone? Social Inequalities in Health and Health Systems, OECD Health Policy Studies, OECD Publishing, Paris.

OECD (2019e), Addressing Problematic Opioid Use in OECD Countries, OECD Health Policy Studies, OECD Publishing, Paris.

OECD (2019f), OECD Economic Surveys: Slovak Republic, OECD Publishing, Paris, February.

OECD (2019g), Health in the 21st Century: Putting Data to Work for Stronger Health Systems, OECD

Publishing, Paris, November.

OECD (2019h), Health at a Glance 2019, OECD Publishing, Paris.

OECD (2018a), Indigenous Employment and Skills Strategies in Canada, OECD Reviews on Local Job Creation, OECD Publishing, Paris.

OECD (2018b), A Broken Social Elevator? How to Promote Social Mobility, OECD Publishing, Paris.

OECD (2017a), Environmental Performance Review: Canada, OECD Publishing, Paris.

OECD (2017b), "Basic income as a policy option: Can it add up?", Policy Brief on the Future of Work, OECD Publishing, Paris.

OECD (2017c), "How does Canada compare on child well-being?", OECD Child Well-Being Data Portal Country Factsheet, November.

OECD (2013), OECD Guidelines on Measuring Subjective Well-being, OECD Publishing, Paris.

OECD (2011), How's Life? Measuring Wellbeing, OECD Publishing, Paris.

OECD (2010), Going for Growth, OECD Publishing, Paris.

O'Flaherty, B. (2019), "Homelessness research: A guide for economists (and friends)", Journal of Housing Economics, 44, pp. 1-25.

Oishi, S. and E. Diener (2014), "Can and Should Happiness be a Policy Goal?", Policy Insights from the Behavioral and Brain Sciences, 1, 1, pp. 195-203.

Pan-Canadian Health Inequalities Reporting Initiative (2018), Key Health Inequalities in Canada: A National Report, Public Health Agency of Canada, Ottawa, August.

Parliamentary Budget Officer (2020), Costing a Guaranteed Basic Income During the COVID Pandemic, Ottawa, 7 July.

Pasma, C. and S. Regehr (2019), "Basic Income: Some Policy Options for Canada", Report prepared for 
the Basic Income Canada Network.

Persaud, N. and H. Ahmad (2017), "Canadian List of Essential Medications", Canadian Family Physician, 63, 4, April, pp. 266-68.

Picot, G. and Y. Lu (2017), "Chronic Low Income Among Immigrants in Canada and its Communities", Statistics Canada, Analytical Studies Branch Research Paper Series, 29 September.

Pollack, C.E., B.A. Griffin and J. Lynch (2010), "Housing Affordability and Health Among Homeowners and Renters", American Journal of Preventive Medicine, 39, 6, pp. 515-21.

Pritchard, A. M. Richardson, D. Sheffield and K. McEwan (2020), "The Relationship Between Nature Connectedness and Eudaimonic Well-Being: A Meta-analysis", Journal of Happiness Studies, 21, pp. 1145-67.

Public Health Agency of Canada (2016), The Direct Economic Burden of Socioeconomic Health Inequalities in Canada, Ottawa.

Qasim, M. and A. Grimes (2018), "Sustainable economic policy and well-being: The relationship between adjusted net savings and subjective well-being", MOTU Working Paper, No. 18-06, Wellington, May.

Raudsepp-Hearne, C., G. D. Peterson, M. Tengö, E.M. Bennett, T. Holland, K. Benessaiah, G.K. MacDonald and L.R. Pfeifer (2010), "Untangling the Environmentalist's Paradox: Why is Human Wellbeing Increasing as Ecosystem Services Degrade?", BioScience, 60, 8, September, pp. 576-89.

Rech, N. (2019), "Homelessness in Canada", The Canadian Encyclopedia, 9 July.

Rehdanz, K. and D. Maddison (2008), "Local environmental quality and life-satisfaction in Germany", Ecological Economics, 64, 4, February, pp. 787-97.

Richards, J. (2020), "No Easy Answers: Insights Into Community Well-being among First Nations", C.D. Howe Ebrief, No. 304, Toronto, 21 May.

Rothwell, D. and J. Robson (2017), "The prevalence and composition of asset poverty in Canada: 1999, 2005, and 2012", International Journal of Social Welfare, 27, 1, June.

Royal Society of Canada (2020), Restoring Trust: COVID-19 and the Future of Long-Term Care, 3 July.

Salvi del Pero, A., W. Adema, V. Ferraro and V. Frey (2016), "Policies to promote access to good-quality affordable housing in OECD countries", OECD Social, Employment and Migration Working Papers, No. 176, February.

Shi, Y., C. Joyce, R. Wall, H. Orpana and C. Bancej (2019), "A life satisfaction approach to valuing the impact of health behaviours on subjective wellbeing", BMC Public Health, 19, 21 November.

Shim, R.S. and M.T. Compton (2018), "Addressing the Social Determinants of Mental Health: If Not Now, When? If Not Us, Who?", Psychiatric Services, 69, 8, August, pp. 844-46.

Sinha, M. (2014), "Childcare in Canada", Analytical Paper, Statistics Canada, 30 October.

Sircova, A. et al. (2014), "A Global Look at Time: A 24-Country Study of the Equivalence of the Zimbardo Time Perspective Inventory", Sage Open, January-March, pp. 1-12.

Social Progress Imperative (2019), Social Progress Index.

Stapleton, J. (2019), "The Working Poor in the Toronto region: A Closer Look at the Increasing Numbers", Metcalf Foundation, Toronto, November.

Stall, N.M. et al. (2020), "For-profit long-term care homes and the risk of COVID-19 outbreaks and resident deaths", CMAJ, 192, 33, 17 August, pp. E940-46.

Statistics Canada (2020a), "Canadian Community Health Survey, 2019", 6 August.

Statistics Canada (2020b), "Household food insecurity, 2017/2018", 24 June.

Statistics Canada (2019), "First results from the Canadian Housing Survey, 2018", 22 November.

Stergiopoulos, V. et al. (2015), "Effect of scattered-site housing using rent supplements and intensive case management on housing stability among homeless adults with mental illness: a randomized 
trial", Journal of the American Medical Association, 313, pp. 905-15.

Stevens, H. and S. Simpson (2017), "Toward a National Universal Basic Income", Canadian Public Policy, 43, 2, June, pp. 120-39.

Stiglitz, J.E., J.-P. Fitoussi and M. Durand (2018), Beyond GDP: Measuring What Counts for Economic and Social Performance, OECD Publishing, Paris.

Stiglitz, J.E., A. Sen and J.-P. Fitoussi (2009), Report of the Commission on the Measurement of Economic Performance and Social Progress, January.

Subedi, R., L. Greenberg and M. Turcotte (2020), "COVID-19 mortality rates in Canada's ethno-cultural neighbourhoods", Statistics Canada, 28 October.

Tarasuk, V. and A. Mitchell (2020), "Household Food Insecurity in Canada 2017-2020", Proof, Food Insecurity Policy Research, University of Toronto.

Tax Policy Center (2020), "How Could We Improve the Federal Tax System? What other countries use return-free filing?", Urban Institute and Brookings Institution, Washington, DC.

Temkin, K., B. Theodos and D. Price (2011), "A Promising Way Forward for Home Ownership: Assessing the Benefits of Shared Equity Programs", Community Investments, 23, 1, Spring, pp. 12-19.

Theodos, B., C.P. Stacy, B. Braga and R. Daniels (2019), "Affordable Homeownership: An Evaluation of Shared Equity Programs", Urban Institute Research Report, 22 May.

Thistle, J. (2017), "Reframing the Discussion: An Indigenous Definition of Homelessness", Homelessness Hub, 27 September.

UNICEF Innocenti (2020), Worlds of Influence: Understanding What Shapes Child Well-Being in Rich Countries, Innocenti Report Card 16, Florence.

UNICEF Canada (2019), Where Does Canada Stand? The Canadian Index of Child and Youth Wellbeing: 2019 Baseline Report.

Wendling, Z.A., J.W. Emerson, A. de Sherbinin, D.C. Esty and M. Levy (2020), 2020 Environmental Performance Index, Yale Center for Environmental Law and Policy, New Haven.

Wolfson, M. (2018), "How a guaranteed income could work", Policy Options, Institute for Research in Public Policy, 5 July.

World Economic Forum (2020), The Global Social Mobility Report 2020: Equality, Opportunity and a New Economic Imperative, Geneva, January.

World Wildlife Fund (2020), The Living Planet Report Canada 2020, Wildlife at Risk, Toronto, September.

Wyonch, R. and S. Maharishi (2020), "Low-Value Care: Health's Future and Fiscal Reckoning", Intelligence Memo, C.D. Howe Institute, Toronto, 3 July.

Yembilah, R. and C. Lamb (2016), "Planning to Eliminate Child Poverty: Thematic overview of child poverty policy in Canada", Canadian Poverty Institute, Ambrose University, Calgary, May.

Zheng, Z. and L. Yang (2019, "Neighborhood Environment, Lifestyle, and Health of Older Adults: Comparison of Age Groups Based on Ecological Model of Aging", Sustainability, 11, 7, April. 